\title{
Changes in alcohol consumption in Scotland during the early stages of the COVID-19 pandemic:
}

Descriptive analysis of repeat cross-sectional survey data

Abigail K. Stevely

Alessandro Sasso

Mónica Hernández Alava

John Holmes

February 2021 
Other formats may be available from:

\section{0 \\ @ phs.otherformats@phs.scot}

\section{Citation}

This report should be cited as: Stevely A, Sasso A, Hernández Alava M and Holmes J. Changes in alcohol consumption in Scotland during the early stages of the COVID-19 pandemic: Descriptive analysis of repeat cross-sectional survey data. Edinburgh: Public Health Scotland; 2021.

Report prepared for Public Health Scotland by Sheffield Alcohol Research Group, School of Health and Related Research (ScHARR), University of Sheffield, 30 Regent Street, Sheffield, S1 4DA, UK 


\section{Contents}

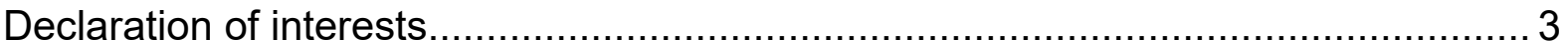

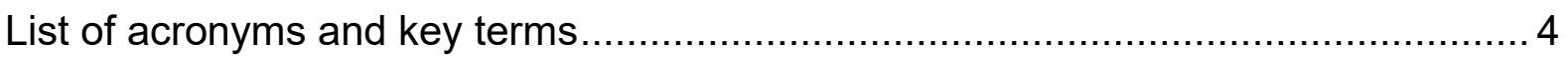

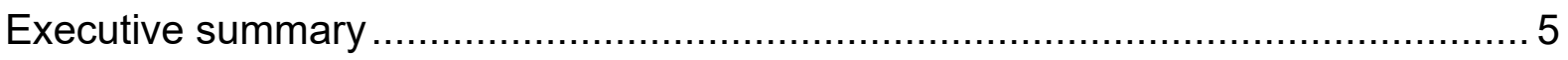

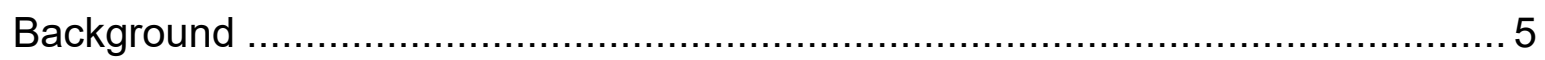

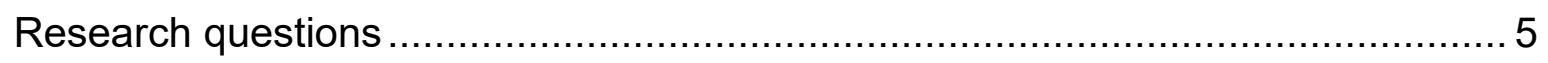

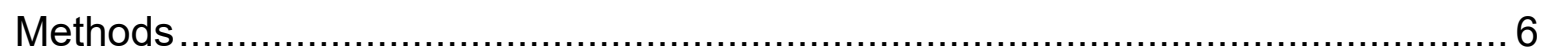

Summary of findings

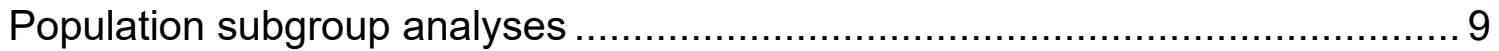

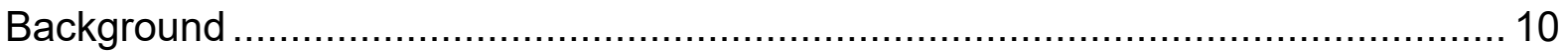

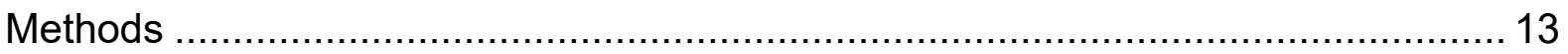

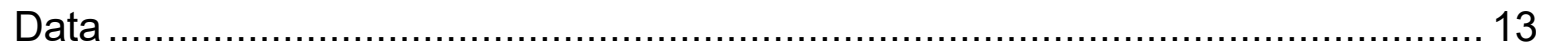

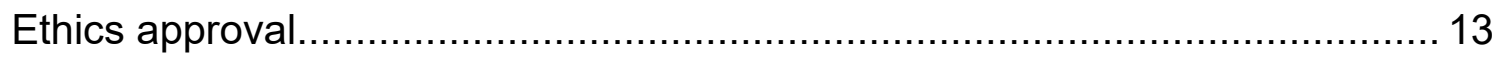

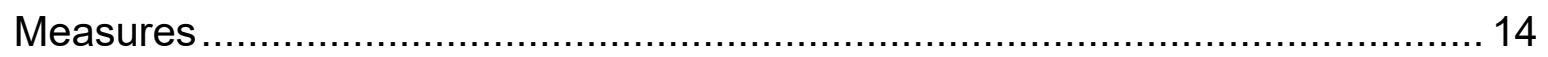

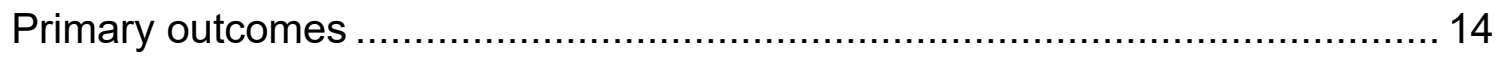

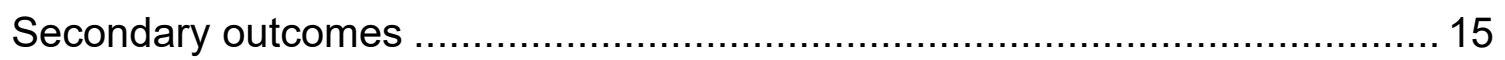

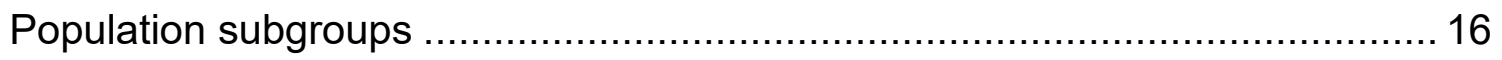

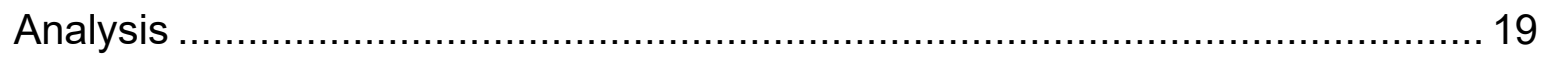

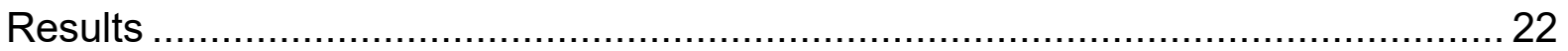

Primary outcomes

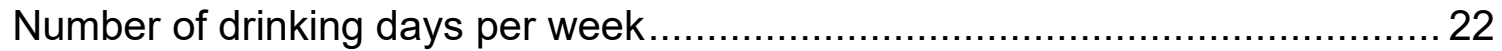

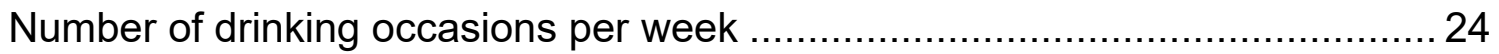

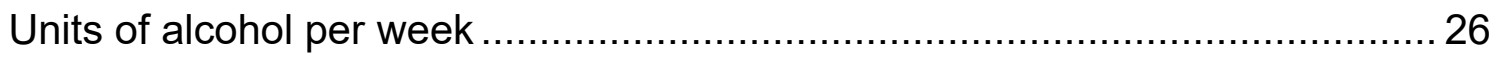

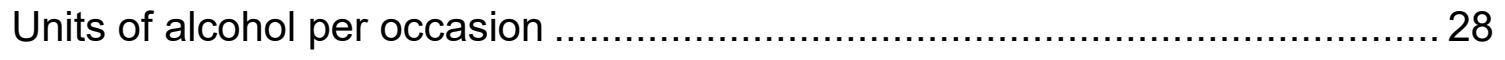

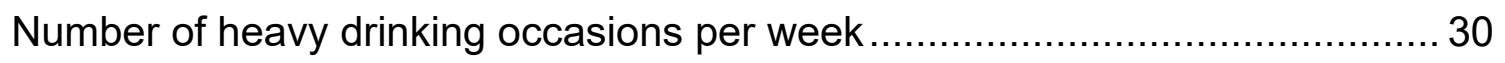

Units of alcohol in the heaviest drinking occasion of the week......................... 32 
Sensitivity analyses

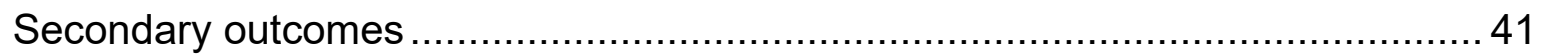

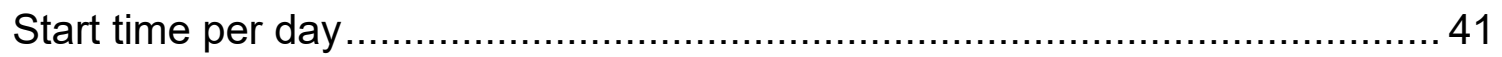

Number of weekday drinking occasions starting before 17:00 per week........... 43

Number of occasions involving drinking alone per week ................................ 45

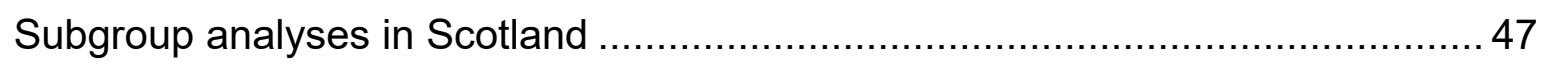

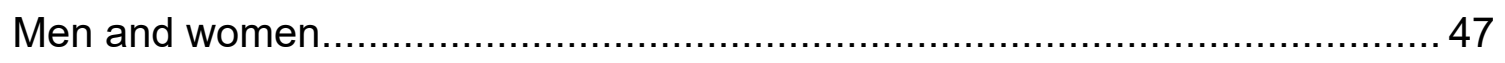

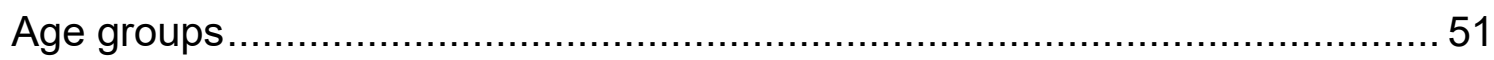

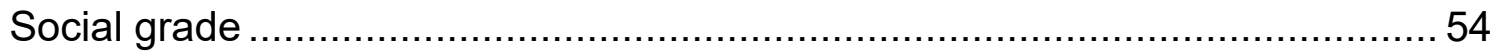

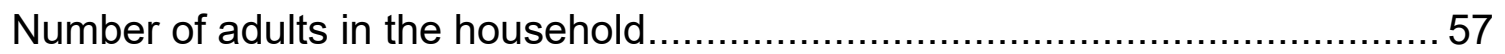

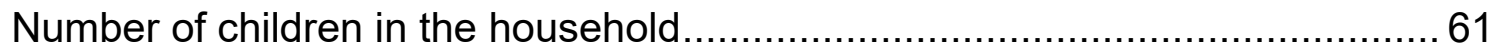

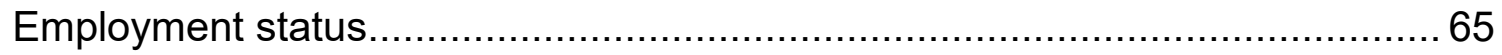

Typical frequency of drinking over the last year ............................................68

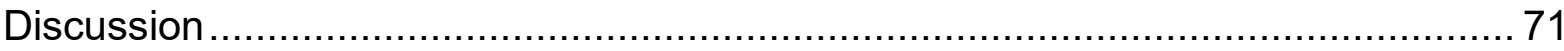

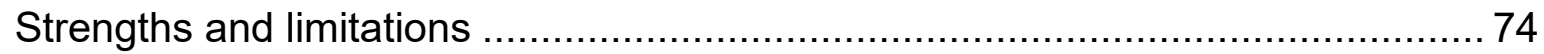

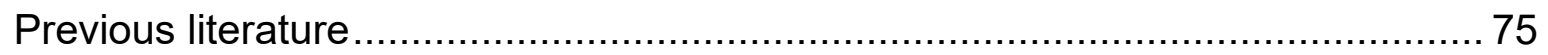

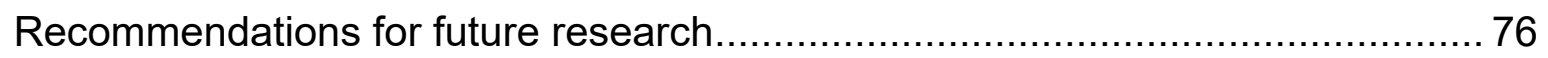

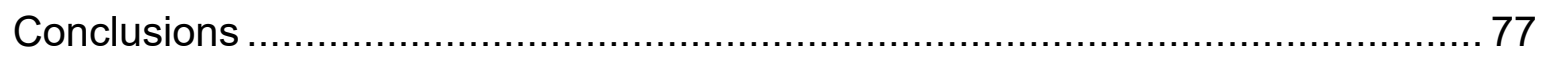

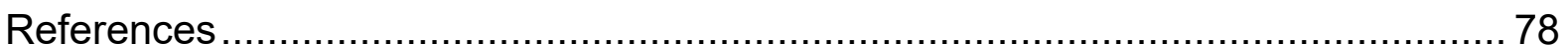




\section{Declaration of interests}

The authors have no interests to declare.

Analysis and report commissioned by Public Health Scotland, with funding from The Scottish Government.

Data preparation underpinning this report was partially supported by a grant from the Economic and Social Research Council (Ref ES/R005257/1). 


\section{List of acronyms and key terms}

ABV: alcohol by volume

HMRC: Her Majesty's Revenue and Customs

Off-trade: businesses such as supermarkets and off licenses, who sell alcohol for consumption off of the premises

On-trade: businesses such as pubs or restaurants, who sell alcohol for consumption on the premises (N.B. some of these premises sold 'takeaway' alcohol for consumption elsewhere during lockdown. They required an off-trade sales license for this.)

PHS: Public Health Scotland

Social grade: National Readership Survey categories based on survey participants' occupation

UK: United Kingdom of Great Britain and Northern Ireland Unit of alcohol: one UK unit is $10 \mathrm{ml}$ or $8 \mathrm{~g}$ of pure alcohol 


\section{Executive summary}

\section{Background}

- A national lockdown was implemented in the United Kingdom on 23 March 2020 in an attempt to limit the spread of COVID-19.

- Most on-trade premises selling alcohol were closed, although alcohol continued to be available in off-trade premises, including supermarkets, specialist alcohol retailers and small convenience stores, which were considered essential retailers. Some on-trade premises also began selling takeaway alcohol.

- Existing data on changes in alcohol consumption show a mixed picture, with some people drinking more and others less, but the underlying surveys are mostly retrospective and rely on people's recollections of their drinking before lockdown.

- There is little evidence on how people consumed alcohol during lockdown such as where they drank, who they drank with, or when.

- It is also important to consider changes in drinking across population subgroups such as sex, age, or social grade. This information will inform service provision and targeting of prevention efforts.

- This report, which was commissioned by Public Health Scotland and funded by The Scottish Government, will primarily focus on changes in alcohol consumption in Scotland and make comparisons with England.

Research questions

- How do levels and patterns of alcohol consumption vary between the pre-lockdown and lockdown periods?

- To what extent has the reduction in on-trade drinking during lockdown been offset by increases in the off-trade?

- How do the characteristics of drinking occasions vary between the pre-lockdown and lockdown periods?

- How do changes in the pattern of alcohol consumption and characteristics of drinking occasions vary across population subgroups? 


\section{Methods}

- We used data from the Alcovision survey from 2017-2020. Alcovision is a continuous cross-sectional online market research survey.

- The primary outcomes are: number of drinking days per week; number of drinking occasions per week; units of alcohol consumed per week; units of alcohol consumed per occasion; number of heavy drinking occasions per week ( $>6$ units on a single occasion for women and $>8$ units for men); units consumed on the heaviest drinking occasion of the week.

- The secondary outcomes are: average start time of drinking per day; number of drinking occasions starting before 17:00 on weekdays (Monday to Friday) per week; number of solitary drinking occasions per week.

- The population subgroups of interest are: sex (male, female); age (18-24, 25-34, 35-54, 55+ years old); social grade (AB, C1, C2, DE); number of adults in the household (1,2,3+); number of children in the household (no children, some children); employment status (working full time, working part time, full time education, unemployed, other); typical frequency of drinking over the last year (at least weekly, less than weekly).

- The main analytical approach was descriptive comparison of the second quarter of 2020 (the lockdown period) and the second quarter of 2019.

\section{Summary of findings}

- In Scotland, there were no significant changes in alcohol consumption levels or the frequency of drinking overall, suggesting that increases in off-trade alcohol consumption offset any reductions in on-trade drinking (Table 1).

- In England, overall levels of alcohol consumption fell despite increases in off-trade consumption levels and frequency.

- The start time of drinking per day shifted later into the evening in both Scotland and England, but there was no significant change in the start time of off-trade drinking.

- There was a fall in the number of weekday occasions starting before 17:00 in England but no significant change in Scotland. The number of off-trade weekday occasions starting before 17:00 showed no significant change. 
- There was no significant change in the number of solitary drinking occasions overall, but there was an increase in off-trade solitary drinking in both Scotland and England. 
Table 1. Summary of changes in alcohol consumption during lockdown in Scotland and England.

\begin{tabular}{|c|c|c|c|c|}
\hline & Scotla & $=11,223)$ & Engla & $=70,126)$ \\
\hline Primary outcomes & Total & Off-trade & Total & Off-trade \\
\hline $\begin{array}{l}\text { Number of drinking days } \\
\text { per week }\end{array}$ & 0.0 & +0.2 & 0.0 & +0.2 \\
\hline $\begin{array}{l}\text { Number of occasions } \\
\text { per week }\end{array}$ & -0.2 & +0.2 & -0.2 & +0.3 \\
\hline $\begin{array}{l}\text { Units of alcohol per } \\
\text { week }\end{array}$ & -0.8 & +2.4 & -1.5 & +1.7 \\
\hline $\begin{array}{l}\text { Units of alcohol per } \\
\text { occasion }\end{array}$ & 0.0 & +1.1 & -0.3 & +0.8 \\
\hline $\begin{array}{l}\text { Number of heavy } \\
\text { occasions per week }\end{array}$ & -0.1 & +0.1 & -0.1 & +0.1 \\
\hline $\begin{array}{l}\text { Units of alcohol in } \\
\text { heaviest occasion per } \\
\text { week }\end{array}$ & -0.2 & +0.9 & -0.7 & +0.3 \\
\hline Secondary outcomes & Total & Off-trade & Total & Off-trade \\
\hline $\begin{array}{l}\text { Start time per day } \\
\text { (minutes) }\end{array}$ & +38.4 & +17.4 & +30.6 & +10.2 \\
\hline $\begin{array}{l}\text { Number of weekday } \\
\text { occasions before 17:00 } \\
\text { per week }\end{array}$ & -0.1 & 0.0 & -0.1 & 0.0 \\
\hline $\begin{array}{l}\text { Number of occasions } \\
\text { involving drinking alone } \\
\text { per week }\end{array}$ & +0.2 & +0.3 & +0.1 & +0.1 \\
\hline
\end{tabular}

Shaded cells indicate significant findings, where the 95\% confidence interval for the mean in the second quarter of 2019 (pre-lockdown) did not overlap with the $95 \%$ confidence interval for the same quarter in 2020 (during lockdown) ${ }^{\star} . \mathrm{n}=$ the number of drinkers included in the analysis in each country.

\footnotetext{
* In the absence of formal statistical testing, we treat any overlapping confidence interval as non-significant. This is a conservative assumption as such differences may be significant in
} 


\section{Population subgroup analyses}

- Overall alcohol consumption levels and the frequency of drinking showed no significant changes for most population subgroups.

- The shift of mean start time of drinking per day to later in the evening in Scotland was more pronounced for women, over 55 year-olds, two adult households, those with no children in the household, and weekly drinkers.

- There was an increase in solitary drinking in Scotland for single adult households, households with three or more adults, and those in full time education. 


\section{Background}

During the COVID-19 pandemic, many governments around the world have sought to reduce the spread of the virus by introducing national or local lockdowns that close most business premises and restrict peoples' freedom to leave their homes. The direct impacts of the pandemic and the effects of lockdowns have caused psychological, social and economic harm to large numbers of people (1).

In the United Kingdom (UK), a national lockdown was implemented on 23 March 2020. During this lockdown, people were only permitted to leave their homes for essential purposes, such as shopping for necessities and work where working from home was not possible $(2,3)$. In the UK, on-trade venues selling alcohol for consumption on the premises were closed from 21 March, following previous advice for people to avoid them from 16 March. However, alcohol remained available in supermarkets, convenience stores, online, and in dedicated off-trade premises throughout the lockdown as the Government deemed these stores essential business (4). The lockdown was gradually lifted from 10 May 2020 and on-trade premises were permitted to reopen from 4 July in England and in a staged process from 6 July onwards in Scotland.

Public health stakeholders have raised concerns and discussed how lockdowns will affect levels of alcohol consumption and associated physical and mental health problems in the short- and long-term $(5,6)$. On the one hand, harmful alcohol consumption may increase during lockdowns due to the distress caused by social isolation, economic insecurity, and the loss of loved ones (7). On the other hand, Rehm et al. have suggested that the closure of on-trade premises could lead to overall falls in alcohol consumption (7).

The available data on changes in alcohol consumption during the UK lockdown is equivocal. In late March, market research companies reported large increases in alcohol sales in the off-trade, such as a $58 \%$ rise in supermarket sales of alcohol ${ }^{*}$ (8). However, HMRC data, which also includes the on-trade, shows that duty returns during lockdown were slightly lower than during the same period in 2019, suggesting sales were down overall (9). Further, estimates of alcohol sales are an imperfect

\footnotetext{
" The metric of this value (i.e. alcohol volume vs sales value) is not clearly reported.
} 
indicator of alcohol consumption as they do not take into account potential stockpiling.

Survey studies can provide additional data on changes in drinking patterns and across different population groups. Early evidence from survey data has found that while some people report heavier consumption during lockdown, similar or greater proportions report lighter consumption (10-13). For example, polling commissioned by Alcohol Change UK and Alcohol Focus Scotland asked 567 adults in Scotland to report changes in their drinking frequency - finding that $29 \%$ of adults who drink were doing so more often and $29 \%$ were doing so less often (13). Further, Jackson et al. analysed monthly cross-sectional survey data from the Smoking and Alcohol Toolkit Studies and found that the prevalence of high risk drinking increased in England but so had the proportion of high-risk drinkers attempting to cut down (14). Overall, it is possible that lockdown may have polarised alcohol consumption, with many people drinking less while higher risk drinking also increased.

In addition to changes in the frequency and volume of alcohol consumption, the way that people drink changed during lockdown. Drinking occasions exclusively took place in the off-trade and, alongside this, changes such as the introduction of social distancing measures, the increase in home working, and employees being placed on the furlough scheme may have prompted shifts in who people drank with, and when. Understanding these shifts in drinking behaviour is important as there is a growing body of evidence that the contexts of drinking affect consumption levels and alcohol-related harms, as well as being visible indicators of changes in drinking culture (15-17).

Furthermore, changes in alcohol consumption and drinking contexts may vary across population subgroups such as by sex, age, social grade, or parental status. For instance, schools and childcare providers were closed during the lockdown, which may have led to parents either drinking less due to their increased time demands and responsibilities or drinking more due to increased stress. Understanding this variation is key for informing service provision and targeting of prevention efforts (7). Public Health Scotland (PHS) commissioned this report to provide new evidence on the impact of COVID-19 and the early lockdown period (23 March to June 2020) on levels and patterns of alcohol consumption in Scotland compared with England and 
to develop further understanding of how alcohol consumption in Scotland differs from the rest of the UK. Public Health Scotland have also commissioned a complementary analysis of retail sales data to provide evidence on population alcohol consumption, which will be published separately.

The present report will explore the extent to which the elimination of on-trade drinking during lockdown was offset by changes in the off-trade, assess how the characteristics of drinking occasions changed, and identify how these changes vary across population subgroups. 


\section{Methods}

\section{Data}

We used data from the Alcovision survey, a continuous cross-sectional survey of adults (18 years old and over) resident in Great Britain undertaken by the market research company Kantar. Alcovision comprises demographic information and a behavioural questionnaire followed by a seven-day retrospective drinking diary, in which participants provide detailed information on their drinking occasions.

Kantar draw nationally representative samples for Alcovision from an online market research panel using monthly quotas defined by age, sex, social grade and geographic region. Residents of Scotland and 18-34 year-olds are over-sampled to permit detailed analyses of these groups.

We use data from December 2016 to June 2020 in Scotland and England. These data were collected continuously throughout the study period, including lockdown, with no changes to sampling methods or measures. Our main sample includes 81,349 drinkers, who reported usually drinking at least once per year. We also used one subsample - diary week drinkers (i.e. those respondents who reported drinking during the last week) - for analyses of drinking contexts (Table 2).

Table 2. Analytic sample sizes in Scotland and England

\begin{tabular}{|l|c|l|}
\hline & Scotland & England \\
\hline Drinkers & 11,223 & 70,126 \\
\hline $\begin{array}{l}\text { Diary week } \\
\text { drinkers }\end{array}$ & 7,830 & 51,440 \\
\hline
\end{tabular}

\section{Ethics approval}

This study was approved by the University of Sheffield's ethics committee (reference number: 017910) and conforms to the principles embodied in the Declaration of Helsinki. Use of these data is allowed under the terms of the contract and non-disclosure agreement between Kantar and the University of Sheffield, which requires research outputs to be submitted to the data provider ahead of publication. 
The data providers' right to request changes is limited to matters of accuracy regarding the data. All participants in the survey gave informed consent.

\section{Measures}

The analyses explored a series of primary and secondary outcomes, and compared these across subgroups.

The diary component of the survey asks participants to identify days in the last week when they drank in the off-trade (e.g. bought alcohol at a supermarket and drank it at home) or the on-trade (e.g. nightclubs, pubs). Participants then provide detailed information on up to two on-trade and two off-trade occasions per day including the timing of the occasion, who they were with, and how much alcohol they drank. For each outcome measure, we explored trends for all drinking occasions and for off-trade occasions only to provide insight into how drinking in the off-trade changed in response to the lockdown and how this affected trends in overall drinking.

\section{Primary outcomes}

Six primary outcomes were selected to explore the frequency, volume and intensity of alcohol consumption. We calculated these for each individual in the sample of drinkers. The measures are:

- Number of drinking days per week;

- Number of drinking occasions per week (i.e. participants may have more than one occasion in a day);

- Units of alcohol consumed per week;

- Units of alcohol consumed per occasion;

- Number of heavy drinking occasions per week (>6 units on a single occasion for women and $>8$ units for men);

- Units consumed on the heaviest drinking occasion in the diary week.

The number of drinking days and occasions is captured directly by Alcovision*. The number of units consumed is calculated from occasion-level information provided by

\footnotetext{
* In previous analyses of Alcovision data, we have used an alternative definition of an occasion based on there being no more than a two hour gap between drinks. We have not used this definition here to allow us to straightforwardly separate on-trade and off-trade occasions.
} 
participants. For each occasion, participants report the type and, where available, brand of alcohol consumed (e.g. sparkling white wine, Smirnoff vodka). Participants also provide the serving size (e.g. pint, small stubby bottle, large wine glass) and the number of servings. We combined this data with information on alcoholic strengths $(A B V)$ to calculate the number of units consumed for each drink reported in the diary week (one UK unit is $10 \mathrm{ml}$ or $8 \mathrm{~g}$ of pure alcohol). We obtained information on ABVs from reliable websites for specific brands (e.g. supermarket websites, brand websites or specialist beer websites). When reliable information on $A B V s$ was not available online, we used assumptions about the average ABVs for each type of drink (vodka, wine, beer, etc.) taken from previous research literature or provided in personal communications by key informants.

In previous analyses, we have identified that a small proportion of Alcovision participants report very high consumption values for particular drinks, occasions or days, or for the diary week as a whole. We have therefore developed and applied methods for capping the data to prevent misreported or extreme values from distorting findings*.

\section{Secondary outcomes}

Three further secondary outcomes were selected to explore the characteristics of drinking occasions in lockdown in more detail. These secondary outcomes focused on drinking occasions in the diary week, so we used the sample of diary week drinkers. The secondary outcomes are:

- Average start time of drinking per day

\footnotetext{
* - We first constrain the amount of alcohol reported for each single type of drink within an occasion (a row in the dataset) to a maximum of 40 units (the amount of alcohol in a litre bottle of whisky).

- We then constrain the amount of alcohol reported in each drinking occasion to a maximum of 40 units. This is done by removing the excess units proportionally from each of the drinks (rows) associated with that occasion.

- We then constrain the amount of alcohol reported per day to a maximum of 40 units. Again, this is done by removing the excess units proportionally from each of the drinking occasions within the same day, for each individual.

- Finally, individuals' weekly alcohol consumption is calculated by summing all of the (capped) units reported during the week. Hence, maximum weekly consumption is constrained to 280 units (i.e. $7 \times 40$ units).
} 
- Number of drinking occasions starting before 17:00 on weekdays (Monday to Friday) per week

- Number of solitary drinking occasions per week.

To calculate each participant's average start time of drinking per day, we took the time of their first drinking occasion per drinking day ${ }^{*}$ and averaged this across all of their drinking days in the diary week. For example, if they reported drinking at 15:00 on Monday and 21:00 on Tuesday their average start time was 18:00.

We classified occasions as solitary if the participant reported drinking alone at some point during the occasion. In some cases, these occasions also involved drinking with others at a different point in the occasion. A limitation of this measure is we do not know whether respondents who socialised online during the lockdown reported these occasions as drinking alone. The Alcovision survey asks respondents who they were with on the occasion and does not differentiate between physical or online company.

\section{Population subgroups}

The population subgroups of interest are:

- Sex (male, female)

- Age $(18-24,25-34,35-54,55+$ years old $)$

- Social grade (AB, C1, C2, $\left.\mathrm{DE}^{\dagger}\right)$

- Number of adults in the household $(1,2,3+)$

- Number of children in the household (no children, some children)

- Employment status (working full time, working part time, full time education, unemployed, other)

- Typical frequency of drinking over the last year (at least weekly, less than weekly).

\footnotetext{
* Occasion start times are measured in bands and we use the earliest values as pointestimates (e.g. between midday and 13:59, between 19:00 and 19:59).

† A measure based on the participants' occupation. AB: higher managerial, administrative and professional; intermediate managerial, administrative and professional. C1: supervisory, clerical and junior managerial, administrative and professional. C2: skilled manual workers. DE: semi-skilled and unskilled manual workers, state pensioners, casual and lowest grade workers, unemployed with state benefits only.
} 
Social grade uses National Readership Survey categories - a measure based on the participants' occupation, ranging from those in higher managerial positions to semi-skilled workers and those who are unemployed (18). For employment status, results are presented for the four main groups, with results for the 'other' group (including those who report that they are retired, registered as sick or disabled, on paternity/maternity leave, or are a househusband/housewife) available in Appendices A and D. The Alcovision survey did not collect data on furloughed workers. Table 3 shows the number of participants in each of the population subgroups of interest. 
Table 3. Descriptive characteristics of the sample (unweighted)

\begin{tabular}{|c|c|c|}
\hline & Number of participants & Percentage of sample \\
\hline \multicolumn{3}{|c|}{ 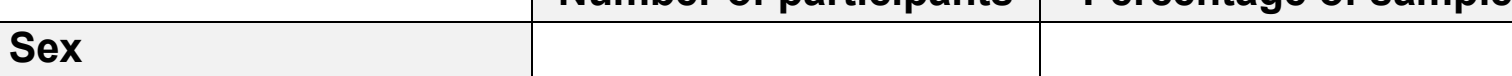 } \\
\hline Male & 40,842 & 50.2 \\
\hline Female & 40,507 & 49.8 \\
\hline \multicolumn{3}{|l|}{ Age (years) } \\
\hline $18-24$ & 17,983 & 22.1 \\
\hline $25-34$ & 18,190 & 22.4 \\
\hline $35-54$ & 26,229 & 32.2 \\
\hline $55+$ & 18,947 & 23.3 \\
\hline \multicolumn{3}{|l|}{ Social grade } \\
\hline$A B$ & 21,588 & 26.5 \\
\hline C1 & 19,178 & 23.6 \\
\hline $\mathrm{C} 2$ & 17,291 & 21.3 \\
\hline $\mathrm{DE}$ & 23,292 & 28.6 \\
\hline \multicolumn{3}{|l|}{$\begin{array}{l}\text { Number of adults in the } \\
\text { household }\end{array}$} \\
\hline 1 & 17,610 & 21.7 \\
\hline 2 & 42,129 & 51.8 \\
\hline $3+$ & 21,610 & 26.6 \\
\hline \multicolumn{3}{|l|}{$\begin{array}{l}\text { Number of children in } \\
\text { the household }\end{array}$} \\
\hline 0 & 55,764 & 68.6 \\
\hline $1+$ & 25,585 & 31.4 \\
\hline \multicolumn{3}{|l|}{ Employment status } \\
\hline Working Part Time & 12,588 & 15.5 \\
\hline Full Time Education & 6,398 & 7.9 \\
\hline Unemployed & 5,771 & 7.1 \\
\hline Other & 20,465 & 25.2 \\
\hline \multicolumn{3}{|l|}{$\begin{array}{l}\text { Typical frequency of } \\
\text { drinking over the last } \\
\text { year }\end{array}$} \\
\hline Usually drink weekly & 48,541 & 59.7 \\
\hline Less than weekly & 32,808 & 40.3 \\
\hline
\end{tabular}

Note: Percentages may not sum to 100 due to rounding. 


\section{Analysis}

The analysis examined quarterly time trends in each primary and secondary outcome in Scotland and England to identify changes between the pre-lockdown and lockdown periods.

Lockdown began on 23 March across the UK. Alcovision diary weeks can start on any day of the week, so some diaries included dates both before and after 23 March. We classed diary weeks with any days in the lockdown period as during lockdown, meaning all diaries beginning after 17 March. Although this means that some lockdown diaries contain up to six days that were pre-lockdown, the gradual move towards a full lockdown from 16 March onwards means this approach is preferred to other options (e.g. classing only diaries beginning after 23 March as during lockdown).

As this definition of pre- and during lockdown does not align perfectly with calendar months, we constructed the quarterly time series such that each quarter starts on the 17th of the relevant month (e.g. quarter one includes diaries beginning between 17th December and 16th March; Table 4). The time series therefore finishes in quarter two of 2020 as we only had data from the first two weeks of quarter three (17 to 30 June 2020). These two weeks of data were not used in the analysis.

Table 4. Dates included in each quarter of the time series

\begin{tabular}{|l|c|}
\hline \multicolumn{1}{|c|}{ Dates } & Quarter \\
\hline 17 December -16 March & 1 \\
\hline 17 March -16 June & 2 \\
\hline 17 June -16 September & 3 \\
\hline 17 September -16 December & 4 \\
\hline
\end{tabular}

We calculated means and $95 \%$ confidence intervals for all outcome variables across the quarterly samples. Changes in the outcomes of interest were assessed by descriptive comparison of these means for the second quarter of 2020 (during lockdown) and the second quarter of 2019 (pre-lockdown). In the absence of formal statistical testing, we treat any overlapping confidence interval as non-significant. This is a conservative assumption as such differences may be significant in some instances where the confidence interval of one group does not include the point 
estimate for the other group (19). Comparing with the same quarter in the previous year provides some adjustment for seasonal trends in our outcome measures. We also conducted a sensitivity analysis comparing the second quarter of 2020 with the preceding quarter for the primary and secondary outcomes and assessed whether this changed our conclusions. Since our sample size for England was larger than for Scotland, changes of a similar magnitude can be statistically significant in England and not in Scotland. This reflected the greater certainty we can have about the results in England.

Alcohol consumption distributions are typically subject to large positive skews. This means that a small number of people drink large amounts of alcohol and can have a disproportionate effect on the mean for the population. The effects of lockdown on alcohol consumption may also have varied across the consumption distribution (i.e. between lighter and heavier drinkers). We conducted sensitivity analyses to check whether our findings differed across the consumption distribution using three variables: total weekly consumption, consumption per occasion and consumption on heaviest drinking occasion. To do this, we compared the pre- and during lockdown values for the median, 75th percentile, 90th percentile, and 95th percentile for each of these three consumption distributions (with the median representing lighter drinkers and the 95th percentile representing the heaviest drinkers).

As discussed in the measures section, our measures of alcohol consumption were capped due to concerns about the unreliability of very high values. We conducted a sensitivity analysis using uncapped consumption for the mean units per week variable.

We used 'raking' (also called rim weighting*) in all analyses to adjust for differences in the marginal distributions of socio-demographic characteristics between the observed sample (Alcovision) and the UK Census. The weights were calculated by the authors and the sociodemographic characteristics considered in the weighting procedure were social grade, geographic region, and age within sex.

\footnotetext{
* The rim weighting process works as follows. First, it applies a weight to individuals such that the weighted distribution of social grade matches the distribution in the UK Census. Subsequently, an algorithm readjusts the weighted distribution based on geographic region, age, and sex. The process is iterated repeatedly until the marginal distribution of all target variables has been matched with the UK Census data.
} 
Results are presented in figures with 95\% confidence intervals and the alignment of the error bars is slightly offset to improve readability. The final data point on the figures presented is the only one during the lockdown period. 


\section{Results}

\section{Primary outcomes}

Graphical results for primary outcomes are presented below with tabulated results for all primary outcomes from 2017-2020 available in Appendix A.

\section{Number of drinking days per week}

The mean number of drinking days per week showed no significant change in Scotland or England during lockdown (Figure 1). This reflects an increase in the number of drinking days per week that respondents reported in the off-trade (Figure 2), which likely offset the elimination of on-trade drinking days. 
Figure 1. Quarterly mean number of drinking days per week in Scotland and England

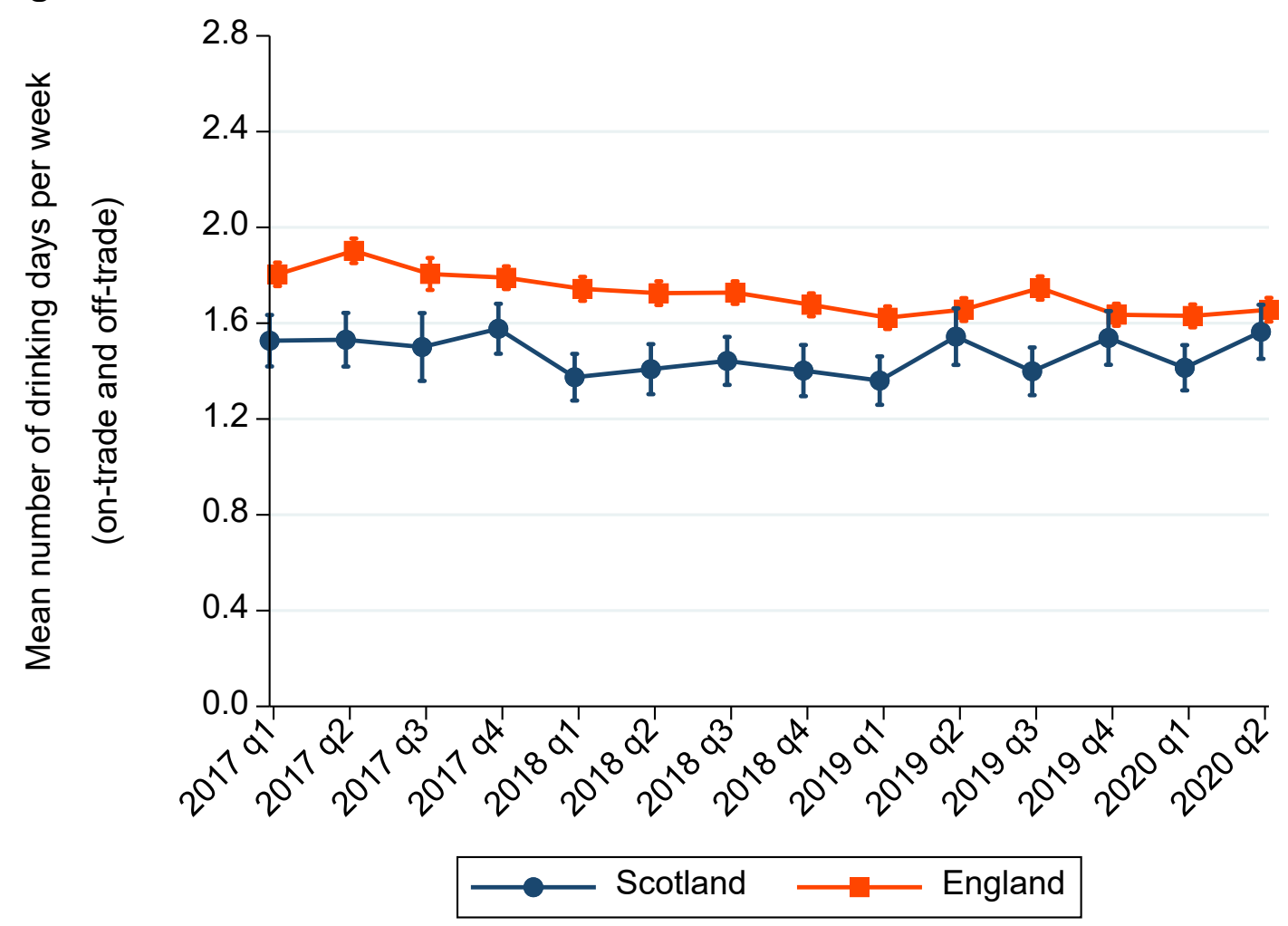

Figure 2. Quarterly mean number of drinking days per week (off-trade) in Scotland and England

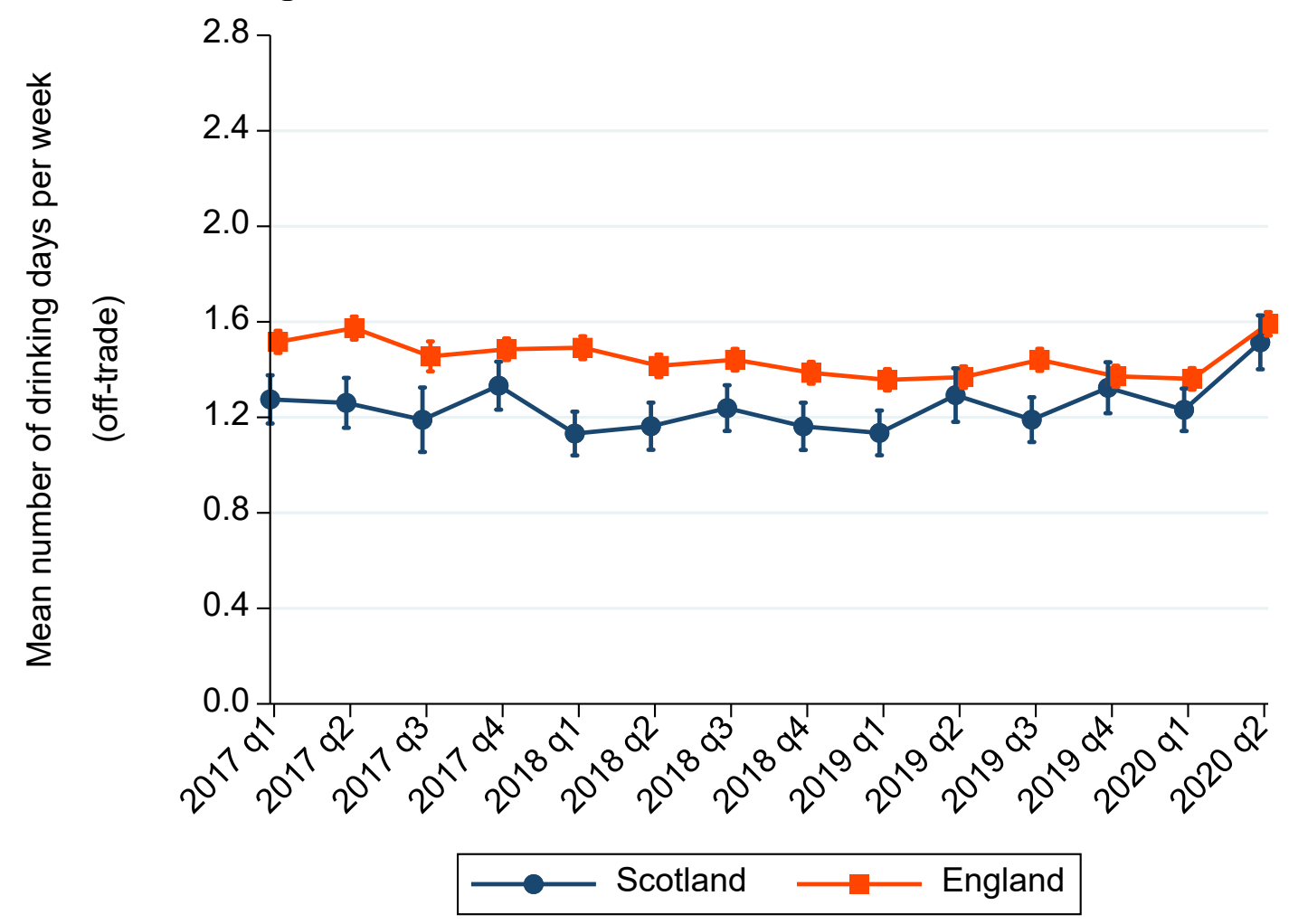




\section{Number of drinking occasions per week}

In order to further understand the changes in drinking frequency, we analysed the number of drinking occasions participants reported across the diary week. In England, this fell from $2.2(\mathrm{Cl}: 2.1-2.2)$ to $2.0(\mathrm{Cl}: 1.9-2.0)$ while there was no significant change in Scotland (2.0 [Cl: 1.9-2.2] to 1.9 [Cl: 1.7-2.0]; Figure 3).

In both Scotland and England, there was an increase in the mean number of off-trade drinking occasions per week during lockdown. This increase was significant in England (1.5 [Cl: 1.5-1.6] to 1.8 [Cl: 1.8-1.9]) and not in Scotland (1.5 [Cl: 1.41.6] to 1.7 [Cl: 1.6-1.9]; Figure 4). 
Figure 3. Quarterly mean number of occasions per week in Scotland and England

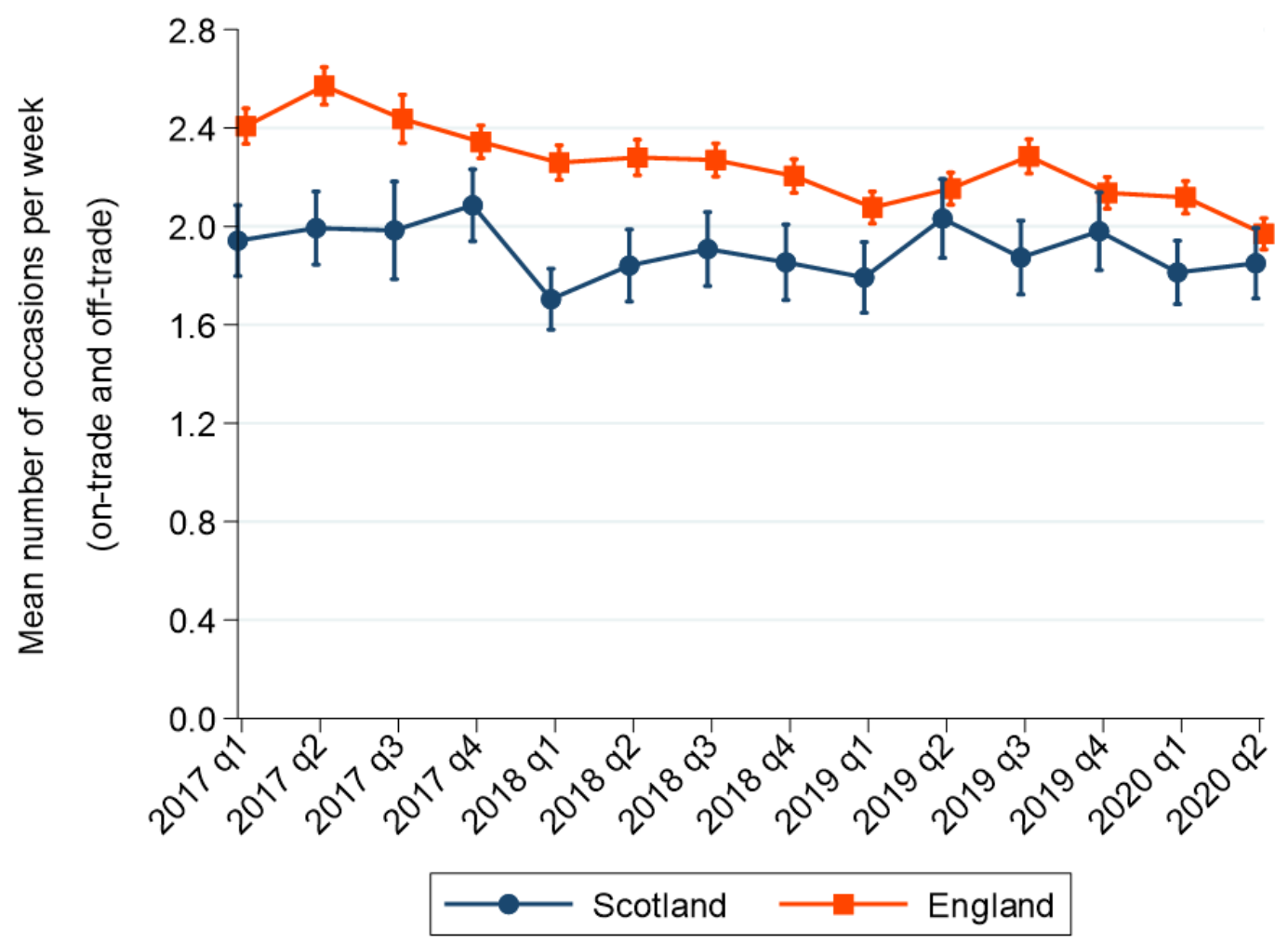

Figure 4. Quarterly mean number of occasions per week (off-trade) in Scotland and England

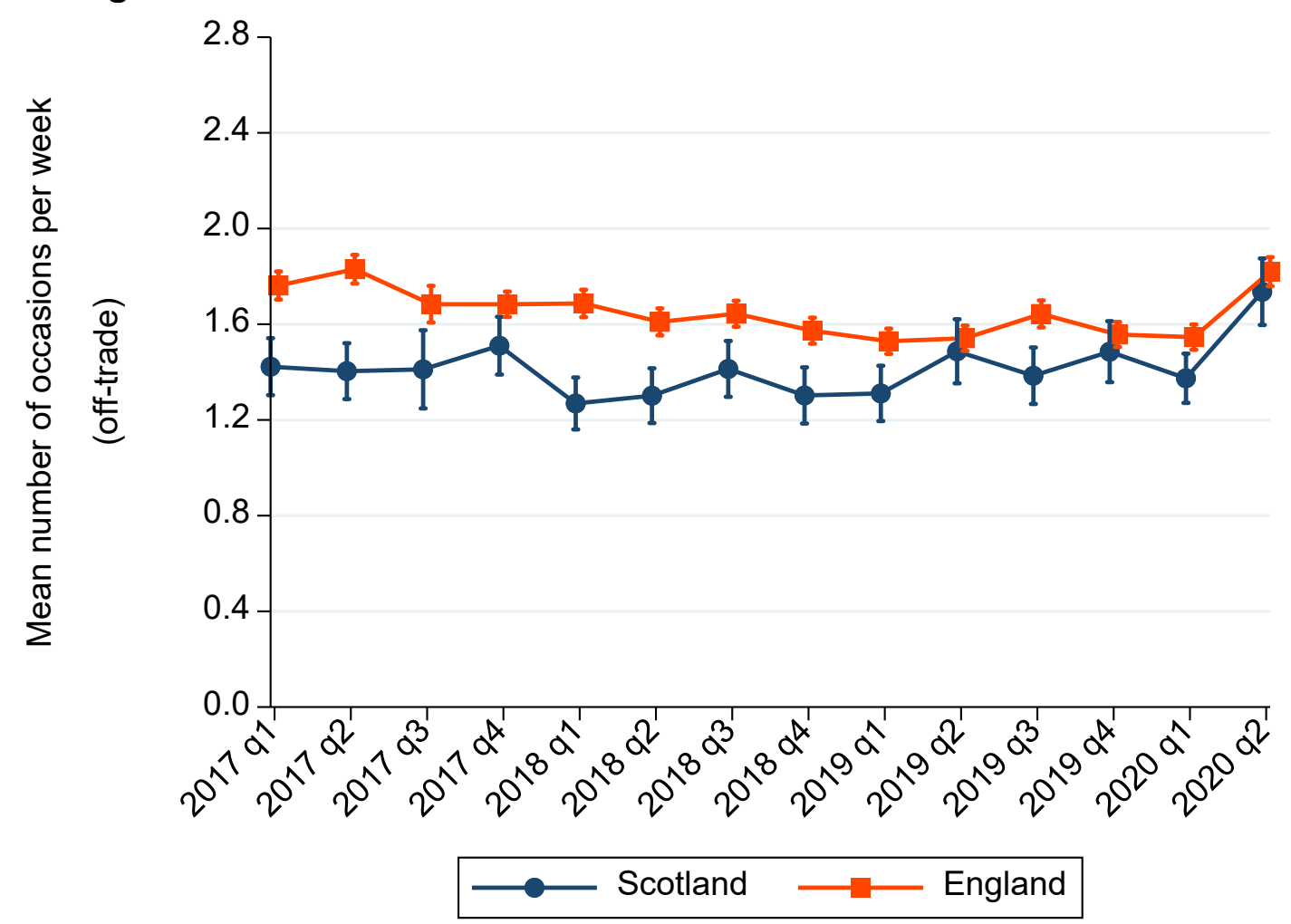




\section{Units of alcohol per week}

In Scotland, there was no significant change in mean units of alcohol consumed per week during lockdown (15.4 [Cl: 13.8-17.0] to 14.6 [Cl: 13.1-16.1]), while in England it fell from $14.9(\mathrm{Cl}: 14.3-15.6)$ to $13.4(\mathrm{Cl}$ : 12.9-14.0; Figure 5). This difference may be due to the greater increase in off-trade alcohol consumption in Scotland (Figure 6), with an increase of 2.4 units compared to 1.7 units in England. The increase in off-trade units per week was only significant in England, despite the change being smaller. 
Figure 5. Quarterly mean units of alcohol per week in Scotland and England

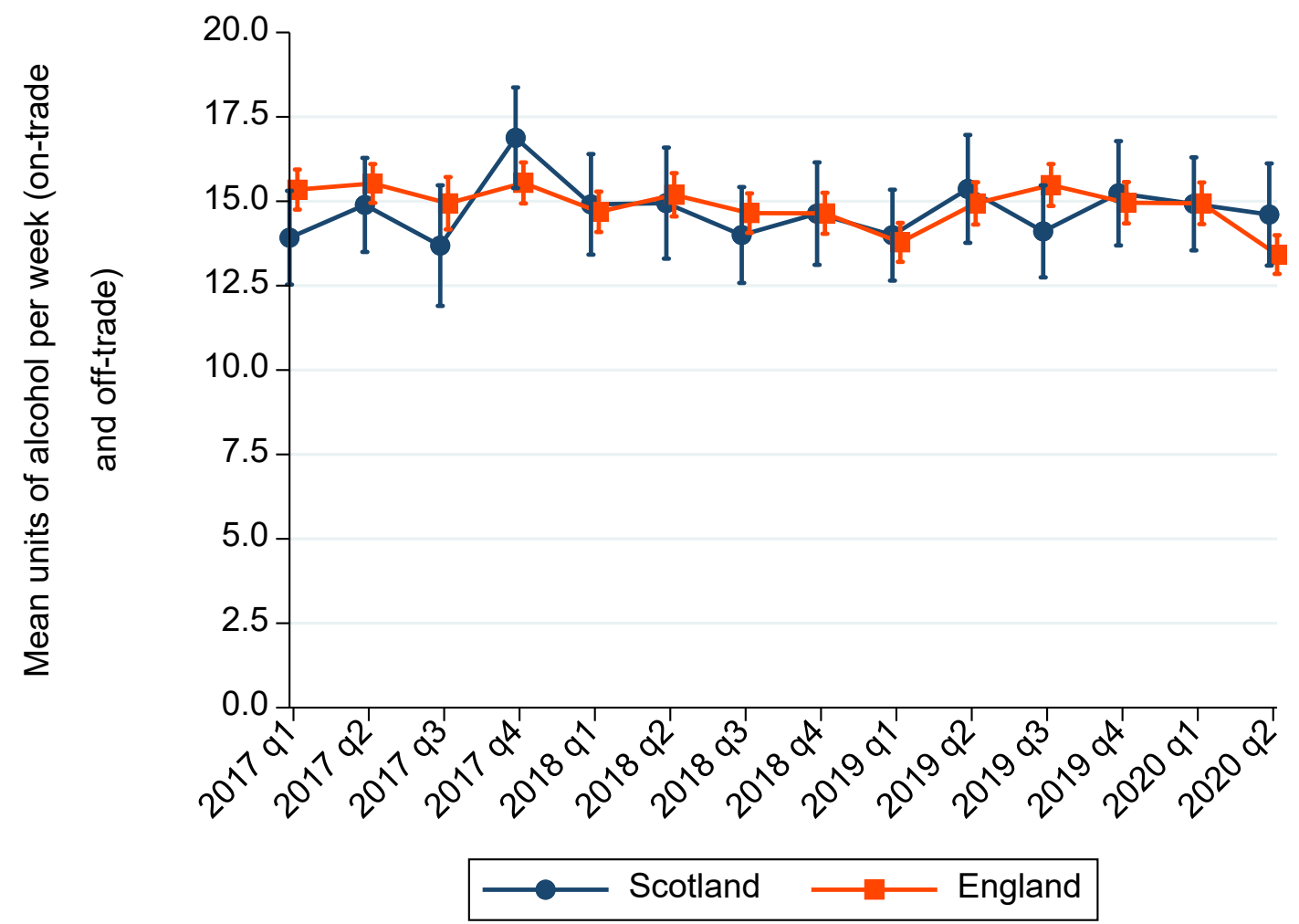

Figure 6. Quarterly mean units of alcohol per week (off-trade) in Scotland and England

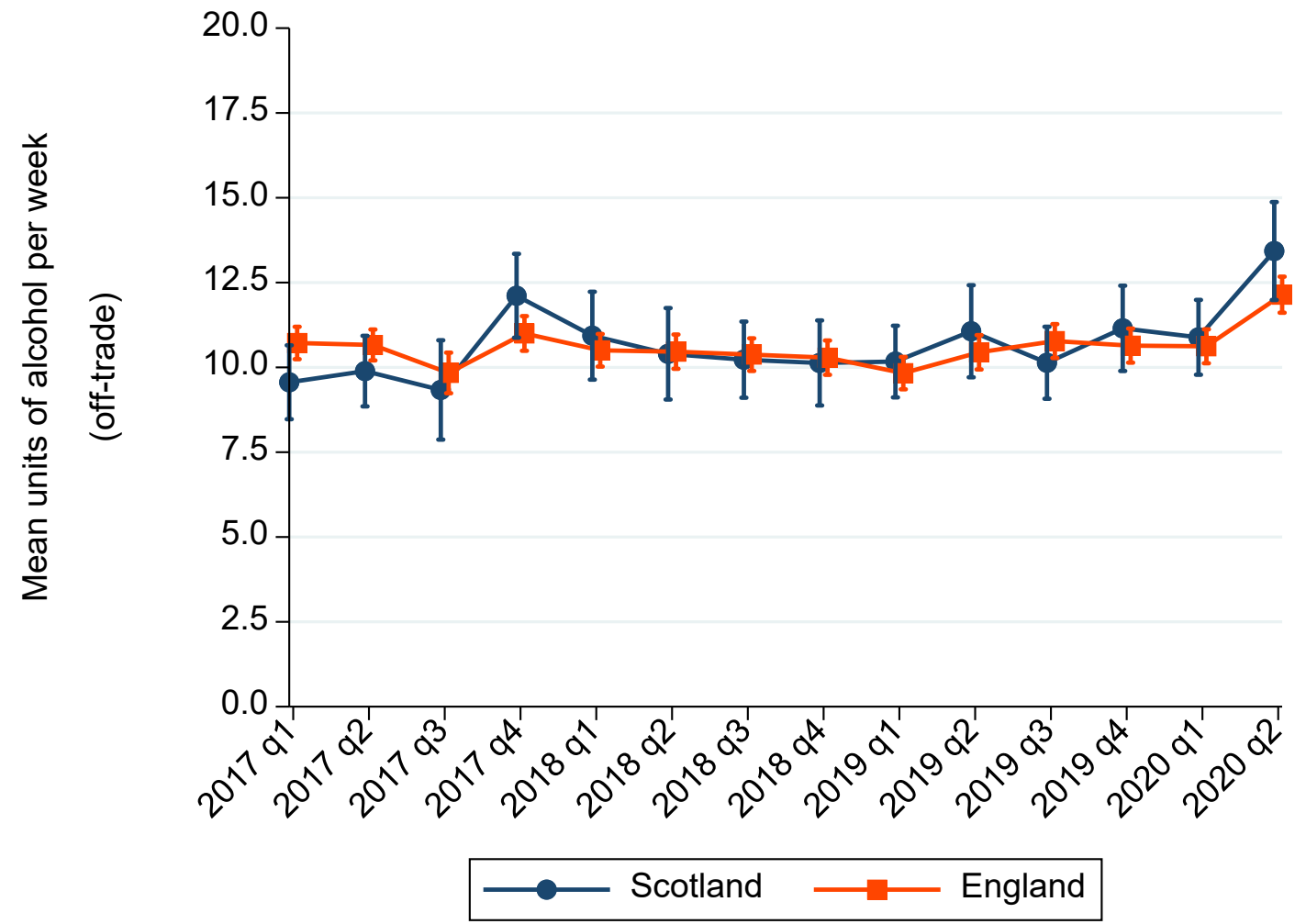

27 


\section{Units of alcohol per occasion}

Mean units of alcohol per occasion showed no significant change during lockdown in either England or Scotland (Figure 7). Off-trade drinking occasions were heavier during lockdown in both countries, with the mean units consumed increasing by 1.1 in Scotland and 0.8 in England (Figure 8). 
Figure 7. Quarterly mean units of alcohol per occasion in Scotland and England

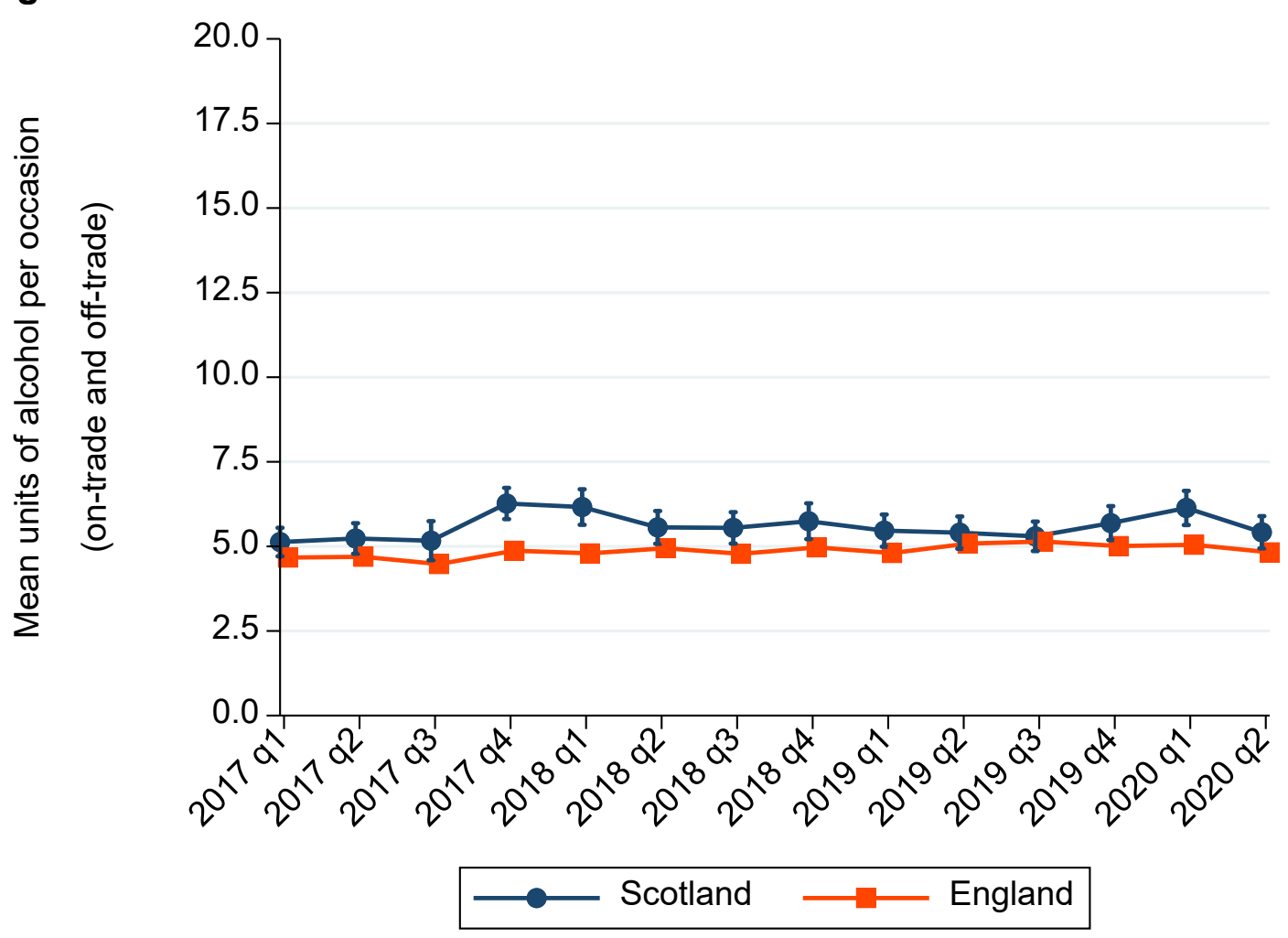

Figure 8. Quarterly mean units of alcohol per occasion (off-trade) in Scotland and England

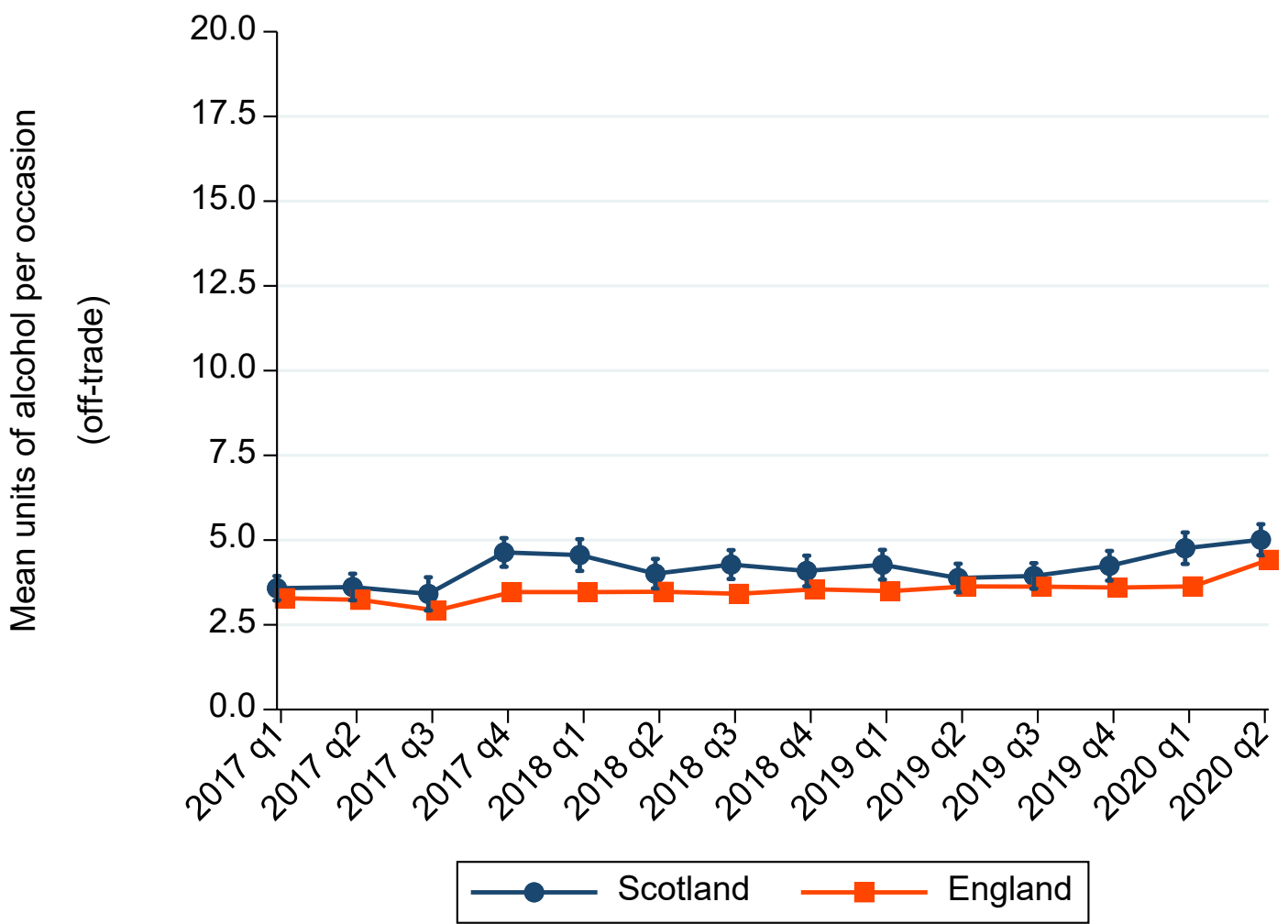




\section{Number of heavy drinking occasions per week}

The mean number of heavy drinking occasions per week, defined as more than eight units for men and more than six units for women, showed no significant change in Scotland (0.8 [Cl: 0.7-0.9] to 0.7 [Cl: 0.6-0.8]) and fell in England from 0.7 (Cl: $0.7-0.8)$ to 0.6 (Cl: 0.6-0.7; Figure 9).

There was a significant increase in the mean number of off-trade heavy drinking occasions in England, but this did not fully offset the reduction in on-trade heavy drinking occasions (Figure 10). 
Figure 9. Quarterly mean number of heavy drinking occasions per week in Scotland and England

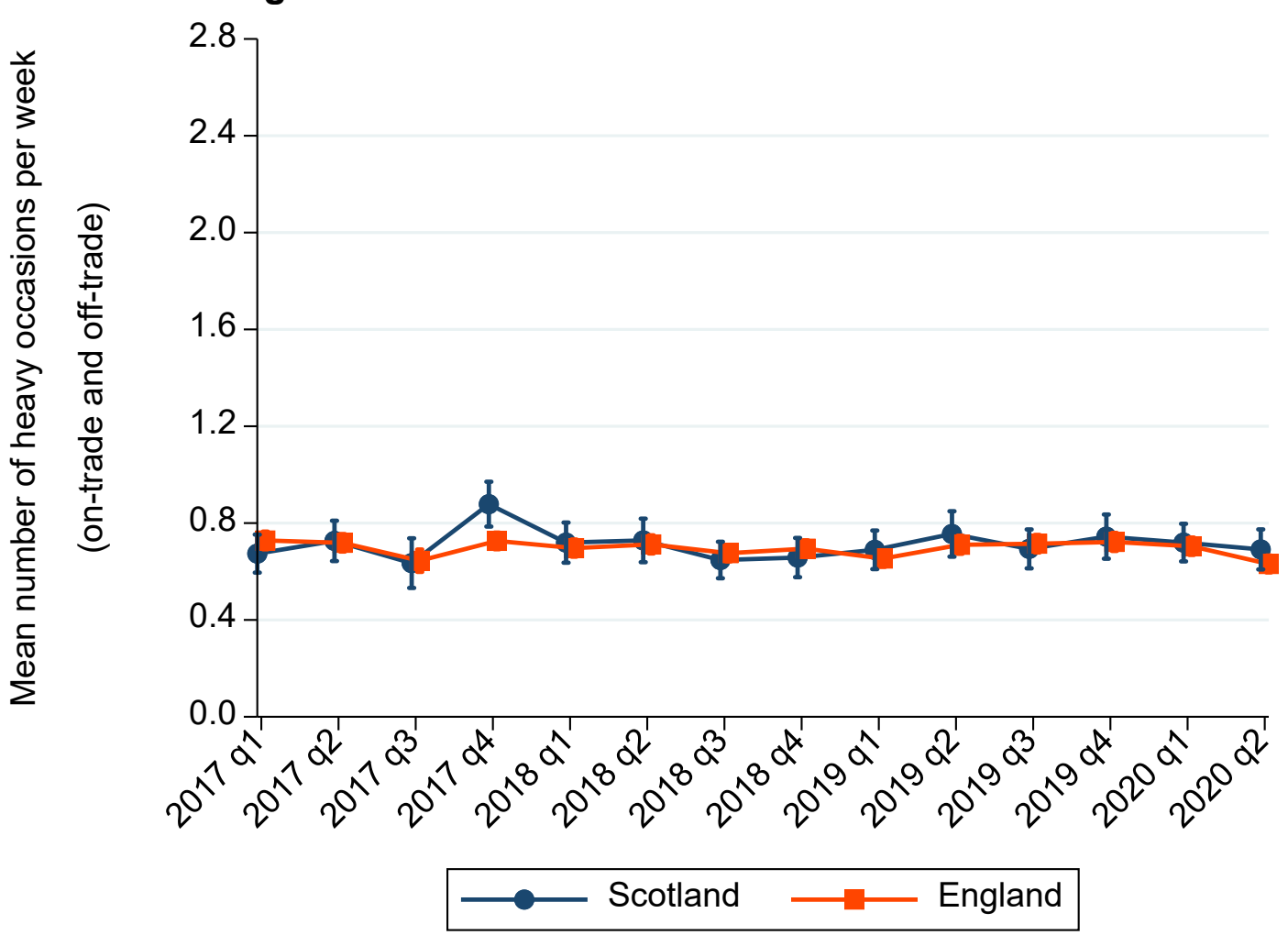

Figure 10. Quarterly mean number of heavy drinking occasions per week (offtrade) in Scotland and England

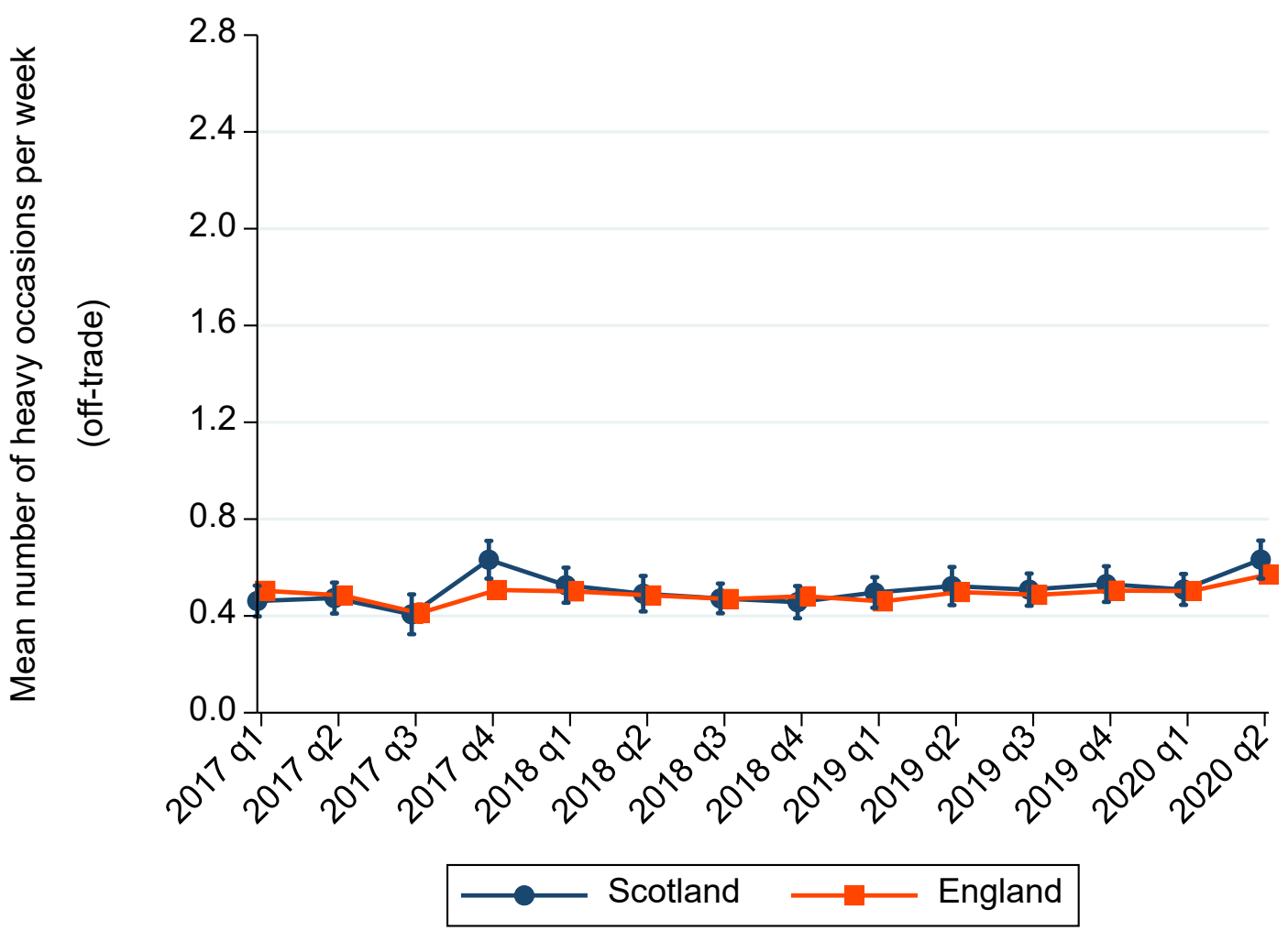


Units of alcohol in the heaviest drinking occasion of the week

Mean units consumed during the heaviest drinking occasion of the week fell in both Scotland and England, although the change was only significant in England (Figure 11). Meanwhile, consumption in the heaviest off-trade drinking occasion showed no significant change (Figure 12). 
Figure 11. Quarterly mean units of alcohol during the heaviest drinking occasion of the week in Scotland and England

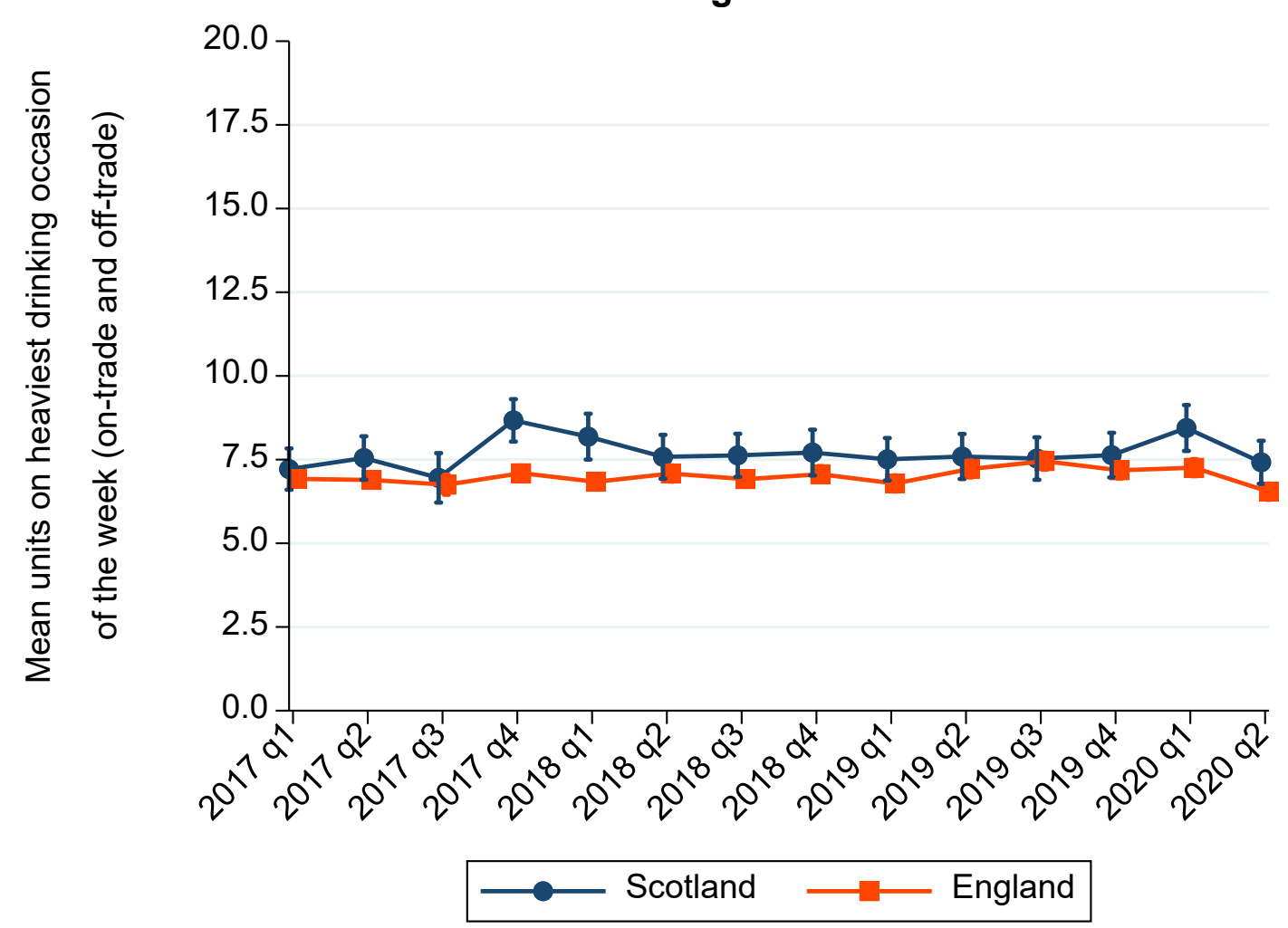

Figure 12. Quarterly mean units of alcohol during the heaviest drinking occasion of the week (off-trade) in Scotland and England

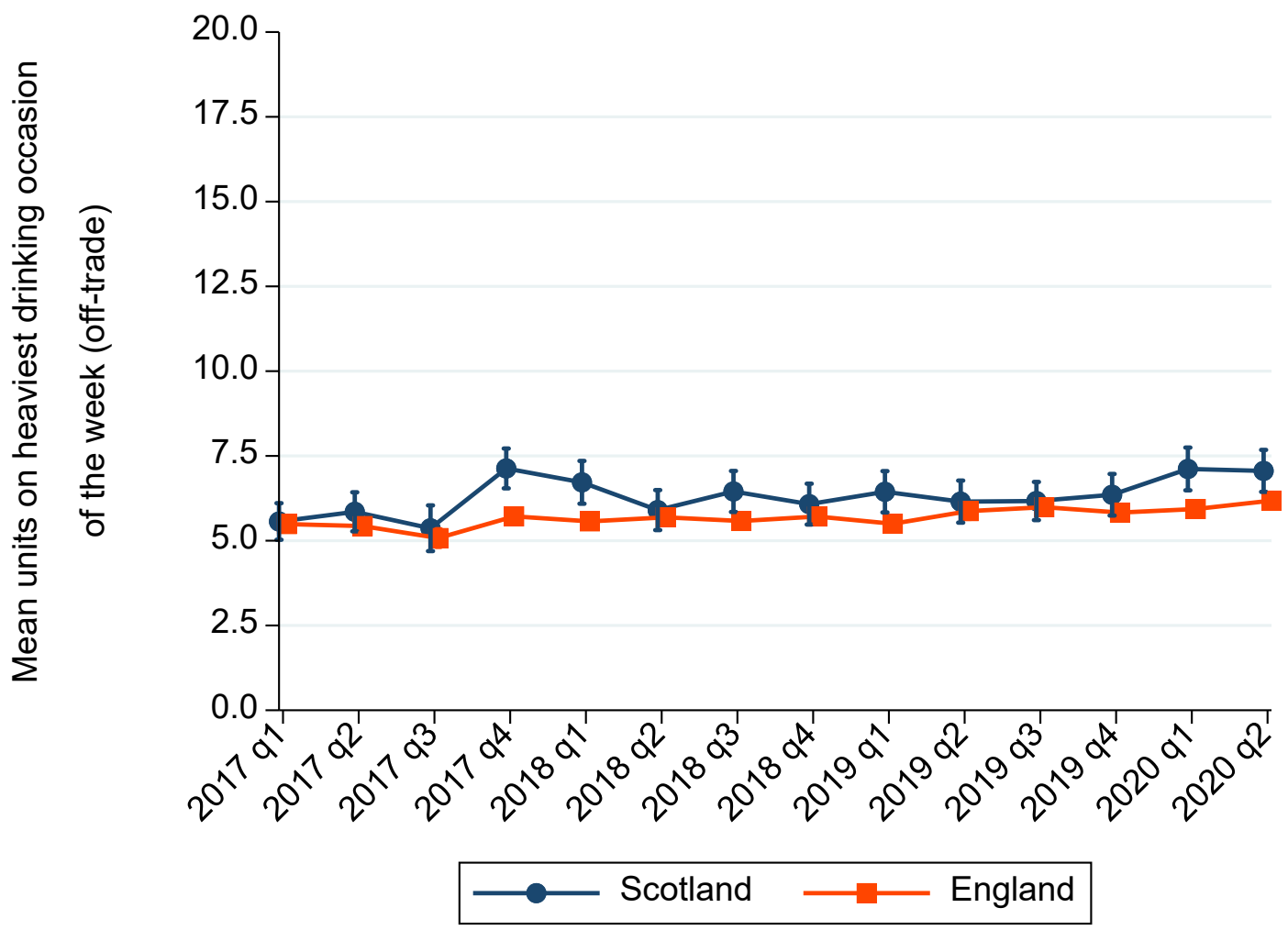




\section{Sensitivity analyses}

\section{Comparing drinking during lockdown to 2020 q1 rather than 2019 q2}

The findings were consistent with the primary results in the sensitivity analysis using the first quarter of 2020 as the comparison point.

\section{Uncapped units of alcohol per week}

The changes during lockdown in the mean units of alcohol consumed per week in England and Scotland were consistent with the primary results in the sensitivity analysis using uncapped measures of alcohol consumption (Appendix B).

\section{Distributional changes in alcohol consumption}

We conducted sensitivity analysis considering the distribution of changes in alcohol consumption. This section presents findings on units of alcohol per week, units of alcohol per occasion, and units in the heaviest drinking occasion of the week. For each measure, the median, 75th percentile, 90th percentile, and 95th percentile of consumption are shown in both Scotland (Figure 13) and England (Figure 14).

By considering levels of alcohol consumption at different percentiles, we can see how the alcohol consumption of the heaviest drinkers changed during lockdown. For example, in a sample of 100 drinkers ordered by their consumption level, the median drinker would be the 50th highest consumer, the 75th percentile would be the 25th highest consumer, the 90th percentile would be the 10th highest consumer and the 95th percentile would be the 5th highest consumer. Tabulated results for all analyses of distributional changes in alcohol consumption are available in Appendix $\mathrm{C}$.

There is limited evidence of variation in trends across the distribution for alcohol consumption outcomes in Scotland and England. There is more evidence of distributional effects in the off-trade for the mean units of alcohol consumed per week, but this appears to reflect heavier drinkers drinking more in the off-trade and maintaining similar levels of consumption overall during lockdown. The increase in off-trade units per week at the 95th percentile of the distribution was less pronounced in England than in Scotland, and there was a slight decline in overall units per week at this percentile in England. 
Figure 13. Alcohol consumption outcomes in Scotland - 50th, 75th, 90th and 95th percentiles of the distribution

Units of alcohol per week (on-trade and off-trade)

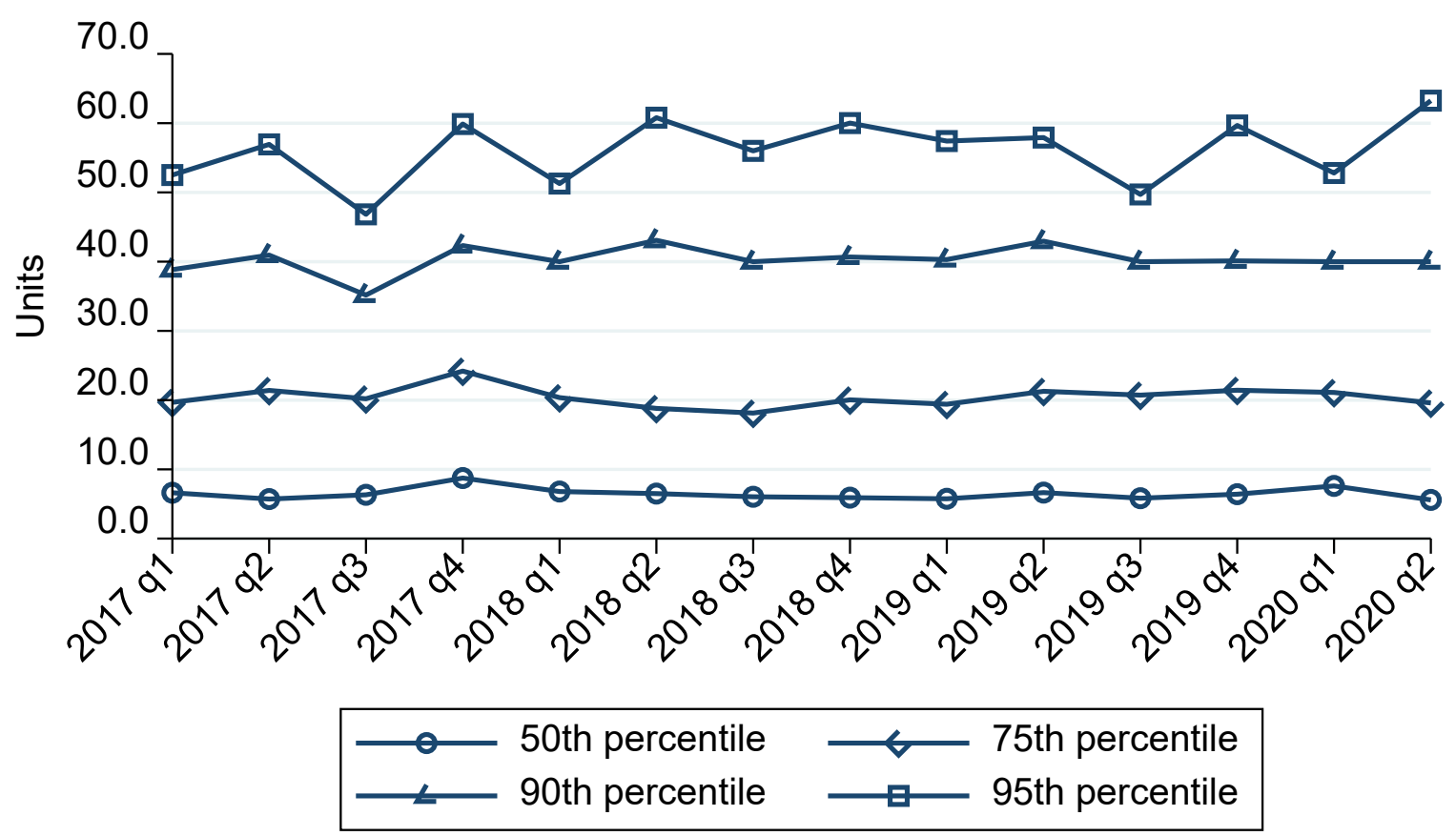

Units of alcohol per week

(off-trade)

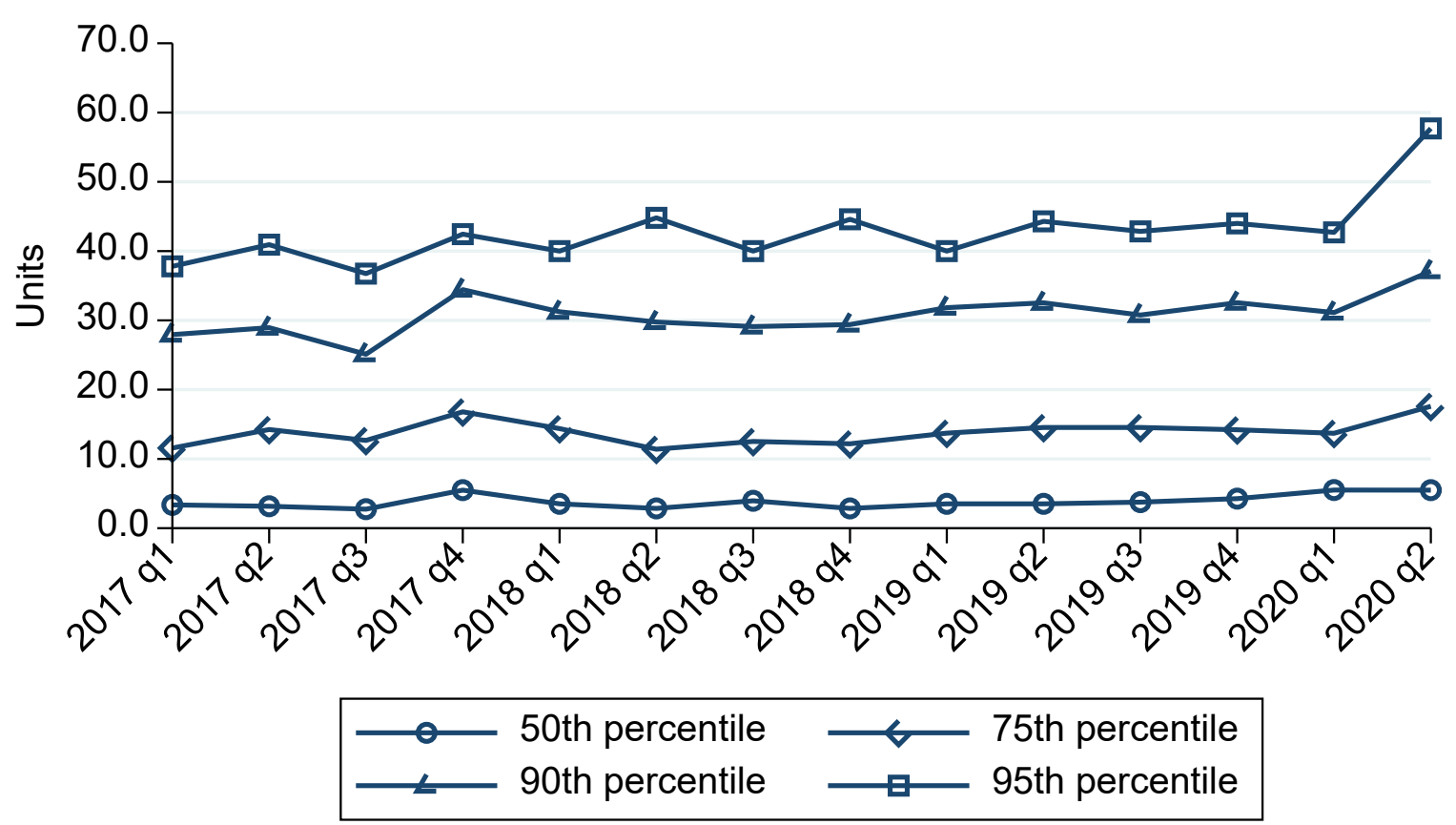


Units of alcohol per occasion (on-trade and off-trade)

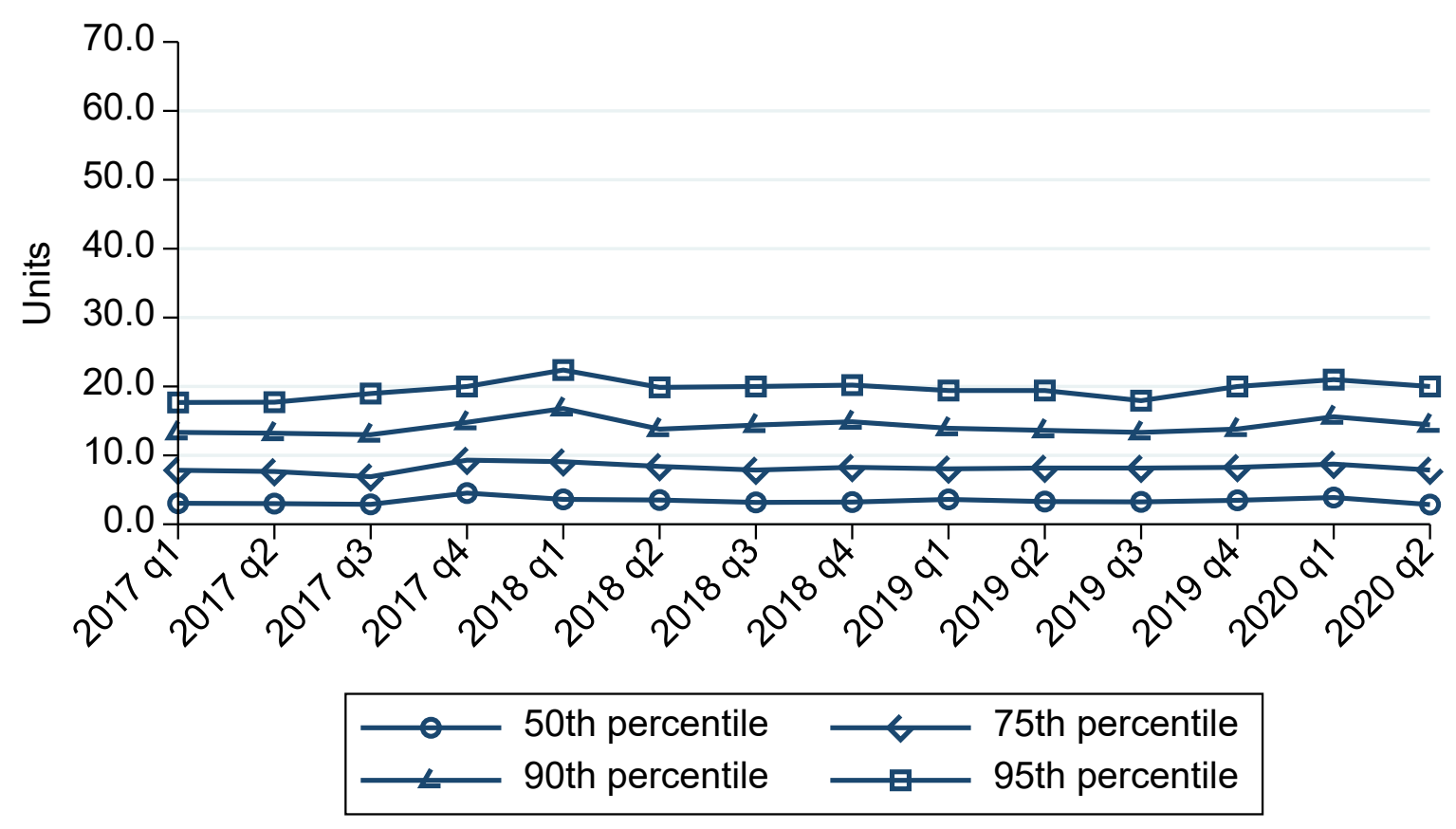

Units of alcohol per occasion

(off-trade)

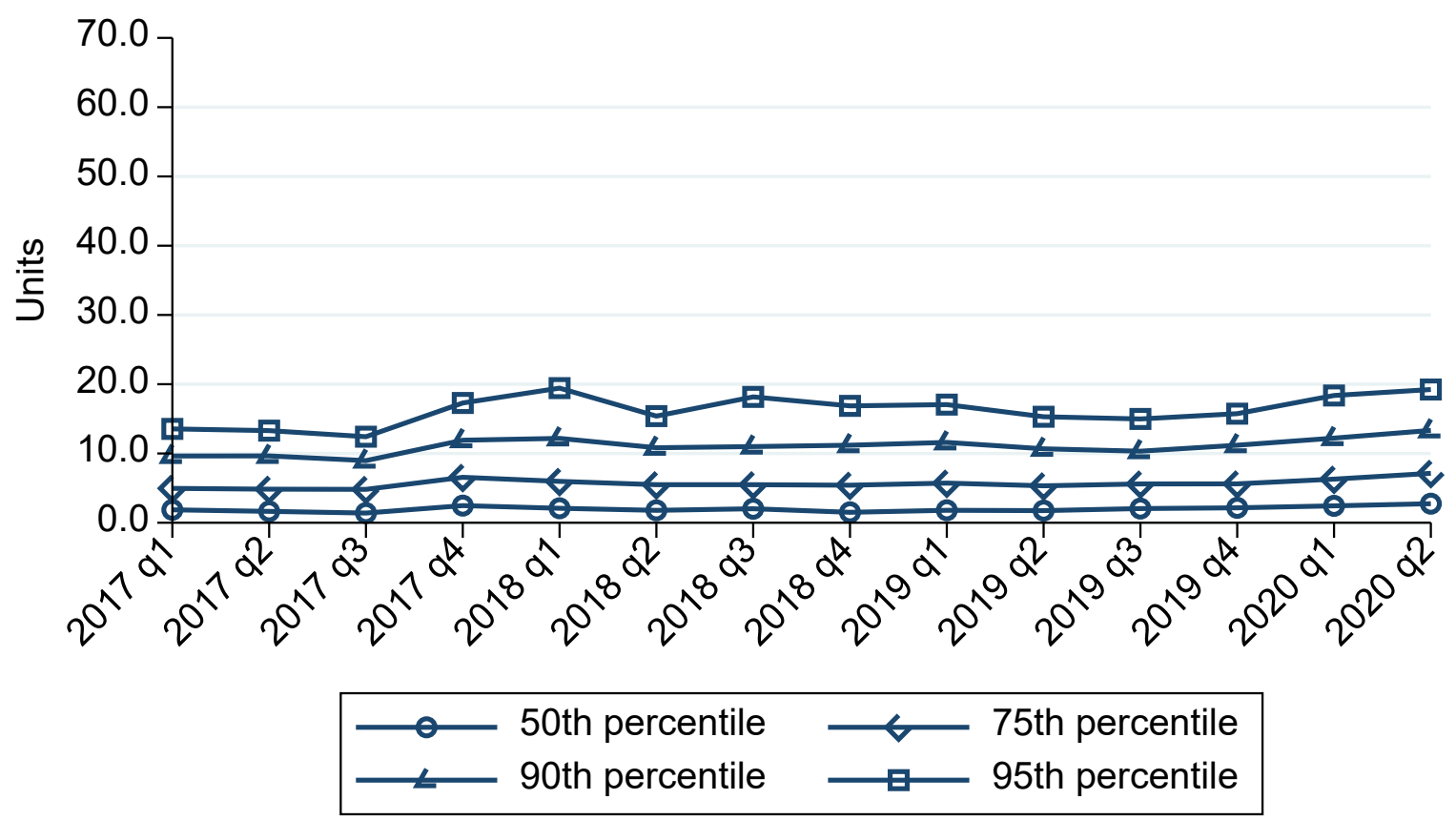


Units on heaviest drinking occasion of the week (on-trade and off-trade)

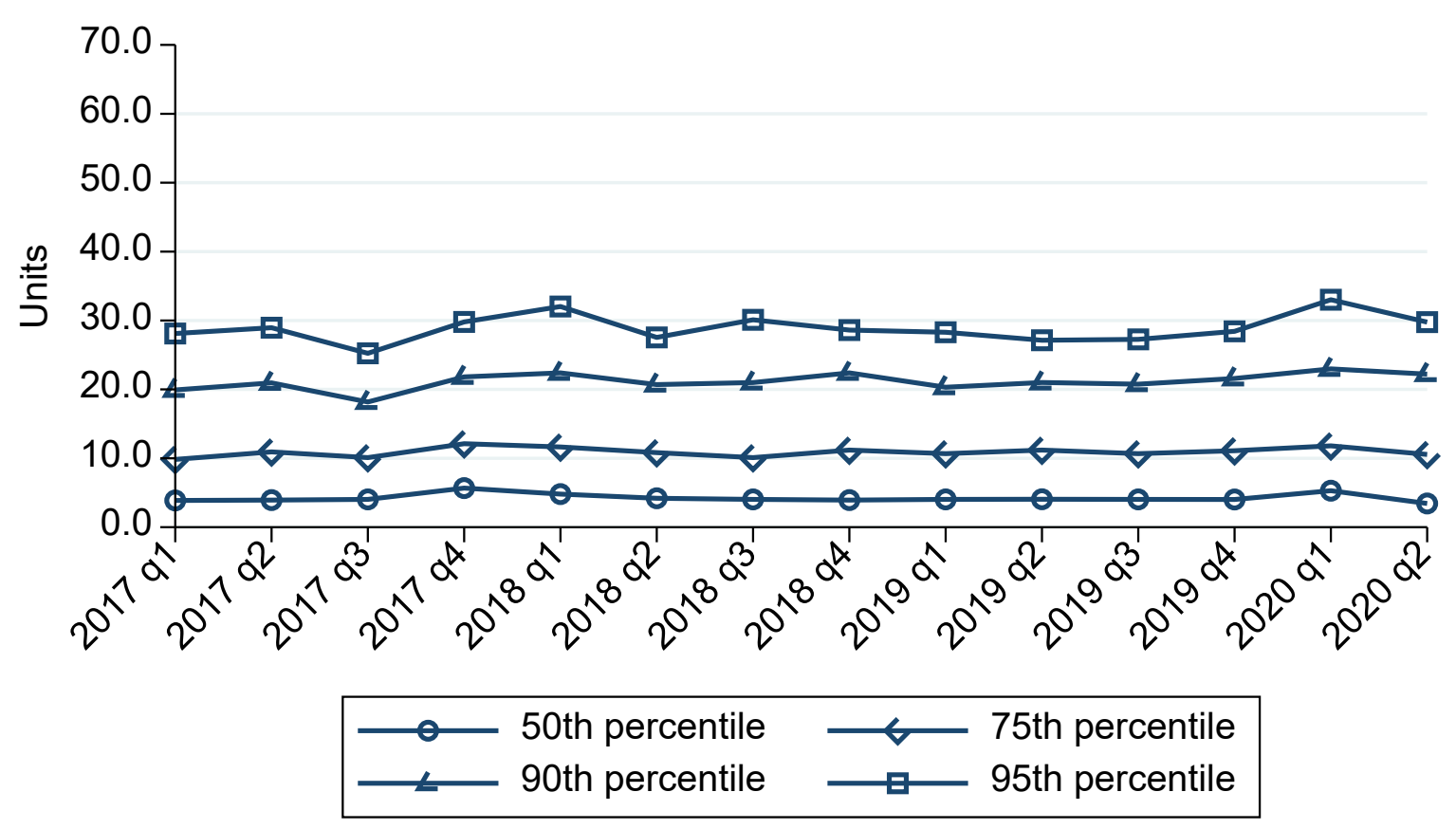

Units on heaviest drinking occasion of the week (off-trade)

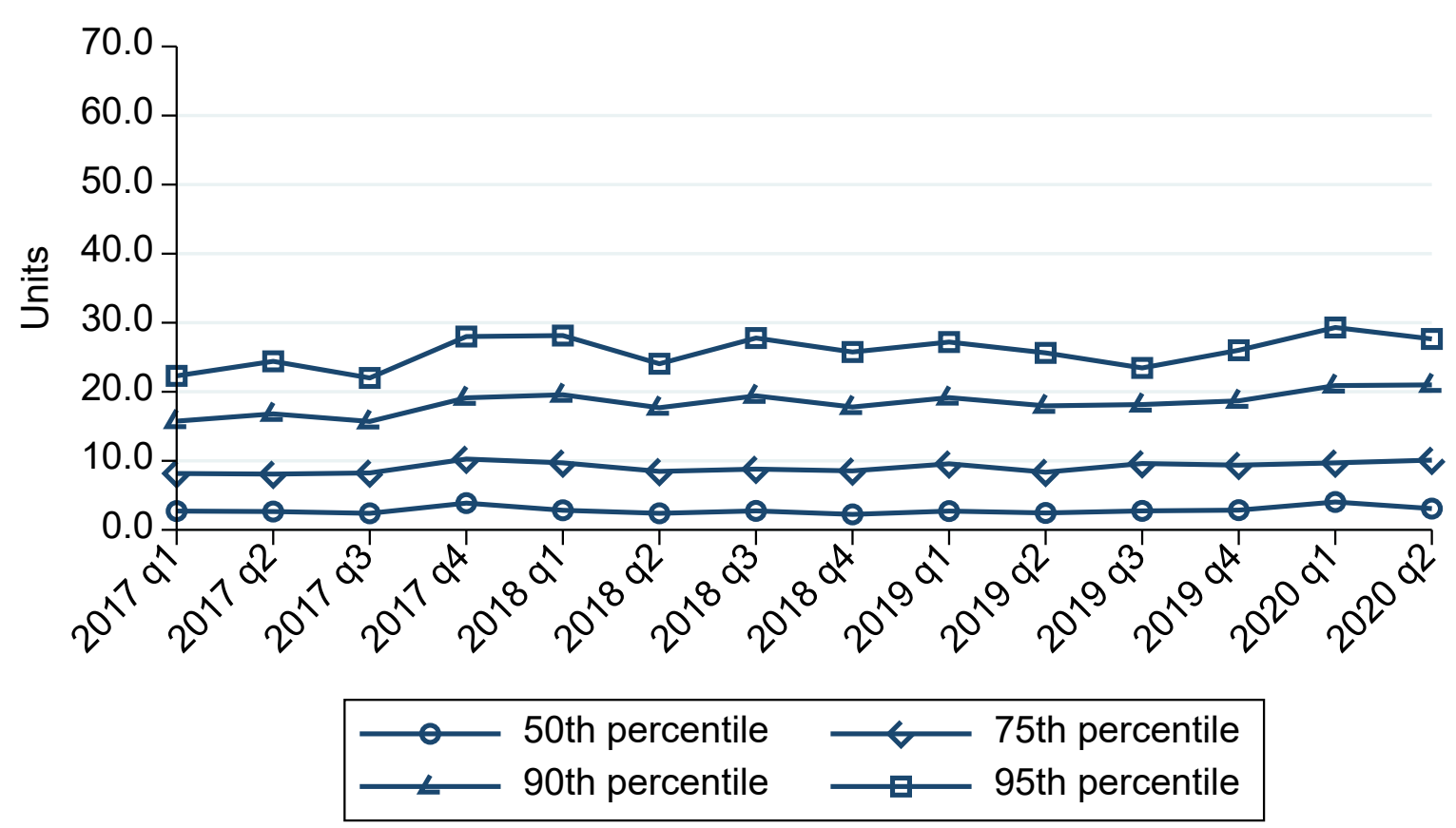


Figure 14. Alcohol consumption outcomes in England - 50th, 75th, 90th and 95th percentiles of the distribution

Units of alcohol per week (on-trade and

off-trade)

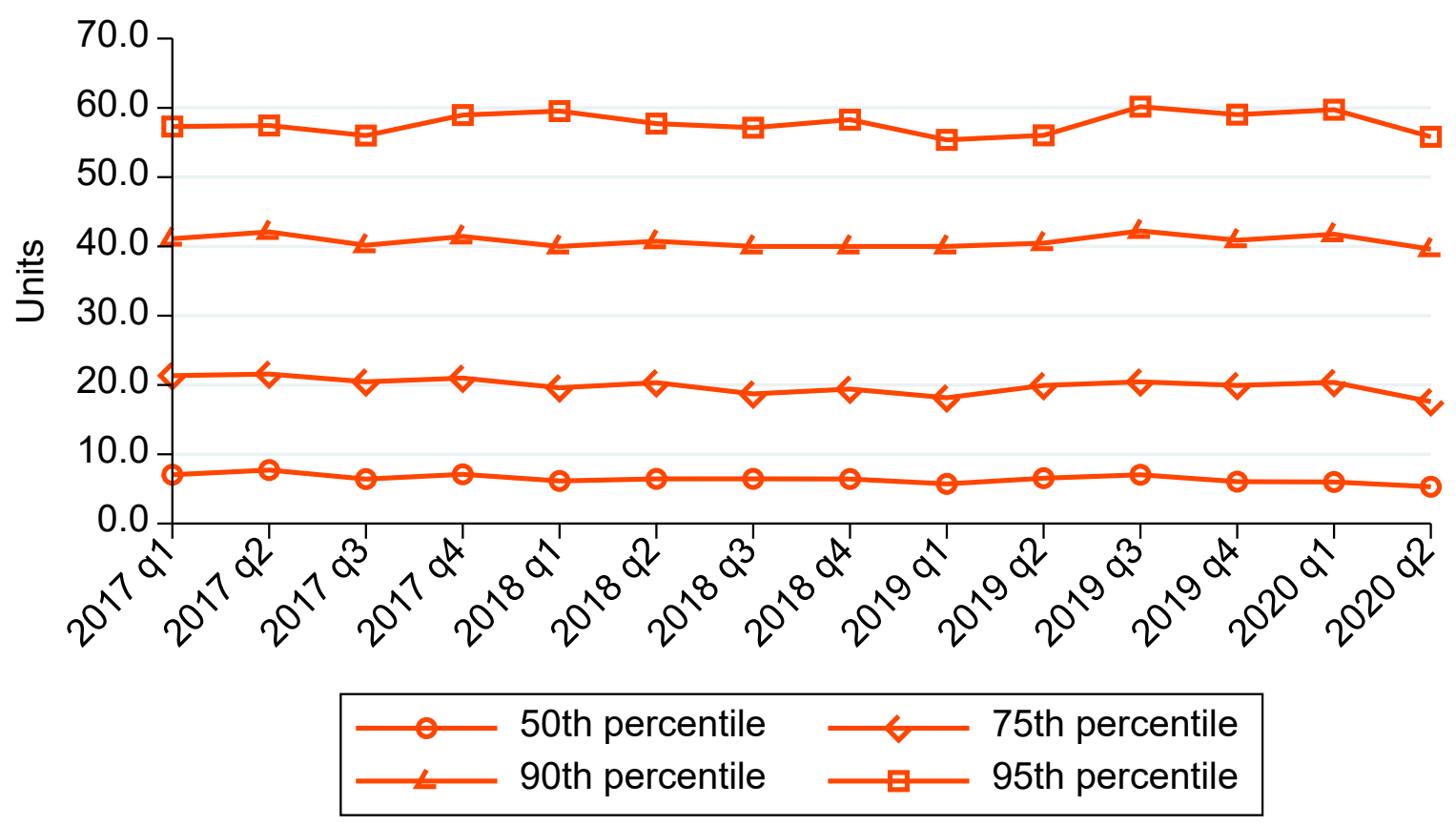

Units of alcohol per week

(off-trade)

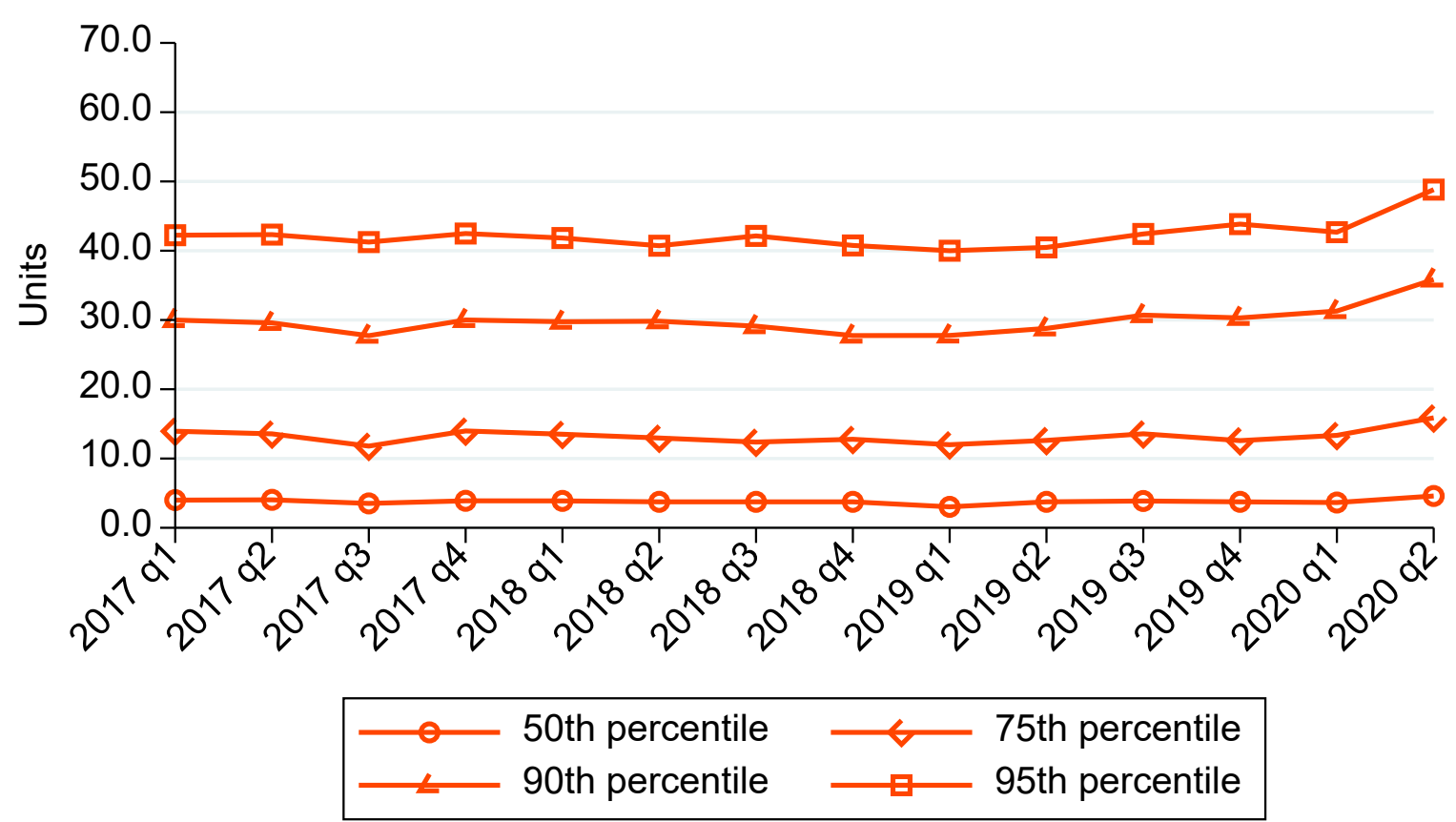


Units of alcohol per occasion (on-trade

and off-trade)

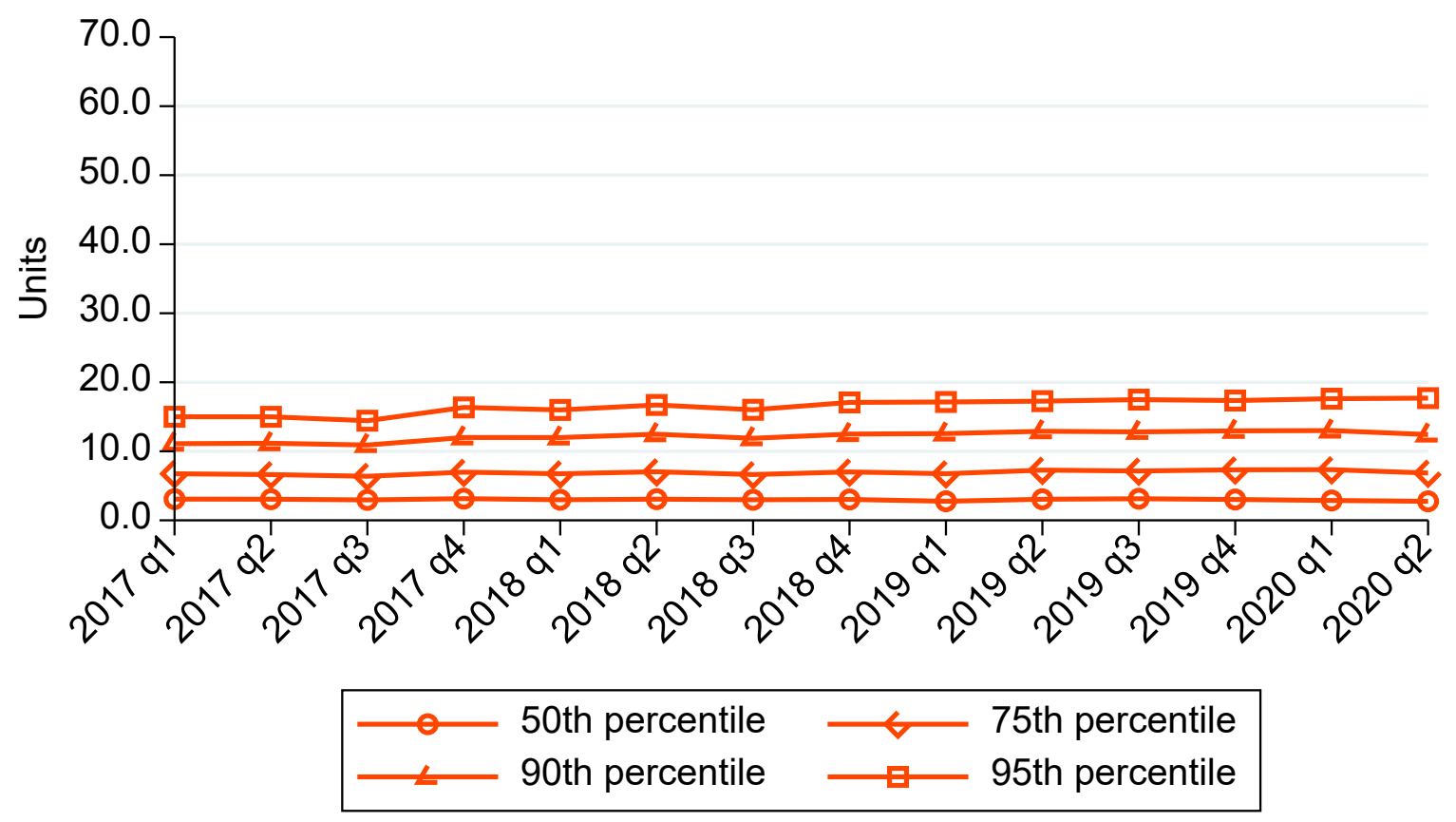

Units of alcohol per occasion

(off-trade)

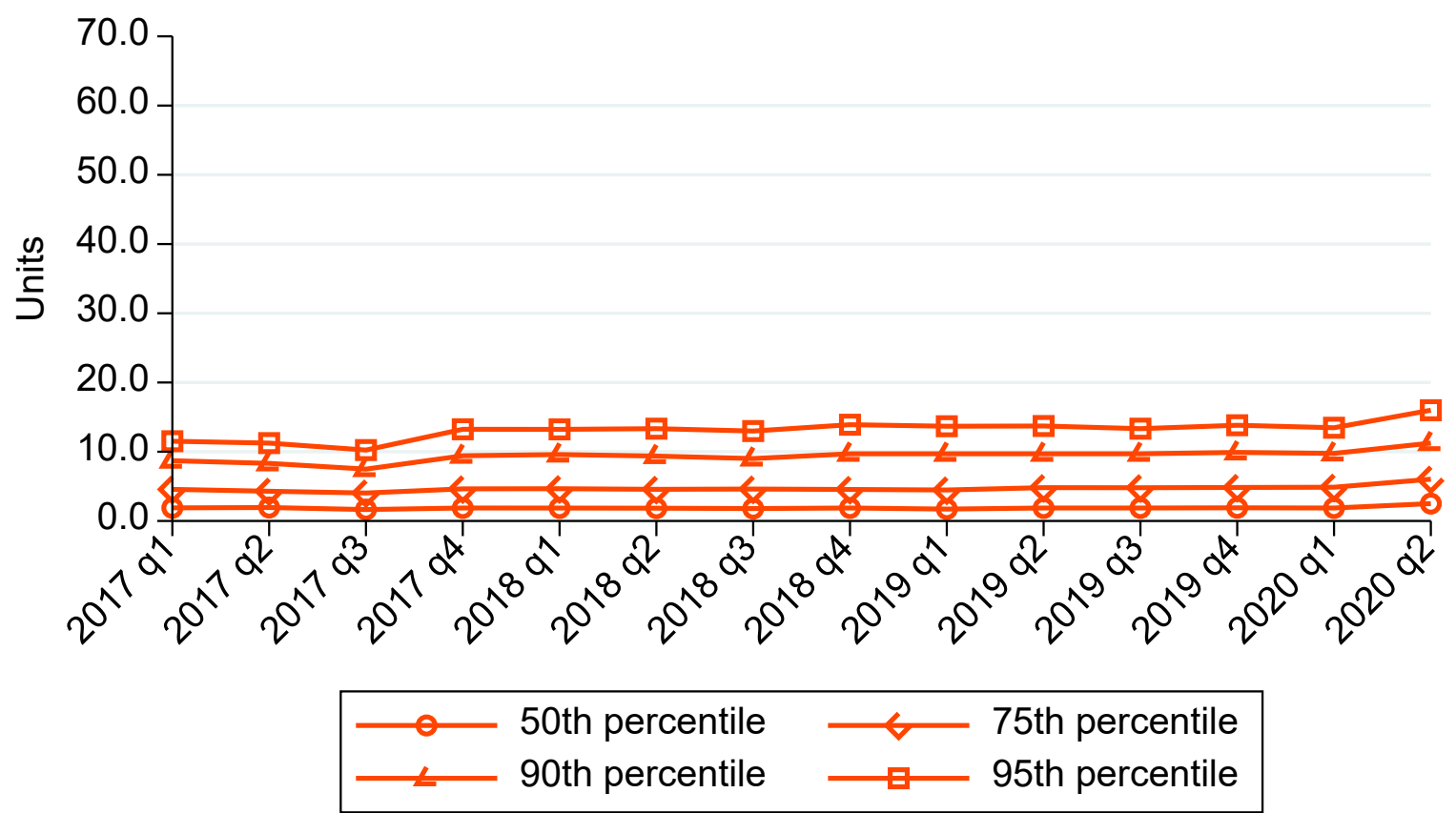


Units on heaviest drinking occasion of the week (on-trade and off-trade)

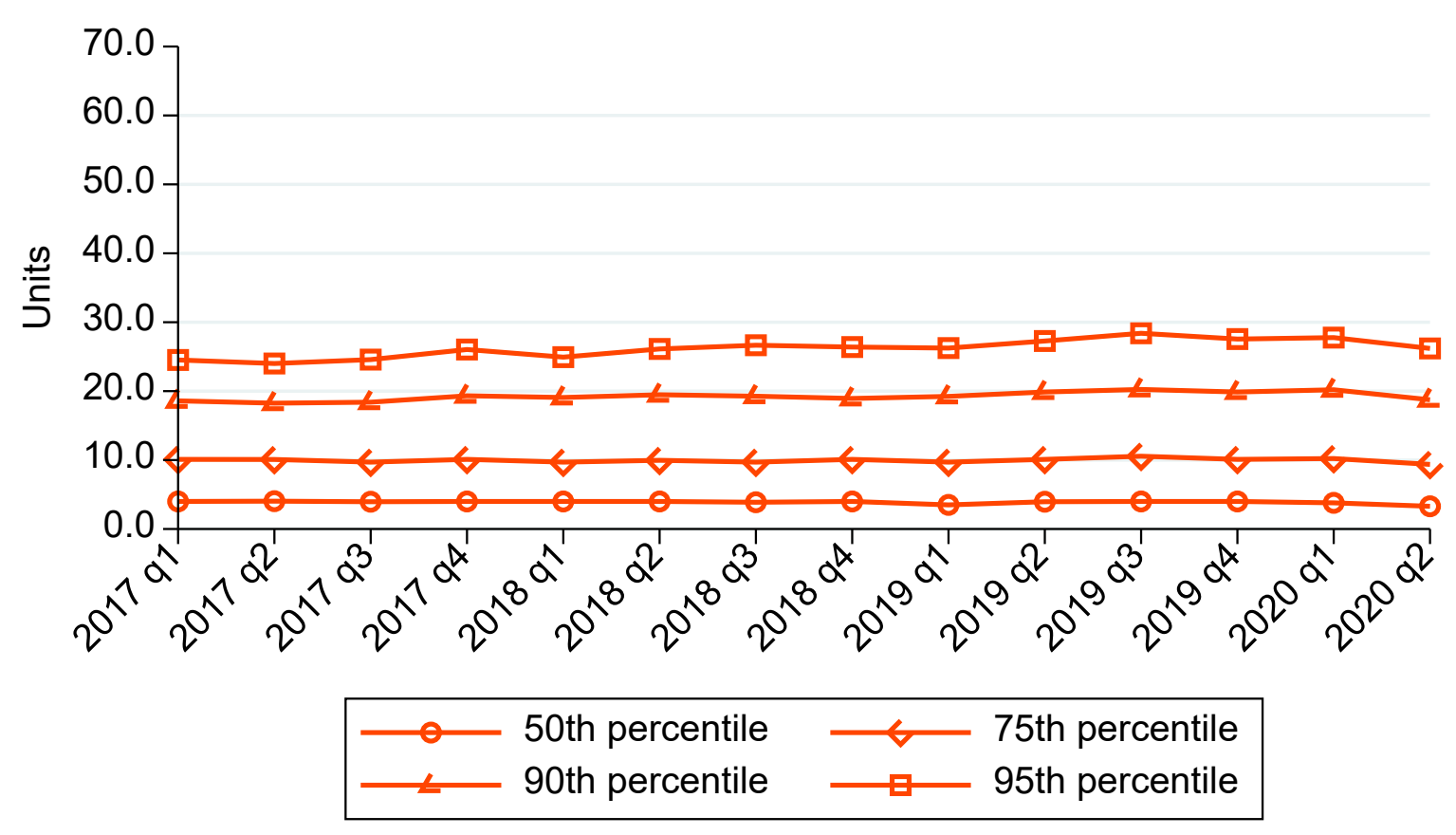

Units on heaviest drinking occasion of the week (off-trade)

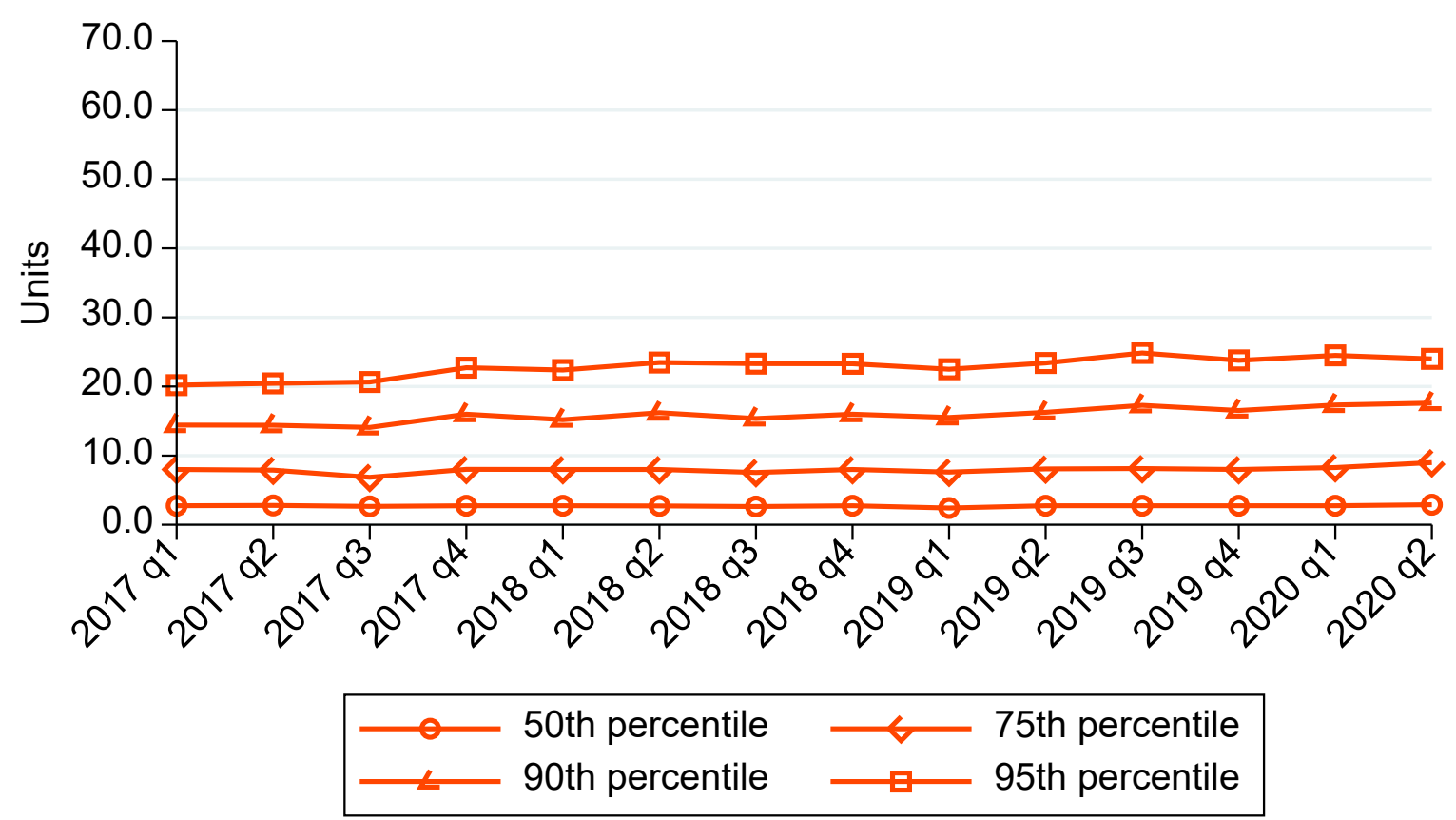




\section{Secondary outcomes}

To understand the effects of lockdown on alcohol consumption in more detail, we analysed three secondary outcomes using data from participants who reported drinking occasions in the diary week. Tabulated results for all secondary outcomes from 2017-2020 are available in Appendix A.

\section{Start time per day}

On days when participants reported drinking, the mean time of the first drinking occasion shifted later in the evening during lockdown in both Scotland and England (Figure 15). In Scotland, this shift was from 17:53 (Cl: 17:38-18:07) to 18:31 (Cl: 18:20-18:43). In England, it was from 17:40 (Cl: 17:34-17:46) to 18:10 (Cl: 18:05$18: 15)^{*}$.

There was no significant change in mean start time for off-trade occasions in Scotland or England (Figure 16).

\footnotetext{
* These start times are based on data collected in bands - we used the earliest times in the bands as point-estimates. The bands used were; before midday, between midday and $1: 59 \mathrm{pm}$, between $2: 00 \mathrm{pm}$ and $4: 59 \mathrm{pm}$, between $5: 00 \mathrm{pm}$ and $5: 59 \mathrm{pm}$, between $6: 00 \mathrm{pm}$ and $6: 59 \mathrm{pm}$, between $7: 00 \mathrm{pm}$ and $7: 59 \mathrm{pm}$, between $8: 00 \mathrm{pm}$ and $8: 59 \mathrm{pm}$, between 9:00pm and 9:59pm, between 10:00pm and 10:59pm, between 11:00pm and 11:59pm, midnight or later.
} 
Figure 15. Quarterly mean start time per day in Scotland and England

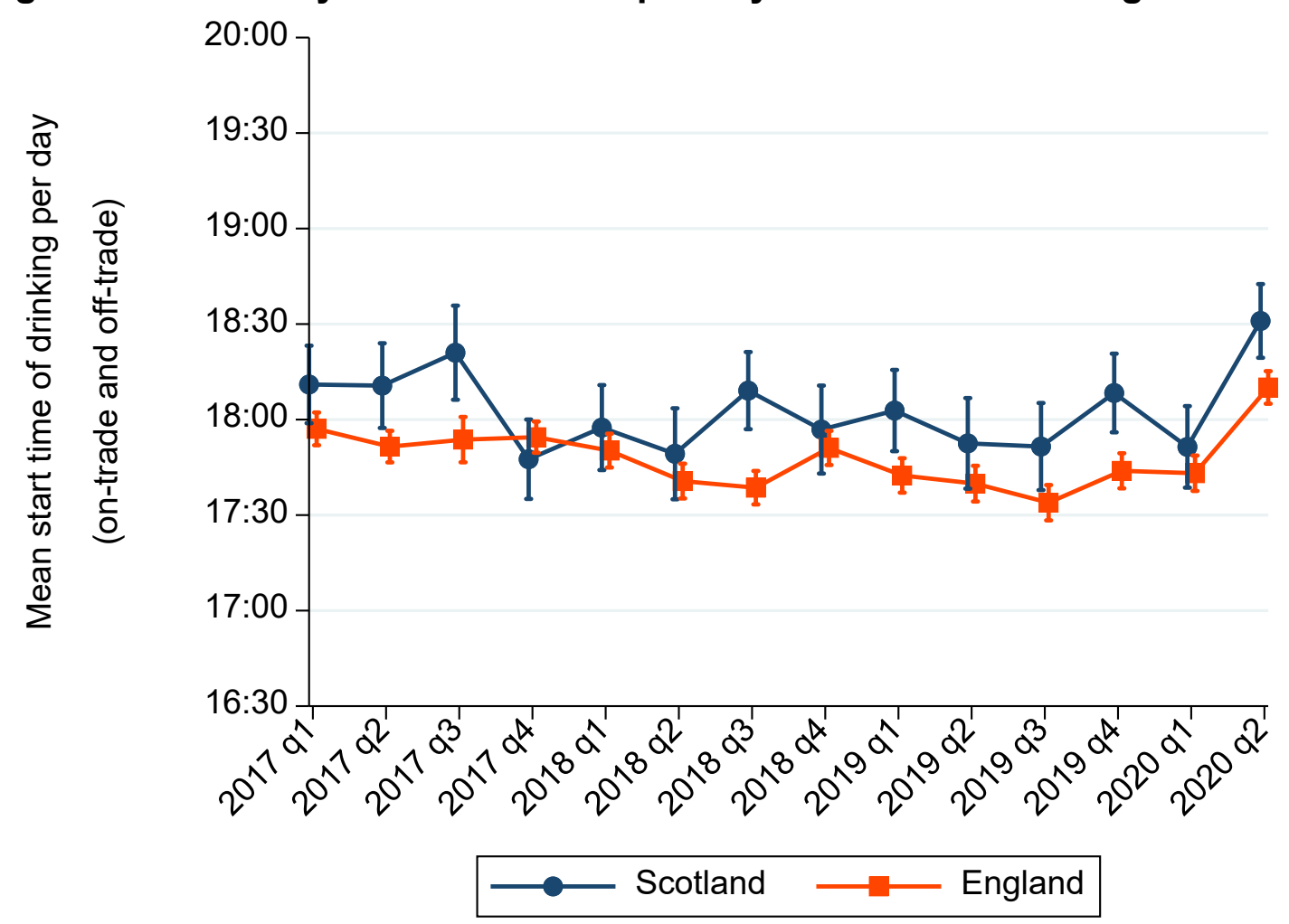

Figure 16. Quarterly mean start time per day (off-trade) in Scotland and England

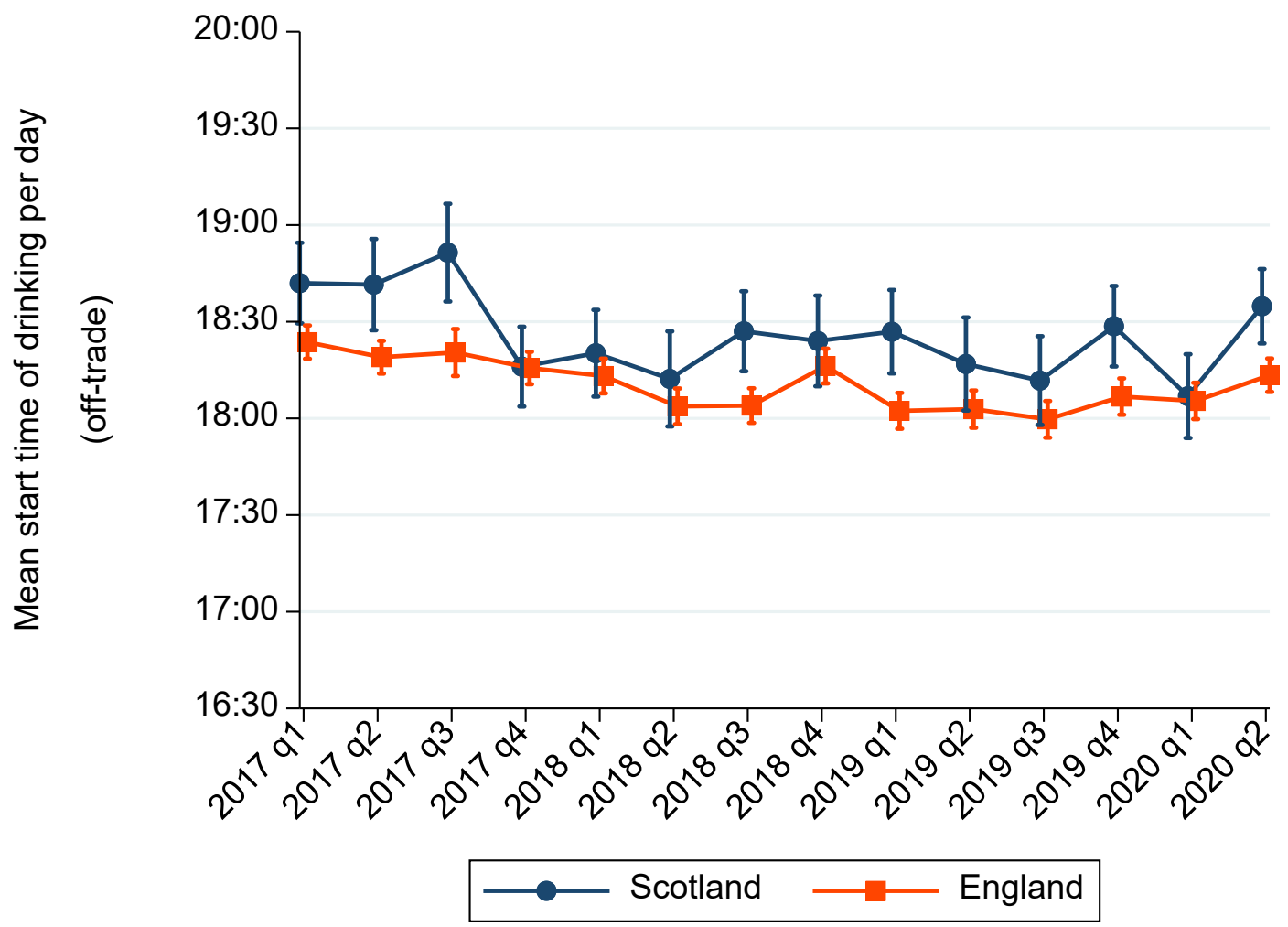




\section{Number of weekday drinking occasions starting before 17:00 per week}

The mean number of drinking occasions starting before 17:00 on weekdays (Monday to Friday) fell to a similar degree in both Scotland and England during lockdown (Figure 17). This change was significant in England with the mean falling from 0.3 $(\mathrm{Cl}: 0.3-0.3)$ to $0.2(\mathrm{Cl}: 0.2-0.3)$ but not significant in Scotland with the mean falling from $0.3(\mathrm{Cl}: 0.2-0.3)$ to $0.2(\mathrm{Cl}: 0.1-0.2)$.

There was no significant change in the mean number of these occasions per week in the off-trade in either Scotland or England (Figure 18). Overall, this suggests that the reduction in earlier on-trade drinking occasions was not replaced with earlier off-trade drinking. 
Figure 17. Quarterly mean number of weekday drinking occasions before 17:00 per week in Scotland and England

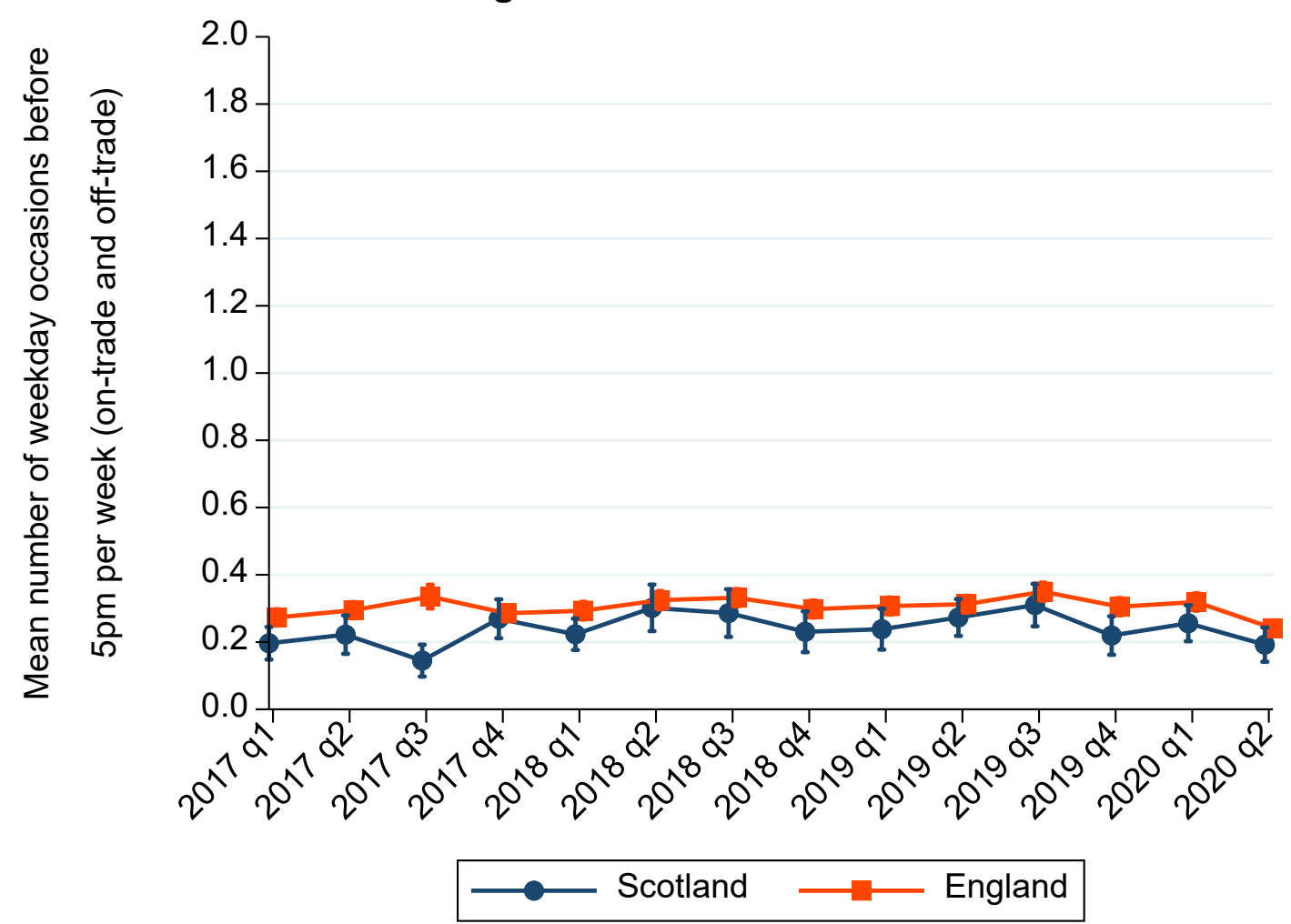

Figure 18. Quarterly mean number of weekday drinking occasions before 17:00 per week (off-trade) in Scotland and England

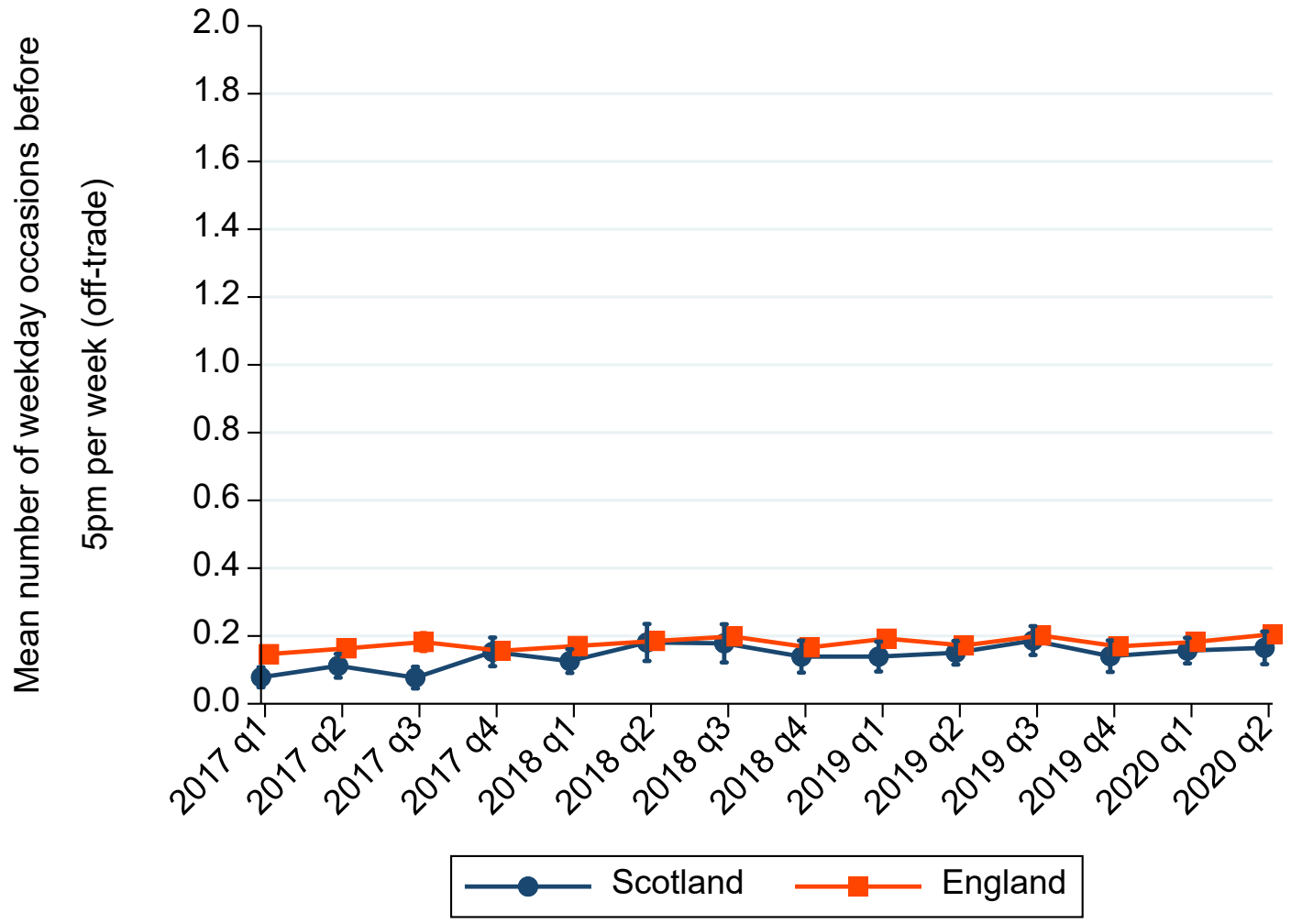


Number of occasions involving drinking alone per week

There was no significant change in the mean number of solitary drinking occasions overall in Scotland or England (Figure 19).

In the off-trade, the mean number of solitary occasions increased both in England from $0.5(\mathrm{Cl}: 0.5-0.6)$ to $0.6(\mathrm{Cl}: 0.6-0.7)$ - and to a much larger extent in Scotland from 0.5 (Cl: $0.4-0.6)$ to 0.9 (Cl: 0.7-1.0; Figure 20). 
Figure 19. Quarterly mean number of solitary drinking occasions per week in Scotland and England

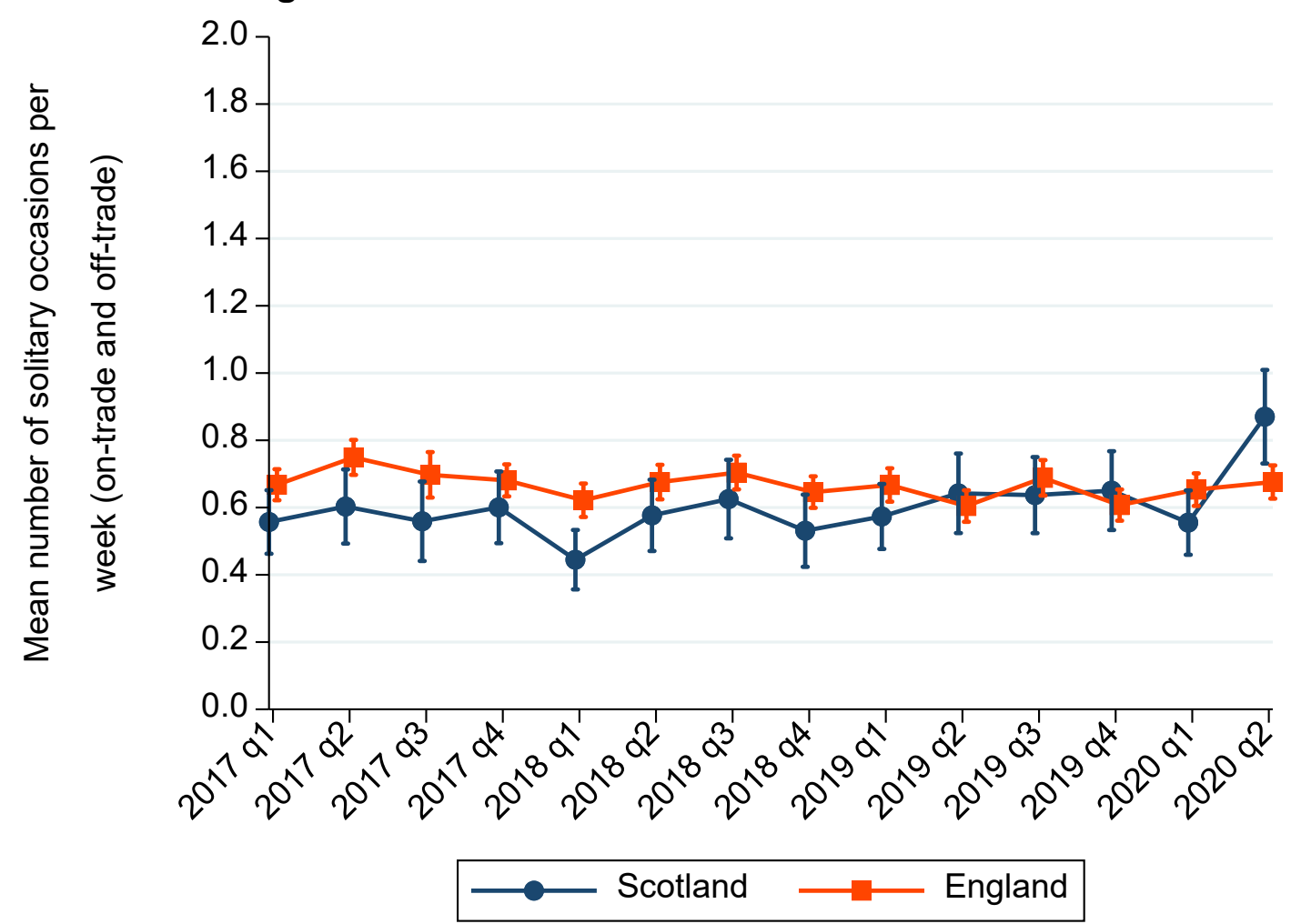

Figure 20. Quarterly mean number of solitary drinking occasions per week (off-trade) in Scotland and England

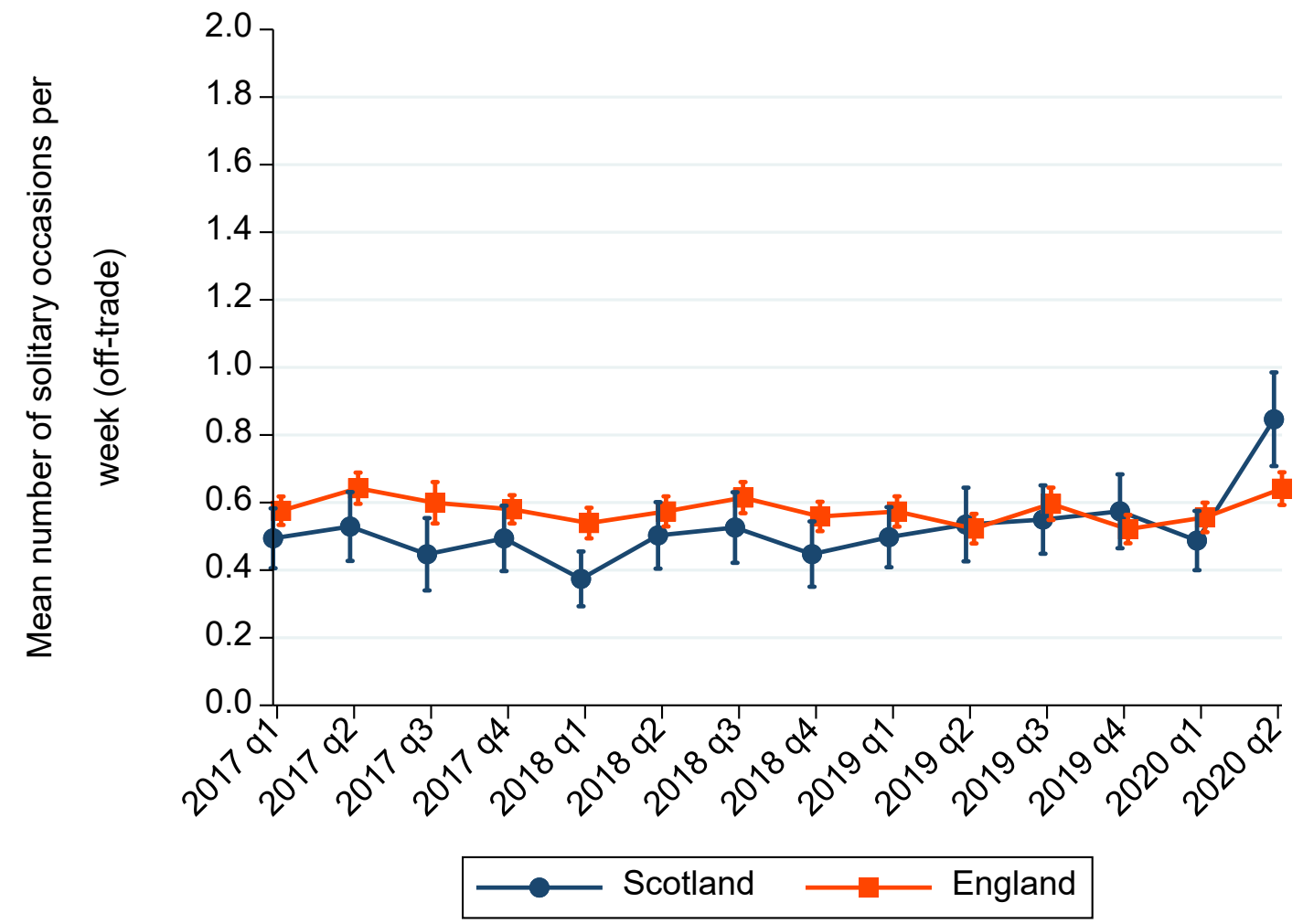




\section{Subgroup analyses in Scotland}

The following sections will consider how lockdown affected different population subgroups in Scotland. Tabulated results for all subgroup analyses in Scotland are available in Appendix A and for England in Appendix D. All graphs for Scotland are available in Appendix $E$ and for England in Appendix $F$.

\section{Men and women}

There were no significant changes in the number of drinking days and drinking occasions per week during lockdown for men or women.

There were no significant changes in the overall level of alcohol consumption during lockdown for men or women. Across the four measures of alcohol consumption (units per week, units per occasion, number of heavy occasions, and units in heaviest occasion), any falls in on-trade consumption were offset by increases in off-trade drinking.

There were some differences between the pre- and during-lockdown periods in men and women's drinking based on the secondary outcome measures. In Scotland, women's average start time shifted later into the evening both overall and in the off-trade (Figure 21). On the other hand, the timing of men's drinking occasions showed no significant change. 
Figure 21. Quarterly mean start time of drinking per day for men and women in Scotland
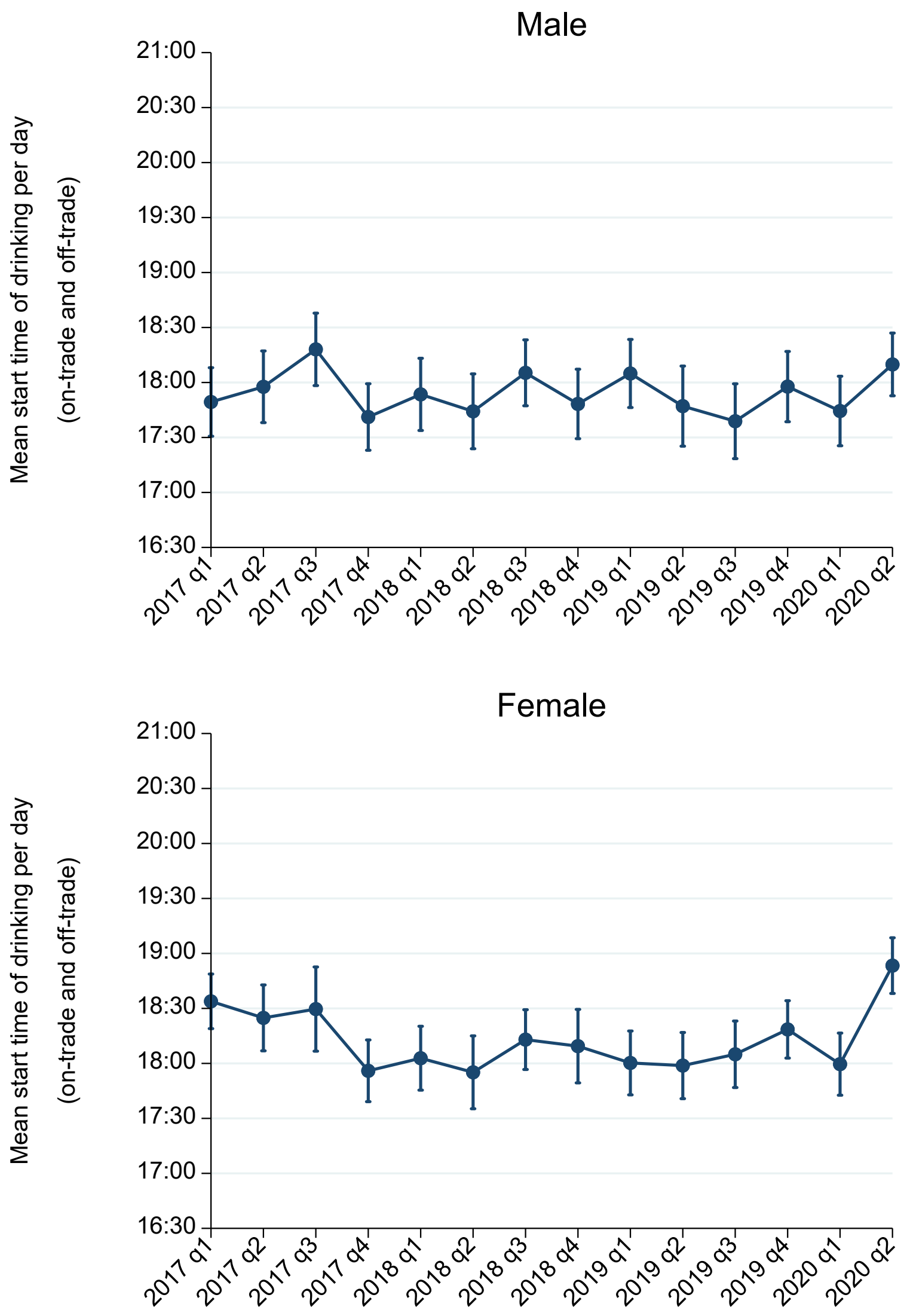
The number of occasions of drinking starting before 17:00 on weekdays showed no significant change for both men and women.

Finally, the number of solitary drinking occasions per week increased for both men and women, although these changes were not significant. There was a significant increase in women's mean number of off-trade solitary drinking occasions from 0.4 (Cl: $0.2-0.5)$ to $0.6(\mathrm{Cl}: 0.5-0.8)$ and a non-significant increase for men from $0.7(\mathrm{Cl}$ : $0.5-0.9)$ to 1.1 (Cl: 0.8-1.3; Figure 22). 
Figure 22. Quarterly mean number of solitary drinking occasions per week (off-trade) for men and women in Scotland
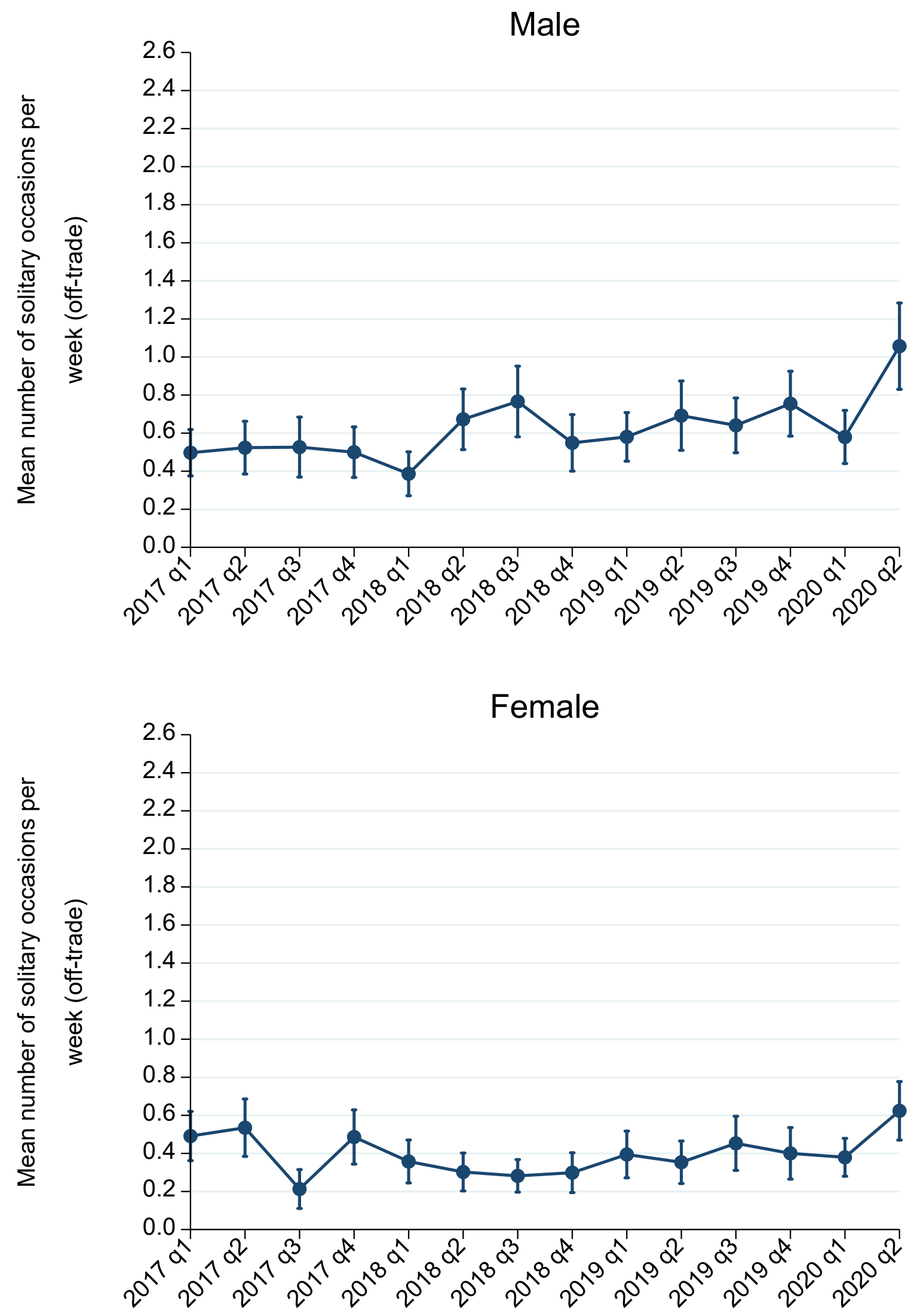


\section{Age groups}

There were no significant changes across all age groups in the number of drinking days per week and number of drinking occasions per week during lockdown. Increases in their off-trade drinking frequency offset the lack of on-trade drinking. Level of alcohol consumption measures also showed no significant change for any age group.

The mean start time of drinking per day showed no significant change for most age groups. However, for 55+ year olds drinking shifted later into the day overall (Figure 23).

There were no significant changes in the frequency of drinking alone or starting drinking before 17:00 on weekdays overall. Any reduction in these occasions in the on-trade was offset by changes in off-trade drinking occasions. 
Figure 23. Quarterly mean start time of drinking per day by age group in Scotland
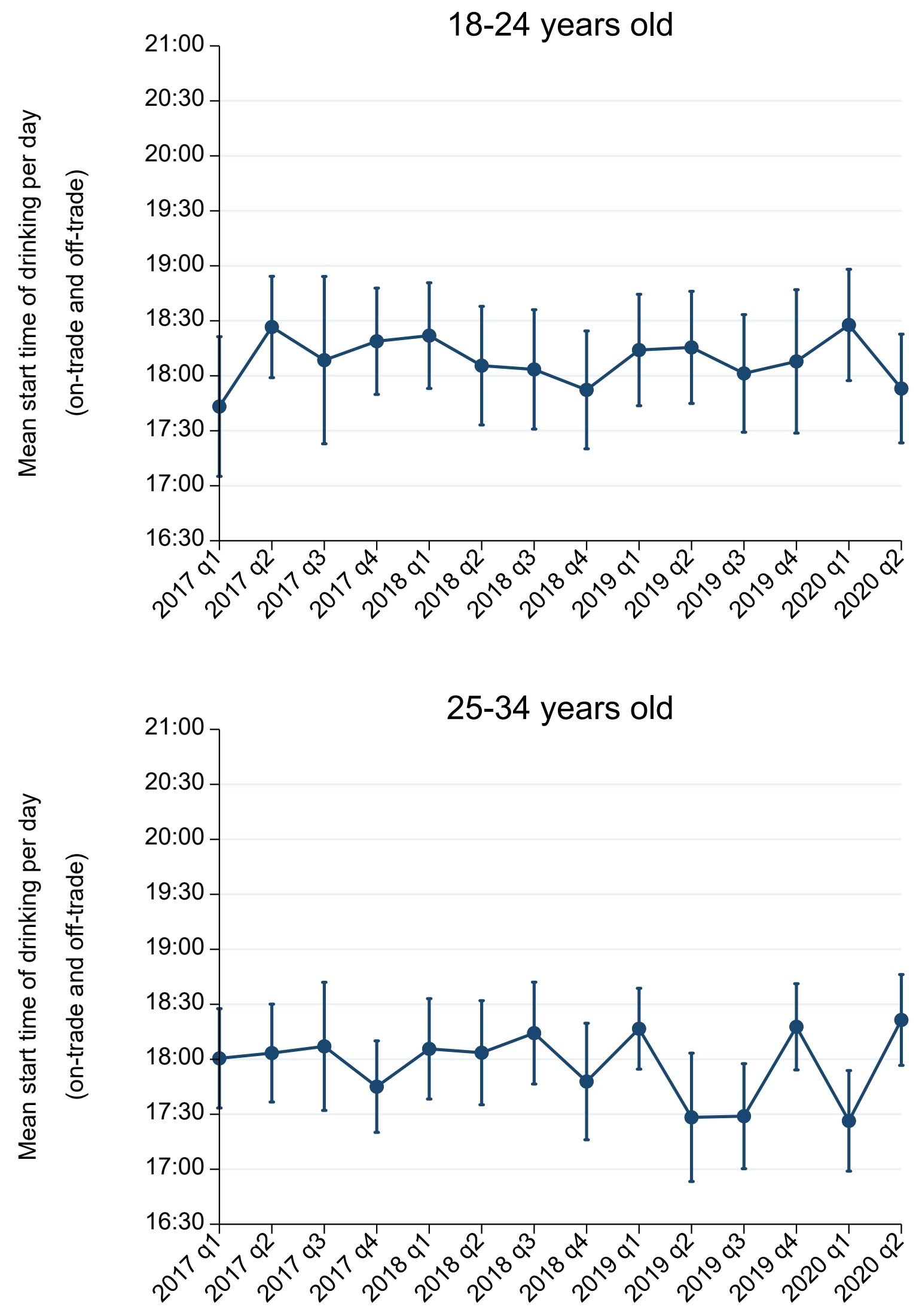

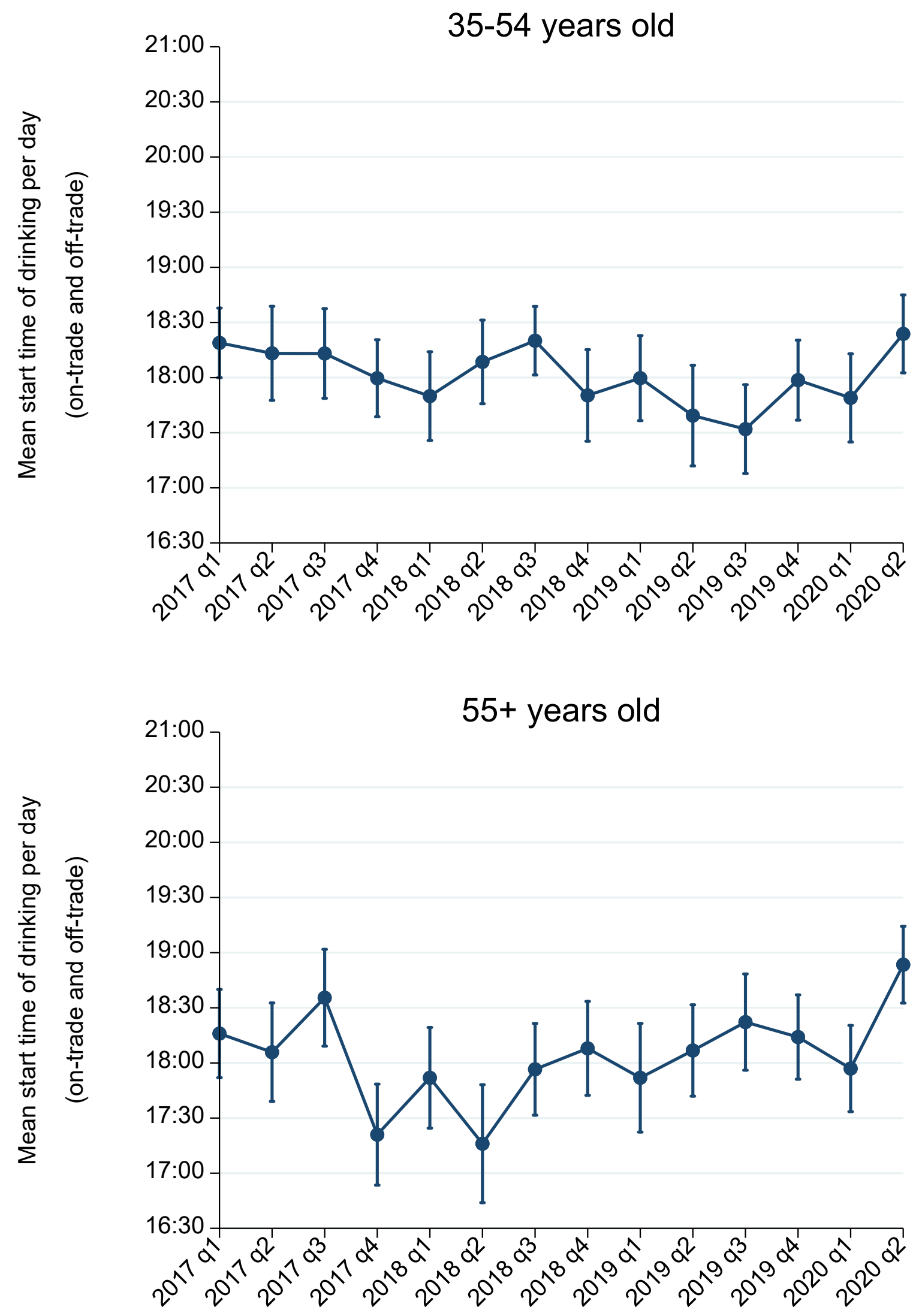


\section{Social grade}

Across all social grades, there were no significant changes in the number of drinking days and drinking occasions per week. Their off-trade drinking frequency increased and offset the fall in on-trade drinking. There were also no significant changes across the four level of alcohol consumption measures.

There were no significant changes in the mean start time of drinking per day, the number of drinking occasions starting before 17:00 on weekdays, or the mean number of solitary drinking occasions. Increases in the number of off-trade solitary drinking occasions offset any reductions in on-trade solitary drinking (Figure 24). 
Figure 24. Quarterly mean number of solitary drinking occasions per week (off-trade) by social grade in Scotland
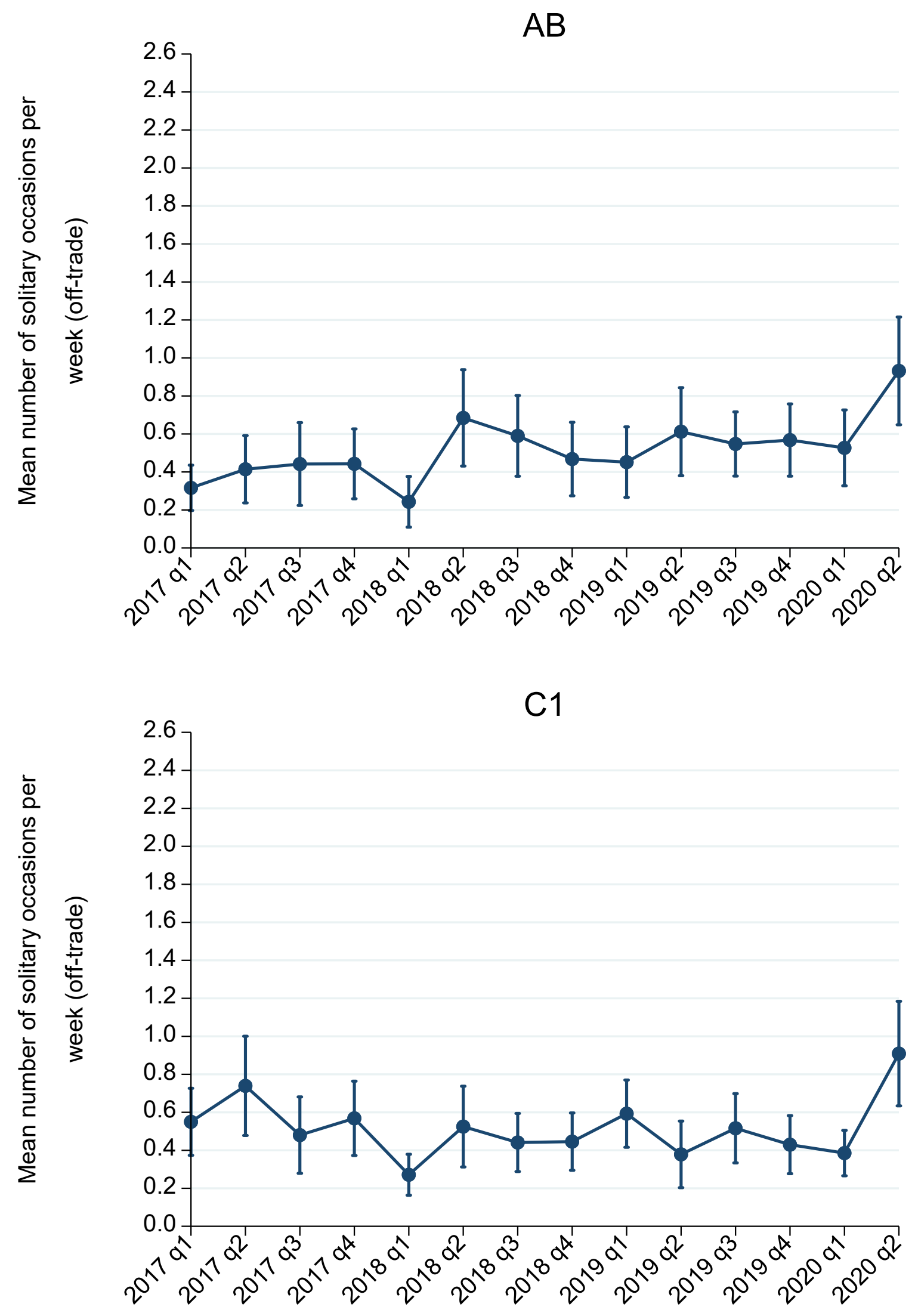

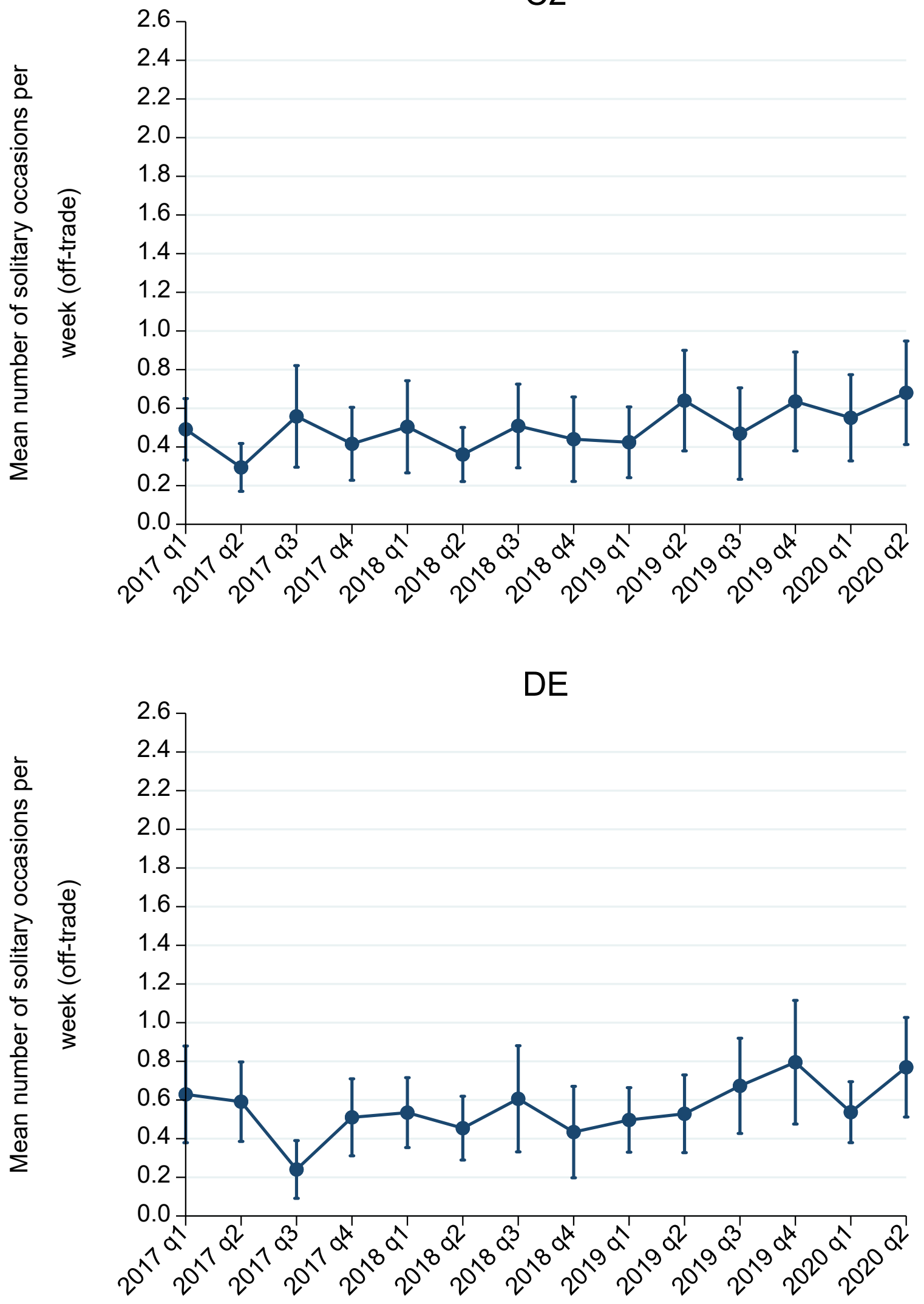


\section{Number of adults in the household}

There were no significant changes overall in drinking frequency or alcohol consumption levels for households with one or two adults. For example, the mean units of alcohol per occasion for households with one adult changed from 5.1 (Cl: 4.3-6.0) to $5.2(\mathrm{Cl}: 4.2-6.1)$ and for households with two adults from 5.9 (Cl: 5.2-6.7) to 5.1 (Cl: 4.5-5.7). Any falls in drinking frequency or consumption levels in the on-trade were offset by off-trade consumption. However, there was an increase in the mean units of alcohol per occasion for households with three or more adults, from $4.5(\mathrm{Cl}: 3.7-5.3)$ to $6.4(\mathrm{Cl}: 5.3-7.5)$.

The mean start time of drinking per day shifted significantly later for households with two adults, from 17:34 (Cl: 17:15-17:54) to 18:35 (Cl: 18:20-18:51), but not single adult households (from 18:08 [Cl: 17:38-18:38] to 18:38 [Cl: 18:12-19:04]) or those with three or more adults (from 18:21 [Cl: 17:53-18:49] to 18:12 [Cl: 17:49-18:34]; Figure 25). 
Figure 25. Quarterly mean start time of drinking per day by number of adults in the household in Scotland

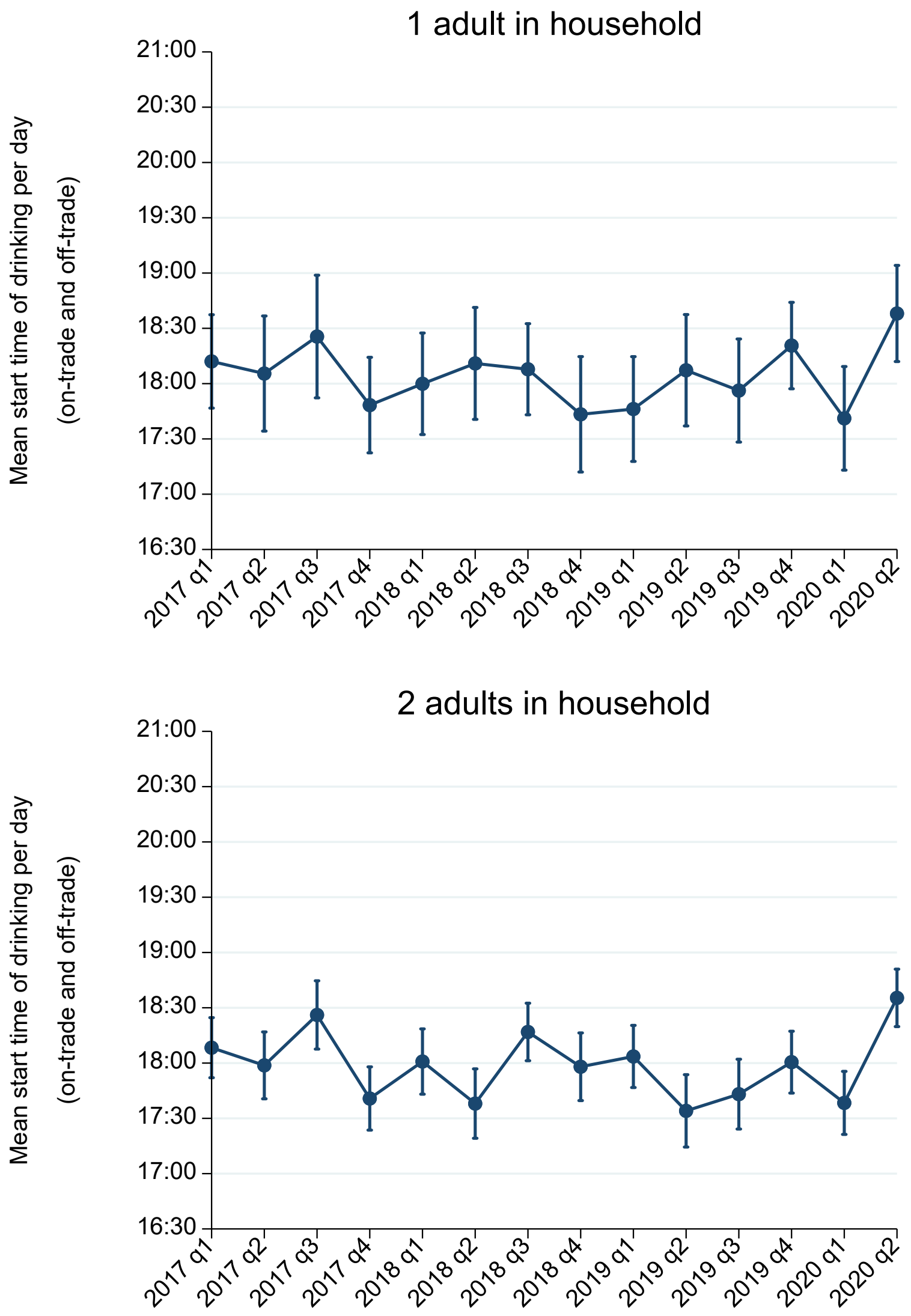




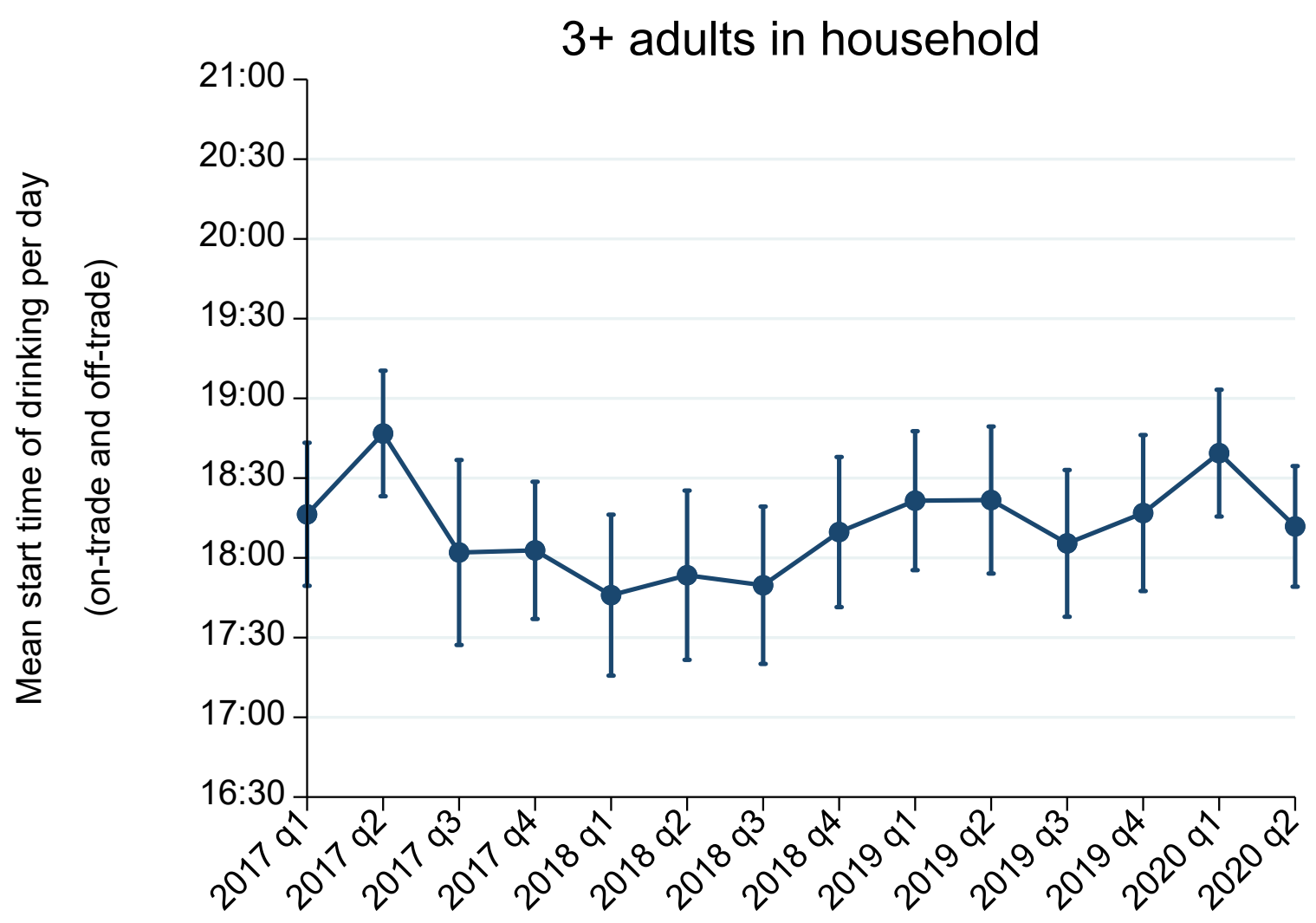

There were no significant changes in the mean number of occasions starting before 17:00 on weekdays.

There was a small significant increase in solitary drinking occasions for households with three or more adults both overall and in the off-trade (Figure 26). There was also an increase for single adult households, although this was not statistically significant. 
Figure 26. Quarterly mean number of solitary drinking occasions per week by number of adults in the household in Scotland
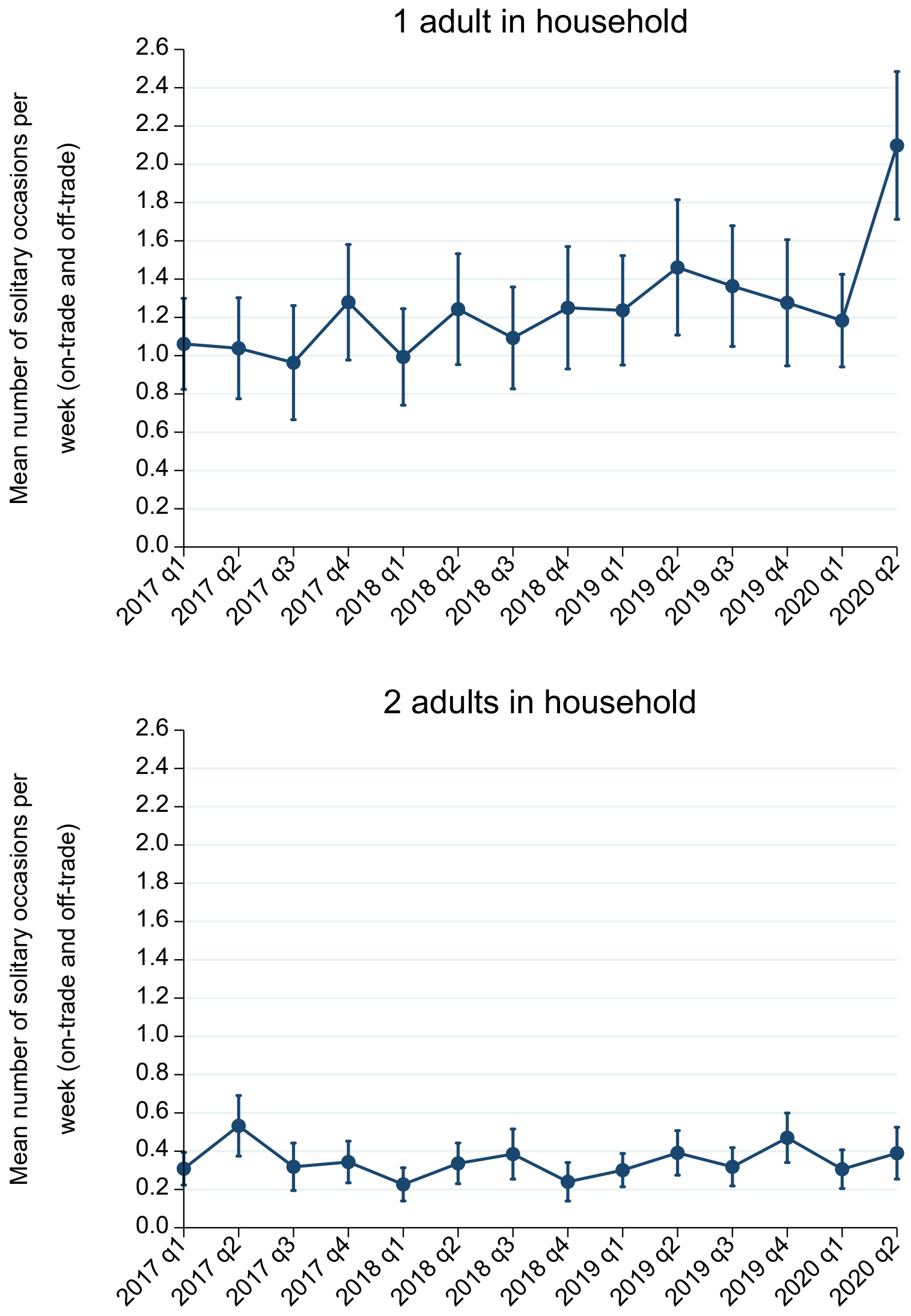


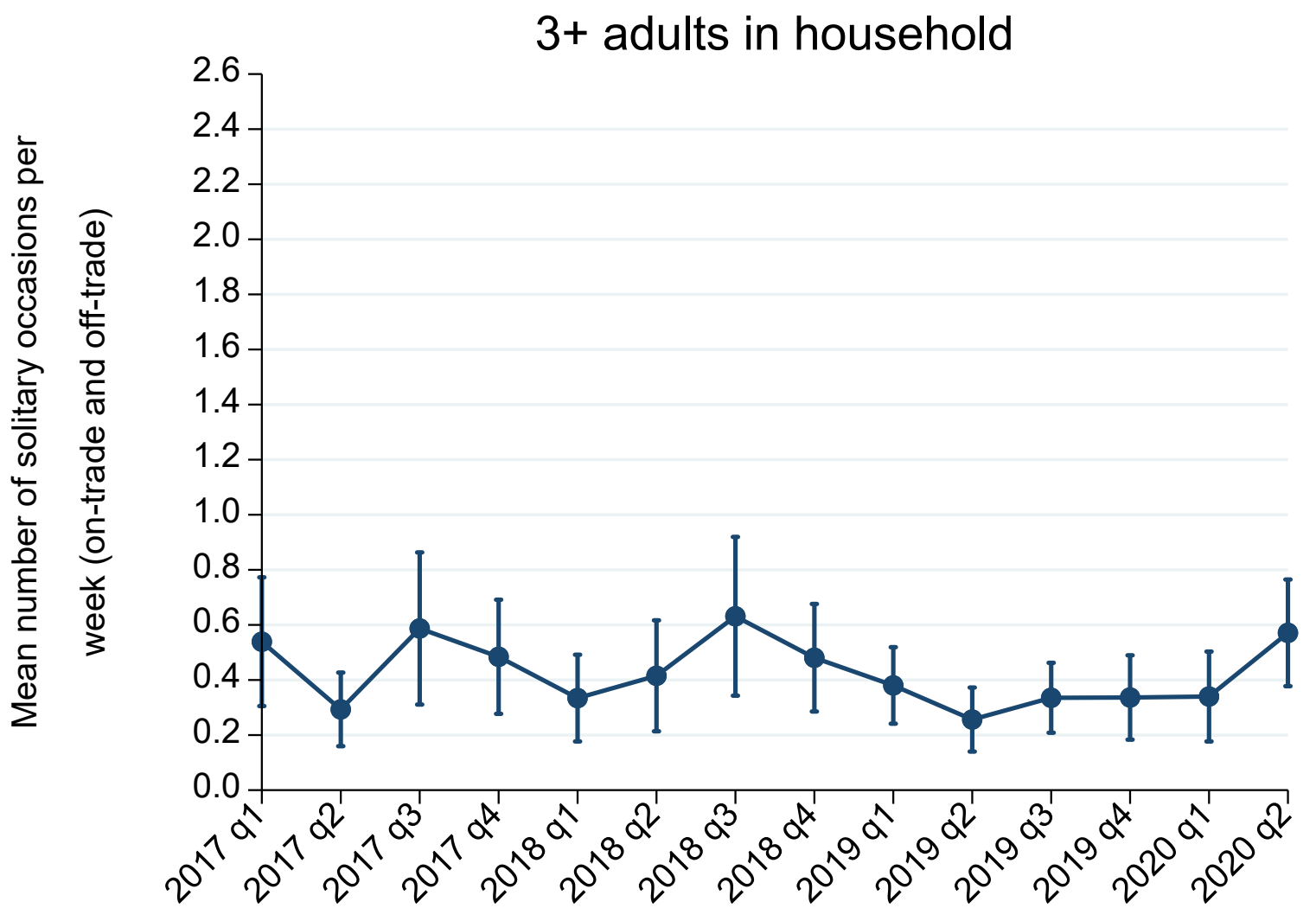

\section{Number of children in the household}

People with and without children in the household showed no significant changes in number of drinking days per week and number of occasions per week, with increases in their off-trade drinking frequency offsetting the lack of on-trade drinking. Level of alcohol consumption measures also showed no significant change for those with and without children in the household. There was a larger increase in the mean number of units per occasion in the off-trade for those with no children. This suggests that they drank more per occasion in the on-trade prior to lockdown.

The mean start time of drinking per day showed no significant change in the off-trade for both groups. Meanwhile, the overall start time for people with no children in the household shifted later at night from $17: 56(\mathrm{Cl}: 17: 40-18: 13)$ to $18: 35$ (Cl: 18:2218.49; Figure 27). There was no significant change in the overall start time for those with children in the household (from 17:44 [Cl: 17:26-18:11] to 18:18 [Cl: 17:5518:41]). 
Figure 27. Quarterly mean start time of drinking per day for people with and without children in Scotland
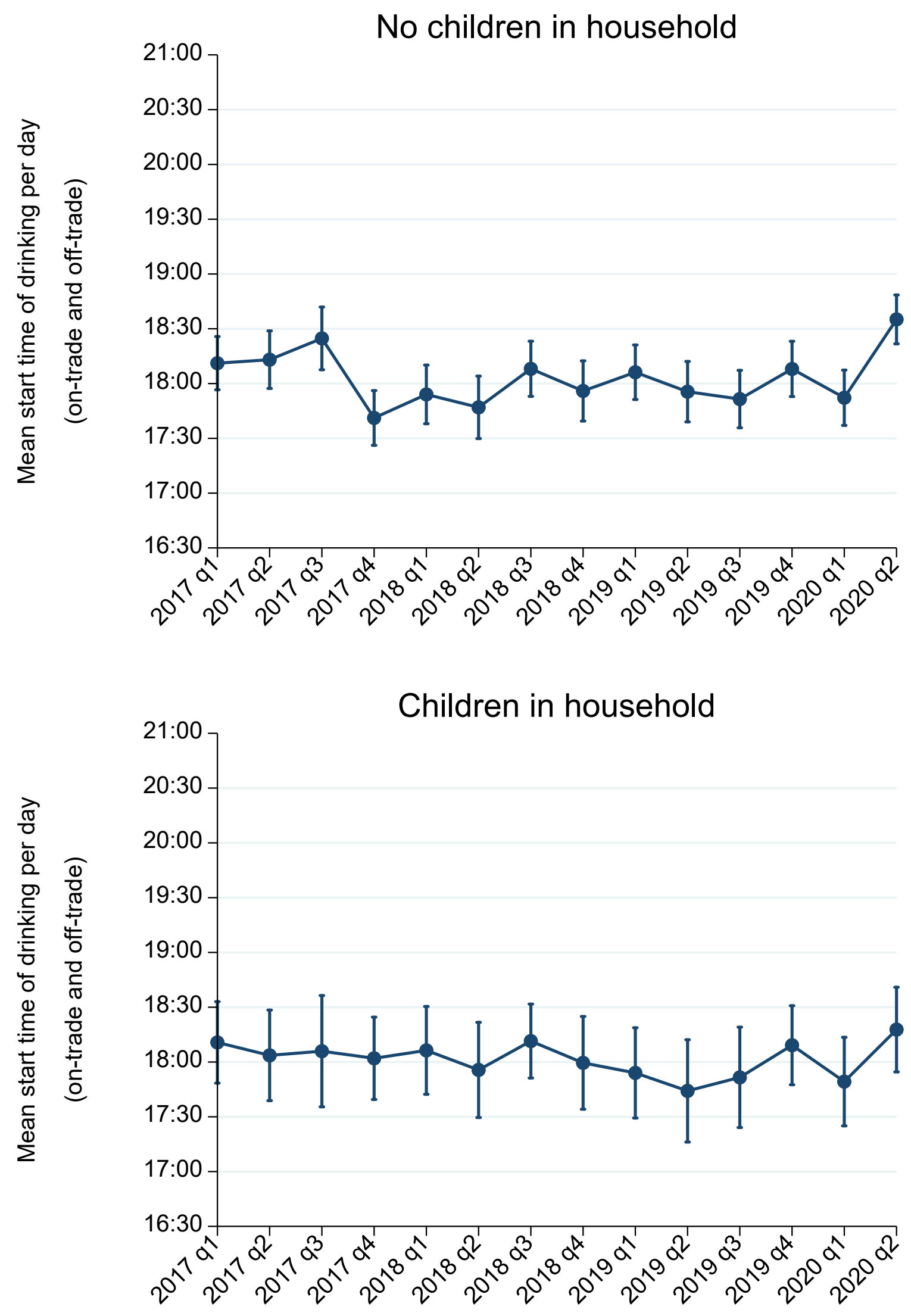
There were no significant changes in the mean number of occasions starting before 17:00 on weekdays, or the overall number of solitary drinking occasions (Figure 28). 
Figure 28. Quarterly mean number of solitary drinking occasions per week for people with and without children in Scotland
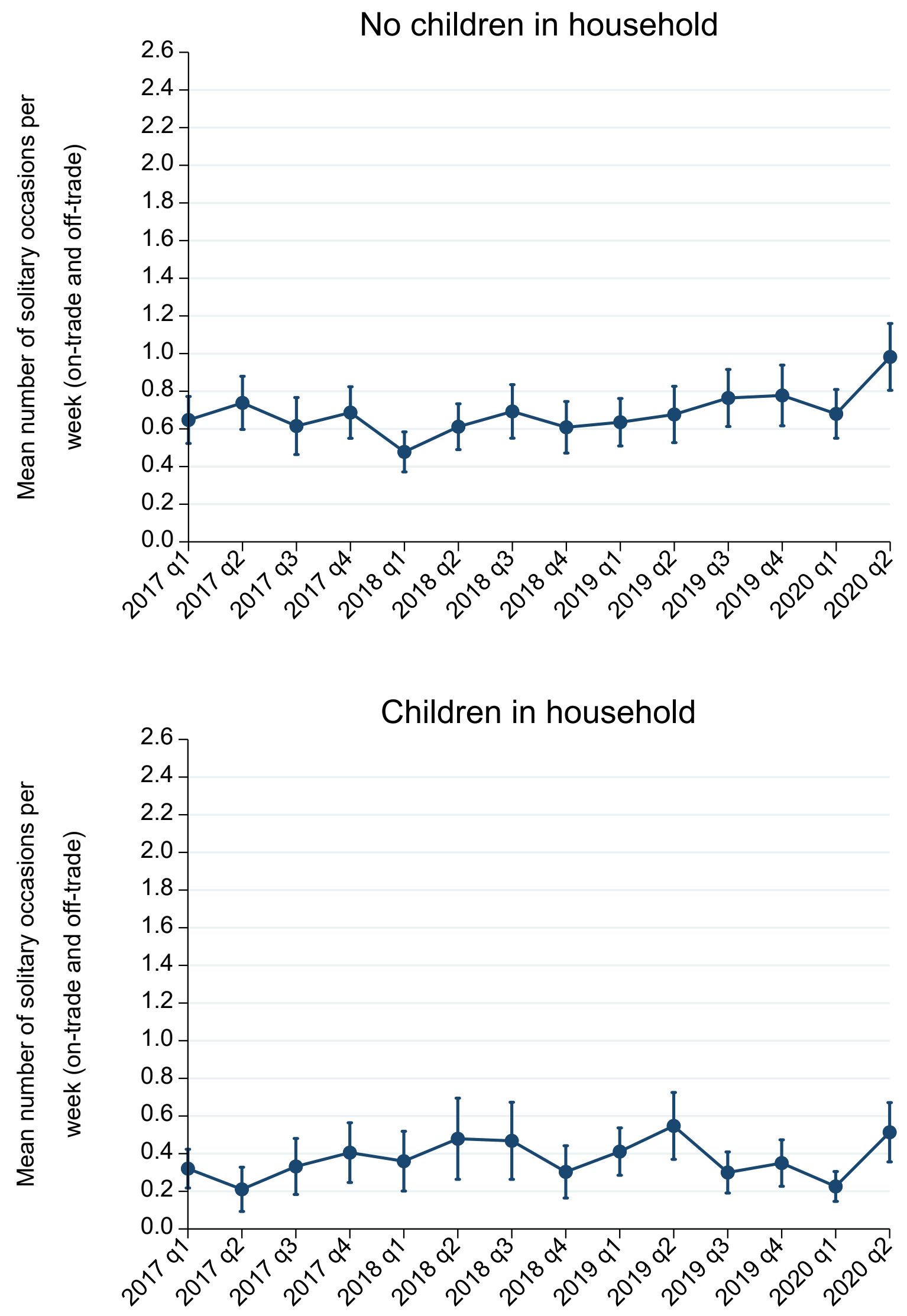


\section{Employment status}

There were no significant changes in overall drinking frequency or level of alcohol consumption measures by employment status. In general, increases in off-trade drinking offset falls in on-trade consumption.

The mean start time of drinking per day generally shifted later into the evening, although this change was only significant for people who were working part time (Figure 29). For those in full time education, the mean start time shifted earlier into the day, although this change was not statistically significant. 
Figure 29. Quarterly mean start time of drinking per day by employment status in Scotland
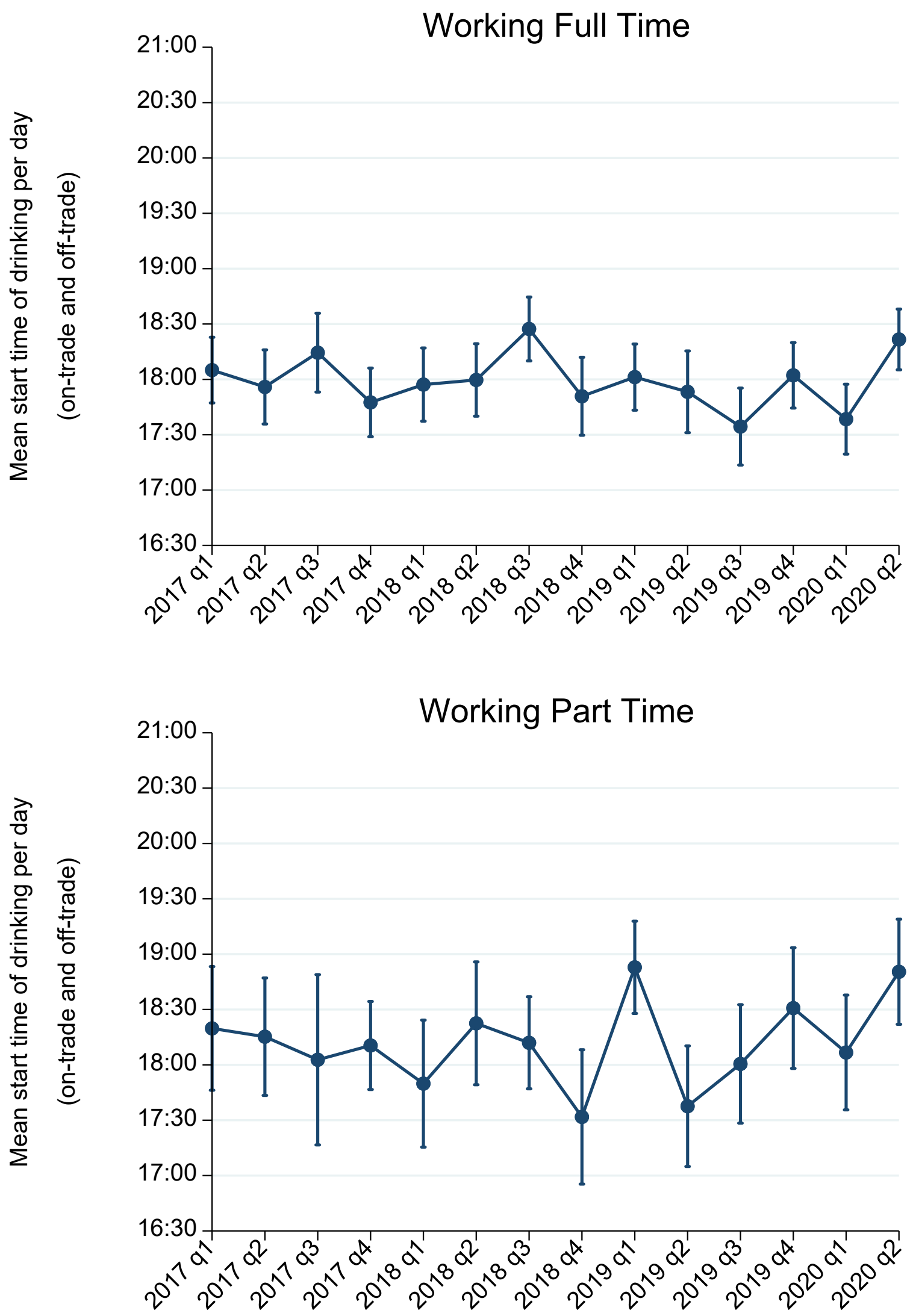
Full Time Education
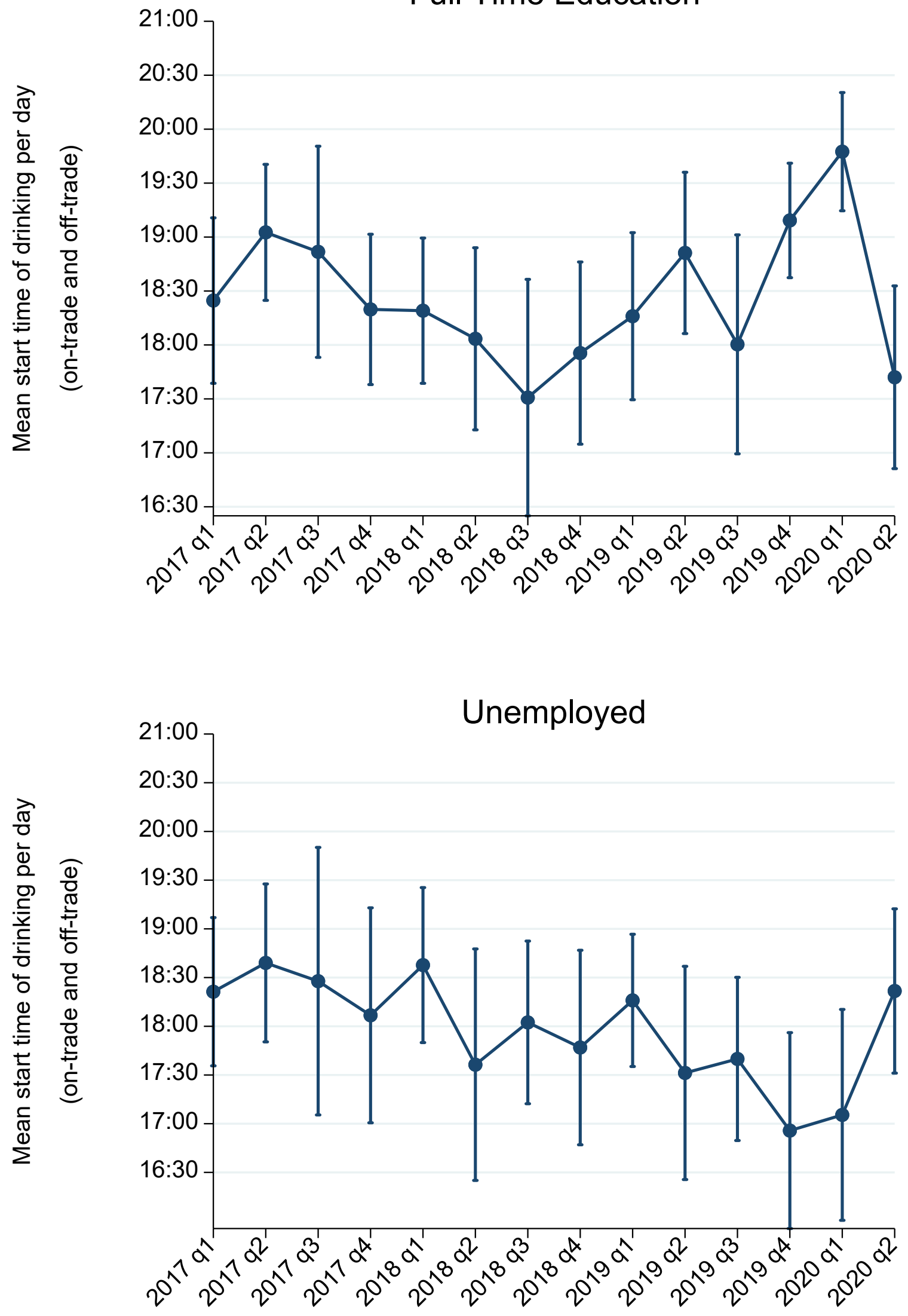

67 
The mean number of occasions starting before 17:00 on weekdays and the mean number of solitary drinking occasions showed few significant changes during lockdown. There was an increase in the mean number of solitary drinking occasions for those in full time education from $0.2(\mathrm{Cl}: 0.1-0.4)$ to $1.3(\mathrm{Cl}: 0.6-2.0)$. The mean number of solitary drinking occasions showed no significant change for those working full time (from 0.7 [Cl: $0.5-0.9]$ to 0.8 [Cl: 0.6-1.0]), working part time (from 0.3 [Cl: $0.1-0.5]$ to 0.5 [Cl: 0.3-0.8]), or unemployed (from 1.2 [Cl: $0.6-1.9]$ to 0.8 [Cl: $0.5-1.2])$.

\section{Typical frequency of drinking over the last year}

There were no significant changes overall in drinking frequency during the diary week for people who report usually drinking at least weekly or those who report drinking less than weekly. Both groups also showed no significant change in levels of alcohol consumption. Weekly drinkers drank more in the on-trade prior to lockdown compared to those who drank less than weekly and they had greater increases in off-trade consumption during lockdown. For example, mean off-trade units per week increased from $17.4(\mathrm{Cl}: 15.2-19.6)$ to $19.4(\mathrm{Cl}: 17.3-21.6)$ for those drinking at least weekly compared to $2.9(\mathrm{Cl}: 2.1-3.6)$ to $3.8(\mathrm{Cl}: 2.9-4.8)$ for less than weekly drinkers (Figure 30 ). Neither of these changes were statistically significant. 
Figure 30. Quarterly mean units of alcohol consumed per week (off-trade) for weekly and less than weekly drinkers in Scotland
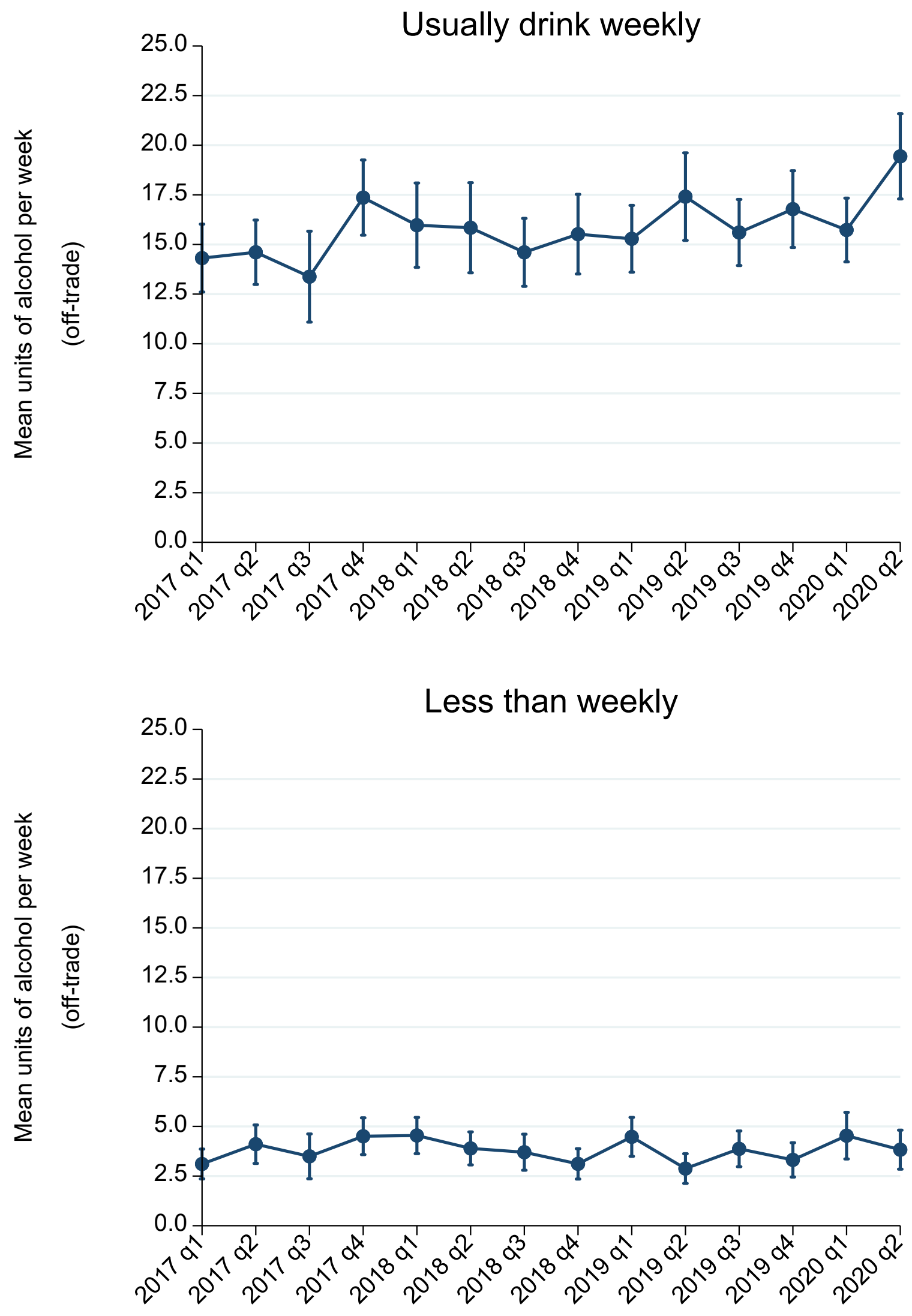
The mean start time of drinking per day showed no significant change for less than weekly drinkers (17:49 [Cl: 17:20-18:17] to 18:32 [Cl: 18:08-18:57]) but shifted later into the evening for weekly drinkers from $17: 54$ (Cl: 17:38-18:10) to 18:31 (Cl:

18:17-18:44). There was no significant change for either group in the mean number of occasions starting before 17:00 on weekdays or the mean number of solitary drinking occasions. 


\section{Discussion}

The frequency and volume of alcohol consumption showed no significant changes in Scotland during lockdown compared to the second quarter of 2019 (Table 1). This suggests that increases in off-trade consumption offset falls in on-trade consumption. We found limited evidence of divergent responses to lockdown in Scotland, with heavier drinkers at the $95^{\text {th }}$ percentile of the distribution increasing their consumption more in the off-trade but maintaining similar levels of consumption overall.

The mean start time of drinking shifted later in the evening in Scotland by 38 minutes. This shift was more pronounced for women, over 55 year olds, two adult households, those with no children in the household, and at least weekly drinkers.

There was no significant change in the number of weekday occasions starting before 17:00 or the number of solitary occasions overall in Scotland. However, there was an increase in solitary drinking for single adult households, households with three or more adults, and those in full time education.

In England, we found a fall in units of alcohol consumed per week. Drinkers increased their off-trade drinking levels and frequency, but this did not fully offset falls in on-trade alcohol consumption.

The mean start time of drinking also shifted later into the evening in England. There was a fall in the mean number of occasions starting before 17:00 on weekdays, and no significant change in the number of solitary drinking occasions. 
Table 1. Summary of changes in alcohol consumption during lockdown in Scotland and England.

\begin{tabular}{|l|c|c|c|c|}
\hline & \multicolumn{2}{|c|}{ Scotland (n=11,223) } & \multicolumn{2}{c|}{ England (n=70,126) } \\
\hline Primary outcomes & Total & Off-trade & Total & Off-trade \\
\hline $\begin{array}{l}\text { Number of drinking days } \\
\text { per week }\end{array}$ & 0.0 & +0.2 & 0.0 & +0.2 \\
\hline $\begin{array}{l}\text { Number of occasions } \\
\text { per week }\end{array}$ & -0.2 & +0.2 & -0.2 & +0.3 \\
\hline $\begin{array}{l}\text { Units of alcohol per } \\
\text { week }\end{array}$ & -0.8 & +2.4 & -1.5 & +1.7 \\
\hline $\begin{array}{l}\text { Units of alcohol per } \\
\text { occasion }\end{array}$ & 0.0 & +1.1 & -0.3 & +0.8 \\
\hline $\begin{array}{l}\text { Number of heavy } \\
\text { occasions per week }\end{array}$ & -0.1 & +0.1 & -0.1 & +0.1 \\
\hline $\begin{array}{l}\text { Units of alcohol in } \\
\text { heaviest occasion per } \\
\text { week }\end{array}$ & -0.2 & +0.9 & +0.7 & +0.3 \\
\hline $\begin{array}{l}\text { Secondary outcomes } \\
\text { involving drinking alone } \\
\text { per week }\end{array}$ & +0.2 & +17.4 & +30.6 & +10.2 \\
\hline $\begin{array}{l}\text { Start time per day } \\
\text { (minutes) }\end{array}$ & +38.4 & Off-trade & Total & Off-trade \\
\hline $\begin{array}{l}\text { Number of weekday } \\
\text { Number }\end{array}$ & -0.1 & +0.0 & +0.1 \\
\hline
\end{tabular}

Shaded cells indicate significant findings, where the 95\% confidence interval for the mean in the second quarter of 2019 (pre-lockdown) did not overlap with the $95 \%$ 
confidence interval for the same quarter in 2020 (during lockdown). ${ }^{*} n=$ the number of drinkers included in the analysis in each country.

* In the absence of formal statistical testing, we treat any overlapping confidence interval as non-significant. This is a conservative assumption as such differences may be significant in some instances where the confidence interval of one group does not include the point estimate for the other group (19). 


\section{Strengths and limitations}

This is the first study to explore the effects of lockdown on drinking occasions. The analysis uses time series survey data with a large sample size $(n=81,349)$, collected continuously throughout the pandemic and beforehand. It provides insight into both consumption outcomes and the context of drinking occasions.

The Alcovision dataset offers novel analytical possibilities, although it also has important limitations (17). Firstly, participants were recruited using quota sampling from an online panel, rather than by random sampling methods (20). These methods are common practice within market research companies and facilitate the efficient and timely collection of large volumes of data. To increase representativeness, we have developed new survey weights calibrated to UK census data, as described in the methods section.

Secondly, the mean number of units per week for Scottish drinkers is similar to English drinkers in Alcovision. This conflicts with sales data that suggests higher consumption levels in Scotland (21), and may mean that Alcovision underestimates consumption levels more in Scotland than in England. Similar consumption estimates in Scotland and England are also seen when comparing across national survey datasets, such as the Scottish Health Survey and the Health Survey for England $(22,23)$. This is likely due to under-recruitment of heavy drinkers within general population samples, which is a common issue in alcohol survey research (24). The sample sizes in the two countries were also different. Changes of similar magnitude were therefore not equally likely to be statistically significant.

Thirdly, the Alcovision survey data from the lockdown period includes some reported on-trade occasions ( $5 \%$ of the reported occasions). These occasions are likely due to participants misreporting drinking of takeaway alcohol from on-trade premises (such as pubs), which was permitted during the lockdown (25). Some of these occasions may also be consumption on premises that were breaking or finding loopholes within the lockdown restrictions, or in specific circumstances where on-trade sales were allowed such as hotels selling alcohol to resident essential workers $(26,27)$. We decided to retain these occasions in the analysis rather than removing or modifying data on genuine drinking occasions. Callinan et al. provides a 
point of international comparison, showing that survey participants also reported on-trade drinking when premises were closed during a lockdown in Australia (28).

Finally, the demographic data used for our subgroup analyses are not collected within Alcovision but are instead collected by the online market research panel from which Alcovision is sampled. Although these data are updated at regular intervals, no information is available on when these updates last occurred for each participant. This means it is not possible to determine whether participants' demographic characteristics (e.g. employment status) changed following lockdown or whether they reflect participants' situation during lockdown. The Alcovision survey did not identify people who were placed on the furlough scheme, so we could not assess differences between their drinking behaviour and the behaviour of those in employment or unemployed. We examined the time trend in these demographic variables and found only small changes in the sample composition during lockdown, suggesting this uncertainty is unlikely to affect our findings as most respondents' data reflected their pre-lockdown status. We interpret the demographics data in this way.

\section{Previous literature}

In their discussion of the expected effects of the COVID-19 pandemic, Rehm et al. suggest that alcohol consumption may fall due to reduced availability, although it may also rise due to increased distress (7). In our analysis, we find that alcohol consumption fell in England but showed no significant change in Scotland. The findings in England are consistent with the effects of reduced alcohol availability, but the apparent lack of change in Scotland may suggest that pre-existing differences between the two countries in alcohol consumption levels and practices produced slightly different responses to lockdown. This difference should not be overstated however in the absence of more detailed statistical analyses. Similarly, our analysis provides only limited insight into the impact on drinking during lockdown of Scotland's more restrictive alcohol policy environment, including restrictions on price-based promotions in the off-trade and a minimum unit price of $£ 0.50$.

Some previous analyses of survey data with smaller sample sizes on the effect of lockdown on drinking in the UK found that high risk drinking increased, especially for those over the age of 25 years and for women $(14,29)$. Our findings conflict with these studies, finding no significant changes in measures of heavy consumption in 
Scotland and falls in heavy consumption in England. The previous literature used measures from AUDIT-C, an alcohol screening tool that asks people about their usual drinking behaviour (30). This is a well validated measure of alcohol consumption, although drinking diaries may provide more accurate estimates of current drinking, since they ask about specific recent drinking occasions rather than relying on estimates of usual consumption over the last month or year (31-33). Furthermore, our findings are consistent with a recent time series analysis of alcohol purchasing data, which found that households did not buy more alcohol than expected when adjusting for typical on-trade purchases (34).

In the international literature, Callinan et al. found falls in harmful drinking in Australia, especially for younger adults (35). We did not find any pattern in changes in alcohol consumption by age in Scotland. Wardell et al. found increases in solitary drinking for single adult households in Canada, and this was associated with increased alcohol-related problems in the last 30 days (36). We also found increases in solitary drinking among those in single adult households, households with three or more adults, and those in full time education in Scotland. This increase in solitary drinking may be associated with an increased risk of alcohol-related harm for these groups in Scotland (36-38).

\section{Recommendations for future research}

Although we have used a large dataset and explored changes in drinking behaviour in detail, this report has presented descriptive analyses only. Future work would benefit from using robust statistical methods, such as time series analysis, to adjust for the seasonality and underlying trends in the data (39).

It would also be helpful to explore changes in other aspects of the context of drinking occasions, such as the activities that take place alongside alcohol consumption $(16,17)$. For example, off-trade occasions may have incorporated new forms of online socialising. Continued monitoring of drinking occasions would also improve our understanding of how drinking evolved as the lockdown restrictions were lifted, and the effects of later subnational measures introduced to control the resurgence of cases $(40,41)$. Since March 2020, the development of the COVID-19 pandemic and associated restrictions on daily life has been complex and will continue to evolve 
over time. Future alcohol research should explore the effects of this changing picture across different subpopulations (42).

\section{Conclusions}

The UK national lockdown introduced on 23 March 2020 was not associated with significant changes in levels of alcohol consumption in Scotland. During this period, the start time of drinking per day shifted later in the evening. Changes in drinking patterns varied across socio-demographic groups, with solitary drinking becoming more common for single adult households, households with three or more adults, and those in full-time education. 


\section{References}

1. Nicola M, Alsafi Z, Sohrabi C, Kerwan A, Al-Jabir A, losifidis C, et al. The socio-economic implications of the coronavirus pandemic (COVID-19): A review. Vol. 78, International Journal of Surgery. Elsevier Ltd; 2020. p. 185-93. Available from: /pmc/articles/PMC7162753/?report=abstract

2. Legislation.gov.uk. The Health Protection (Coronavirus) (Restrictions) (Scotland) Regulations 2020. Queen's Printer for Scotland; 2020.

3. Legislation.gov.uk. The Health Protection (Coronavirus, Restrictions) (England) Regulations 2020. Queen's Printer of Acts of Parliament; 2020.

4. BBC News. Coronavirus: Off-licences added to list of "essential" retailers. 2020. Available from: https://www.bbc.co.uk/news/business-52033260

5. Stockwell T, Andreasson S, Cherpitel C, Chikritzhs T, Dangardt F, Holder H, et al. The burden of alcohol on health care during COVID-19. Drug and Alcohol Review. Blackwell Publishing; 2020. Available from: https://onlinelibrary.wiley.com/doi/abs/10.1111/dar.13143

6. Testino G. Are Patients With Alcohol Use Disorders at Increased Risk for Covid-19 Infection? Alcohol Alcohol. 2020 Jun 25;55(4):344-6.

7. Rehm J, Kilian C, Ferreira-Borges C, Jernigan D, Monteiro M, Parry CDH, et al. Alcohol use in times of the COVID 19: Implications for monitoring and policy. Drug Alcohol Rev. 2020 May 2;39(4):301-4. Available from: https://onlinelibrary.wiley.com/doi/abs/10.1111/dar.13074

8. Financial Times. Global drinks makers race to keep party spirit going. Food \& beverage. 2020. Available from: https://www.ft.com/content/8b17eb62-efd9-432e9538-a5471536a239

9. HMRC. UK Alcohol Duty Statistics. 2020. p. 27-9. Available from: https://assets.publishing.service.gov.uk/government/uploads/system/uploads/attach ment_data/file/827842/2019_JUL_UK_Alcohol_Stats_Commentary.pdf 
10. Alcohol Change UK. Drinking during lockdown - Opinium survey data tables. 2020. Available from: https://alcoholchange.org.uk/publication/drinking-duringlockdown-opinium-survey-data-tables

11. Drinkaware. Employers urged to support staff well being as research reveals furloughed workers drinking more on lockdown. 2020. Available from: https://www.drinkaware.co.uk/professionals/press/employers-urged-to-support-staffwell-being-as-research-reveals-furloughed-workers-drinking-more-on-lockdown

12. Portman Group. YouGov / Portman Group survey on alcohol consumption during the COVID 19 lockdown. 2020. Available from:

https://www.portmangroup.org.uk/wp-content/uploads/2020/06/YouGov-PortmanGroup-survey-on-alcohol-consumption-during-the-COVID-19-lockdown-2.pdf

13. Alcohol Focus Scotland. Alcohol Focus Scotland and Alcohol Change UK Polling Statistics Summary. 2020. Available from: https://www.alcohol-focusscotland.org.uk/news/scots-report-changing-drinking-patterns-during-coronaviruslockdown/

14. Jackson SE, Garnett C, Shahab L, Oldham M, Brown J. Association of the COVID-19 lockdown with smoking, drinking and attempts to quit in England: an analysis of 2019-20 data. Addiction. 2020 Nov 26;add.15295. Available from: https://onlinelibrary.wiley.com/doi/10.1111/add.15295

15. Stevely AK, Holmes J, Meier PS. Contextual characteristics of adults' drinking occasions and their association with levels of alcohol consumption and acute alcohol-related harm: A mapping review. Addiction. 2019;115(2):218-29.

16. Meier PS, Warde A, Holmes J. All drinking is not equal: How a social practice theory lens could enhance public health research on alcohol and other health behaviours. Addiction. 2017;113(2):206-13. Available from: http://dx.doi.org/10.1111/add.13895

17. Ally AK, Lovatt M, Meier PS, Brennan A, Holmes J. Developing a social practice-based typology of British drinking culture in 2009-2011: implications for alcohol policy analysis. Addiction. 2016;111(9):1568-79. Available from: http://dx.doi.org/10.1111/add.13397 
18. Ipsos MediaCT. Social Grade: A Classification Tool. National Readership Survey; 2009.

19. Greenland S, Senn SJ, Rothman KJ, Carlin JB, Poole C, Goodman SN, et al. Statistical tests, $P$ values, confidence intervals, and power: a guide to misinterpretations. Eur J Epidemiol. 2016 Apr 1;31(4):337-50. Available from: https://link.springer.com/article/10.1007/s10654-016-0149-3

20. Mercer AW, Kreuter F, Keeter S, Stuart EA. Theory and Practice in Nonprobability Surveys. In: Public Opinion Quarterly. Oxford University Press; 2017. p. 250-79.

21. Giles L. Monitoring and Evaluating Scotland's Alcohol Strategy (MESAS). Public Health Scotland. 2020.

22. NHS Digital. Health Survey for England 2018: Adult's heath related behaviours. 2019. Available from: www.statisticsauthority.gov.uk/assessment/codeof-practice

23. Scottish Government. Scottish Health Survey 2018: main report - revised 2020. 2020. Available from: https://www.gov.scot/publications/scottish-health-survey2018-volume-1-main-report/pages/24/

24. Meier PS, Meng Y, Holmes J, Baumberg B, Purshouse R, Hill-McManus D, et al. Adjusting for unrecorded consumption in survey and per capita sales data: Quantification of impact on gender- and age-specific alcohol-attributable fractions for oral and pharyngeal cancers in Great Britain. Alcohol Alcohol. 2013 Mar 1;48(2):241-9. Available from: https://academic.oup.com/alcalc/article/48/2/241/177803

25. ITV News. Takeaway beers allowed during England's Covid lockdown after government U-turn. 2020. Available from: https://www.itv.com/news/2020-1104/takeaway-beers-allowed-during-englands-covid-lockdown-after-government-uturn

26. BBC News. Sheffield pub where drinkers hid in cupboards loses licence. 2020. Available from: https://www.bbc.co.uk/news/uk-england-south-yorkshire53151949 
27. BBC News. Harrogate pub loses licence over "blatant" lockdown breach. 2020. Available from: https://www.bbc.co.uk/news/uk-england-york-north-yorkshire53500829

28. Callinan S, Mojica-Perez Y, Wright CJC, Livingston M, Kuntsche S, Laslett A, et al. Purchasing, consumption, demographic and socioeconomic variables associated with shifts in alcohol consumption during the COVID-19 pandemic. Drug Alcohol Rev. 2020 Nov 10;dar.13200. Available from: https://onlinelibrary.wiley.com/doi/10.1111/dar.13200

29. Niedzwiedz CL, Green MJ, Benzeval M, Campbell D, Craig P, Demou E, et al. Mental health and health behaviours before and during the initial phase of the COVID-19 lockdown: longitudinal analyses of the UK Household Longitudinal Study. J Epidemiol Community Health. 2020 Sep 25;jech-2020-215060. Available from: http://dx.doi.org/10.1136/jech-2020-215060

30. Babor TF, Higgins-Biddle JC, Saunders JB. AUDIT: The alcohol use disorders identification test: Guidelines for use in primary care (second edition). Geneva: WHO; 2001.

31. Bloomfield K, Hope A, Kraus L. Alcohol survey measures for Europe: A literature review. Drugs Educ Prev Policy. 2013;20(5):348-60. Available from: http://www.alcsmart.ipin.edu.pl/files/prop_01.pdf

32. Heeb J-L, Gmel G. Measuring alcohol consumption: A comparison of graduated frequency, quantity frequency, and weekly recall diary methods in a general population survey. Addict Behav. 2005;30(3):403-13. Available from: http://www.sciencedirect.com/science/article/pii/S0306460304001698

33. Pires J, Padrão P, Damasceno A, Silva-Matos C, Lunet N. Impact of Different Reference Period Definitions in the Quantification of Alcohol Consumption: Results from a Nationwide STEPS Survey in Mozambique. Alcohol Alcohol. 2012;47(3):32833.

34. Anderson P, Llopis EJ, O'donnell A, Kaner E. Impact of COVID-19 Confinement on Alcohol Purchases in Great Britain: Controlled Interrupted TimeSeries Analysis During the First Half of 2020 Compared With 2015-2018. Alcohol 
Alcohol. 2020;2020:1-11. Available from: https://academic.oup.com/alcalc/advancearticle/doi/10.1093/alcalc/agaa128/5988868

35. Callinan S, Smit K, Mojica-Perez Y, D'Aquino S, Moore D, Kuntsche E. Shifts in alcohol consumption during the COVID-19 pandemic: early indications from Australia. Addiction. 2020 Oct 2;add.15275. Available from: https://onlinelibrary.wiley.com/doi/10.1111/add.15275

36. Wardell JD, Kempe T, Rapinda KK, Single A, Bilevicius E, Frohlich JR, et al. Drinking to Cope During COVID-19 Pandemic: The Role of External and Internal Factors in Coping Motive Pathways to Alcohol Use, Solitary Drinking, and Alcohol Problems. Alcohol Clin Exp Res. 2020 Sep;acer.14425. Available from: https://onlinelibrary.wiley.com/doi/abs/10.1111/acer.14425

37. Keough MT, O'Connor RM, Stewart SH. Solitary drinking is associated with specific alcohol problems in emerging adults. Addict Behav. 2018 Jan 1;76:285-90. Available from: https://pubmed.ncbi.nlm.nih.gov/28888175/

38. Skrzynski CJ, Creswell KG. Associations between solitary drinking and increased alcohol consumption, alcohol problems, and drinking to cope motives in adolescents and young adults: a systematic review and meta-analysis. Vol. 115, Addiction. Blackwell Publishing Ltd; 2020. p. 1989-2007. Available from: https://onlinelibrary.wiley.com/doi/10.1111/add.15055

39. Cruz M, Bender M, Ombao H. A Robust Interrupted Time Series Model for Analyzing Complex Healthcare Intervention Data. 2017;36:4660-76. Available from: https://arxiv.org/pdf/1707.01861.pdf

40. The Economist. Covid-19 - The second wave in Britain. 2020. Available from: https://www.economist.com/britain/2020/10/17/the-second-wave-in-britain

41. BBC News. Covid in Scotland: What are the new lockdown rules? 2020. Available from: https://www.bbc.co.uk/news/uk-scotland-53166816

42. Wright CJC, Livingston M, Dwyer R, Callinan S. Second, third, fourth COVID19 waves and the 'pancession': We need studies that account for the complexities of how the pandemic is affecting alcohol consumption in Australia. Drug Alcohol Rev. 
2020 Oct 12; dar.13188. Available from:

https://onlinelibrary.wiley.com/doi/10.1111/dar.13188 
www.healthscotland.scot/MUPevaluation

\section{$y$ @MESAS_phs}

